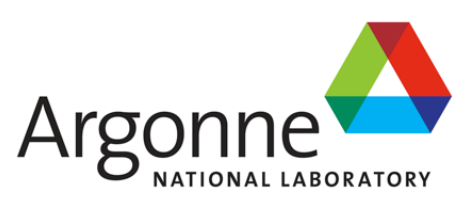

ANL-VTR-51

\title{
ZPPR-15 Criticality Measurements
}

Nuclear Science and Engineering Division 


\section{About Argonne National Laboratory}

Argonne is a U.S. Department of Energy laboratory managed by UChicago

Argonne, LLC under contract DE-AC02-06CH11357. The Laboratory's main facility

is outside Chicago, at 9700 South Cass Avenue, Argonne, Illinois 60439. For

information about Argonne

and its pioneering science and technology programs, see www.anl.gov.

\section{DOCUMENT AVAILABILITY}

Online Access: U.S. Department of Energy (DOE) reports produced after 1991 and a growing number of pre-1991 documents are available free at OSTI.GOV (http://www.osti.gov/), a service of the US Dept. of Energy's Office of Scientific and Technical Information.

Reports not in digital format may be purchased by the public from the National Technical Information Service (NTIS):

U.S. Department of Commerce

National Technical Information

Service 5301 Shawnee Rd

Alexandria, VA 22312

www.ntis.gov

Phone: (800) 553-NTIS (6847) or (703) 605-6000

Fax: (703) 605-6900

Email:orders@ntis.gov

Reports not in digital format are available to DOE and DOE contractors from the Office of Scientific and Technical Information (OSTI):

U.S. Department of Energy

Office of Scientific and Technical Information

P.O. Box 62

Oak Ridge, TN 37831-0062

www.osti.gov

Phone: (865) 576-8401

Fax: (865) 576-5728

Email: reports@osti.gov

Disclaimer

This report was prepared as an account of work sponsored by an agency of the United States Government. Neither the United States Government nor any agency thereof, nor UChicago Argonne, LLC, nor any of their employees or officers, makes any warranty, express or implied, or assumes any legal liability or responsibility for the accuracy, completeness, or usefulness of any information, apparatus, product, or process disclosed, or represents that its use would not infringe privately owned rights. Reference herein to any specific commercial product, process, or service by trade name, trademark, manufacturer, or otherwise, does not necessarily constitute or imply its endorsement, recommendation, or favoring by the United States Government or any agency thereof. The views and opinions of document authors expressed herein do not necessarily state or reflect those of the United States Government or any agency thereof, Argonne National Laboratory, or UChicago Argonne, LLC. 
ANL-VTR-51

\section{ZPPR-15 Criticality Measurements}

Richard M. Lell, Michael A. Smith, Zhaopeng Zhong

Argonne National Laboratory

April 30, 2020 


\begin{abstract}
A reference critical configuration was established for each phase of the ZPPR-15 experimental program. The reference critical configuration for each phase corresponds to a configuration in which the measured excess reactivity was adjusted to a standard set of reporting conditions with an average reactor temperature of $293 \mathrm{~K}$, a zero interface gap and all operational control rods parked 30 inches from the axial centerline of the core.

The ZPPR staff published the measured excess reactivity and the statistical uncertainty in the measurement. In reality, the published uncertainty for each reference critical configuration is only a small component of the total uncertainty for that configuration. Additional uncertainties related measurement technique, configuration geometry and material compositions exist. The geometry and material composition uncertainties are the dominant uncertainties for ZPPR-15.

A full uncertainty analysis was performed for each ZPPR-15 reference critical configuration. The significant uncertainties related to measurement technique, configuration geometry and material compositions were quantified, and a total uncertainty was derived for each reference critical configuration.

The ZPPR-15 experimental records were used to create detailed as-built Monte Carlo models for the reference critical configurations established in ZPPR-15A loading 15, ZPPR-15B loading 88, ZPPR-15C loading 166 and ZPPR-15D loading 185. The as-built models neglect the small, non-uniform gap between matrix halves at full closure, any structures outside the matrix tubes and minor components, e.g., impurities, in some materials. The biases associated with the neglected items were quantified. The experimental value of $\mathrm{k}_{\mathrm{eff}}$ and its associated uncertainty for each reference critical configuration were adjusted to account for biases introduced by items that are neglected in the as-built model for that configuration.
\end{abstract}




\section{TABLE OF CONTENTS}

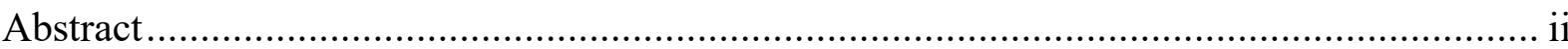

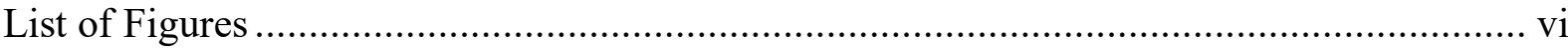

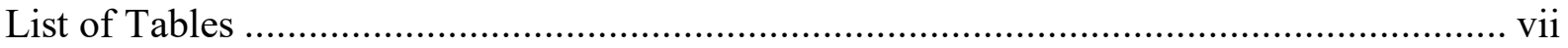

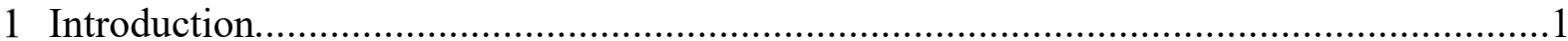

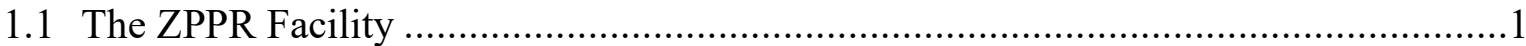

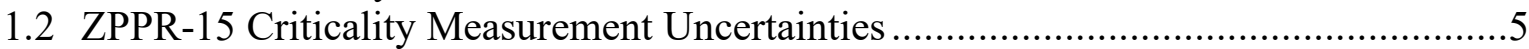

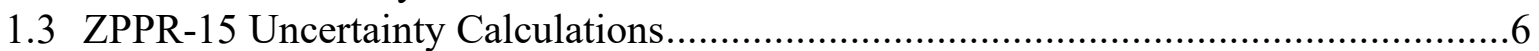

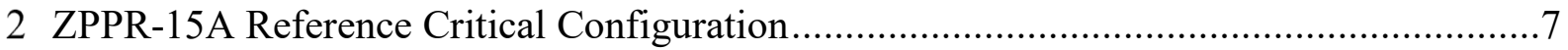

2.1 ZPPR-15A Measurement Technique Uncertainties...............................................10

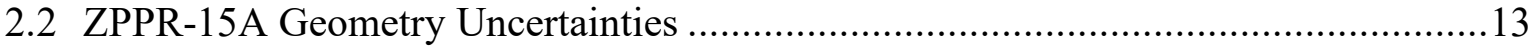

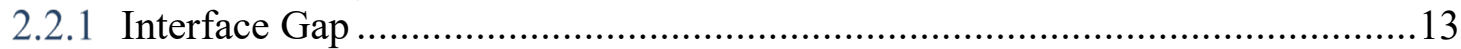

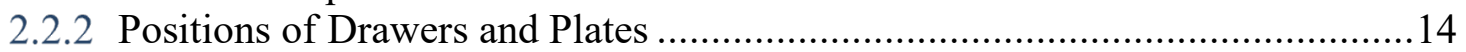

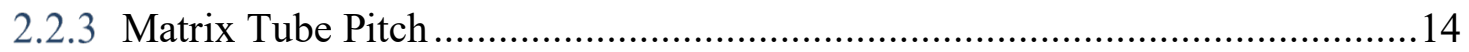

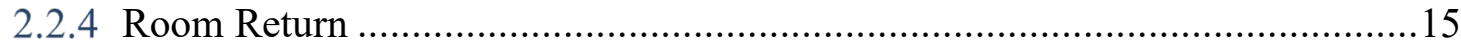

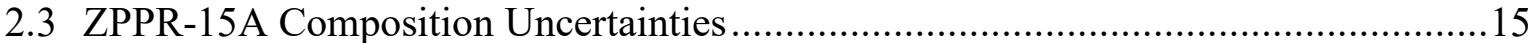

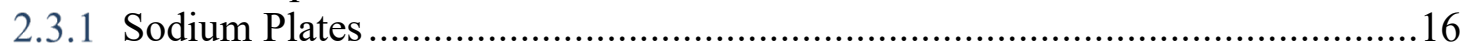

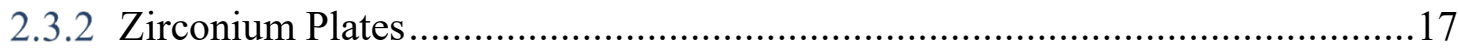

2.3.3 Depleted Uranium Plates...........................................................................17

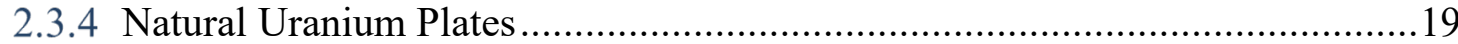

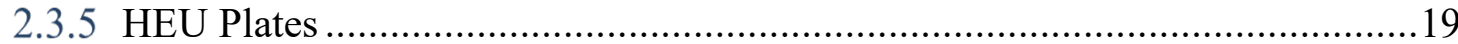

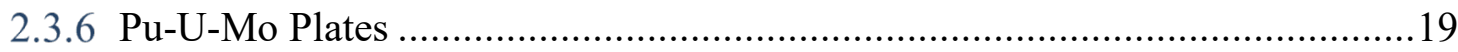

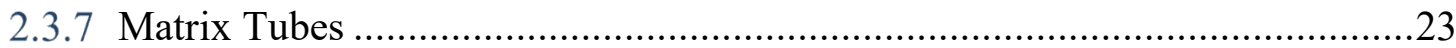

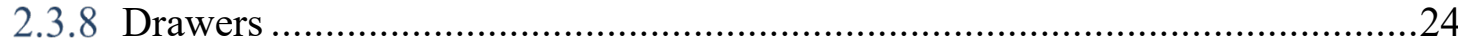

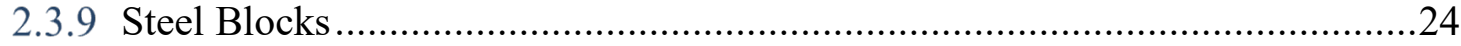

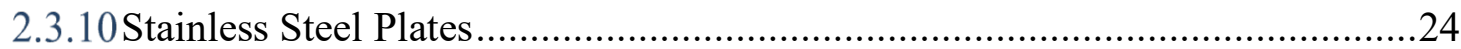

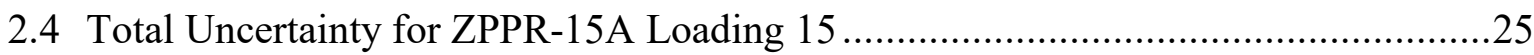

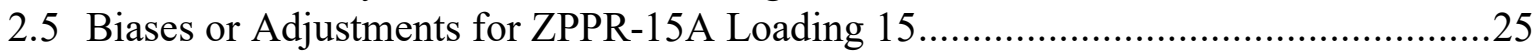

2.6 Final Adjusted Experimental keff for ZPPR-15A Loading $15 \ldots \ldots \ldots \ldots \ldots \ldots \ldots \ldots \ldots \ldots \ldots \ldots \ldots . .27$

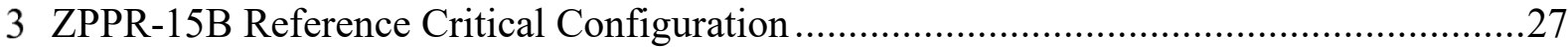

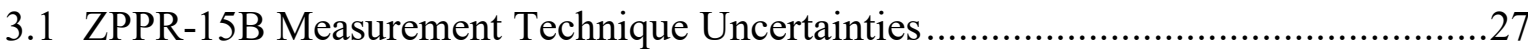

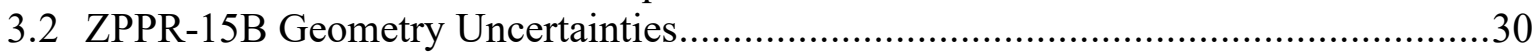

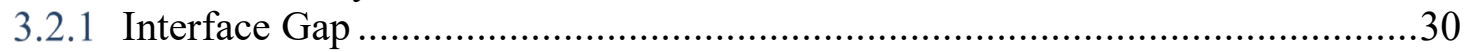

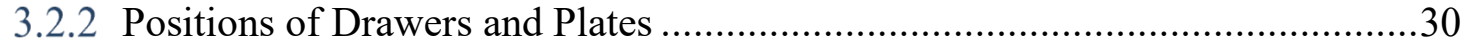

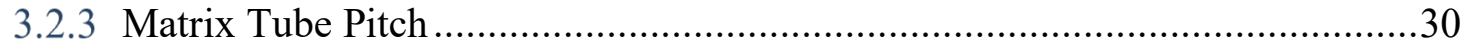

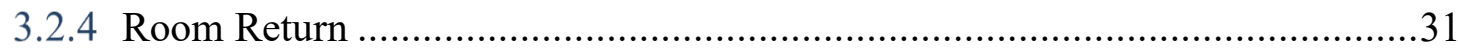

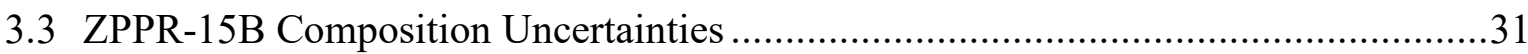

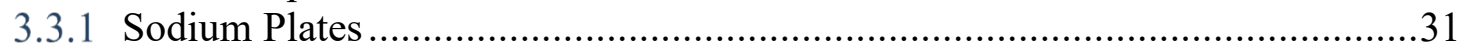

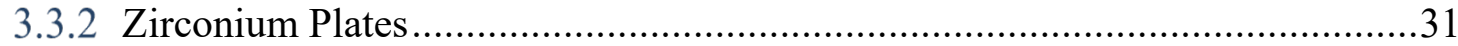

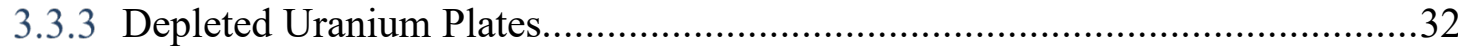

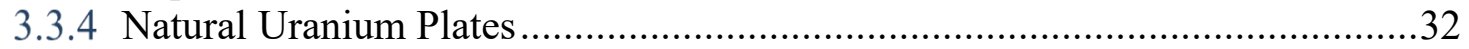




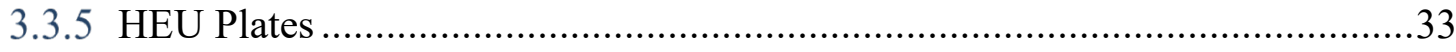

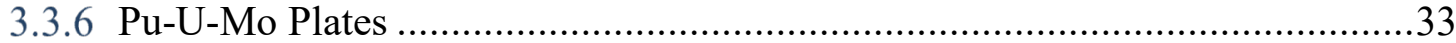

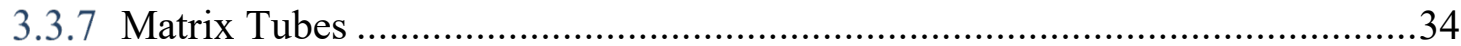

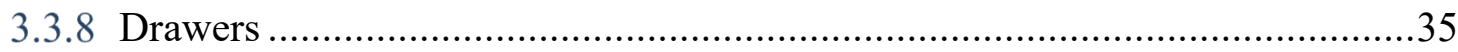

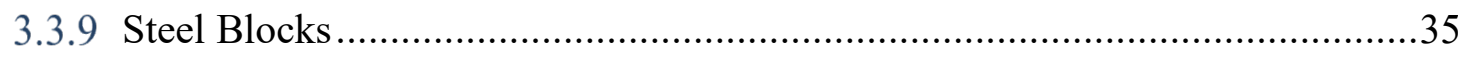

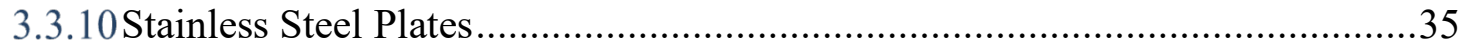

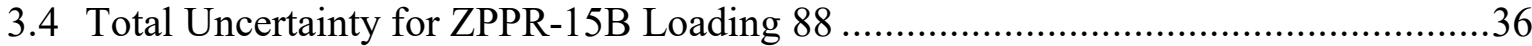

3.5 Biases or Adjustments for ZPPR-15B Loading 88 ……….....................................36

3.6 Final Adjusted Experimental keff for ZPPR-15B Loading 88 ....................................38

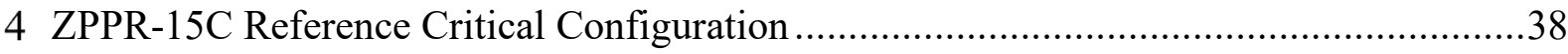

4.1 ZPPR-15C Measurement Technique Uncertainties .................................................38

4.2 ZPPR-15C Geometry Uncertainties.................................................................

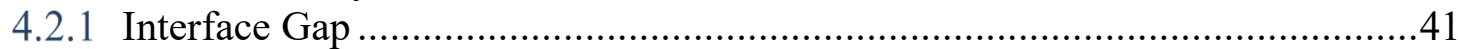

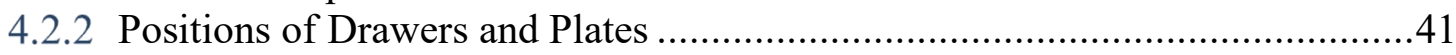

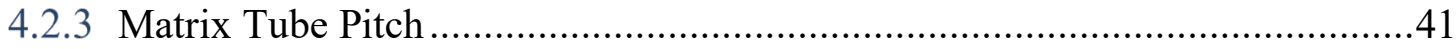

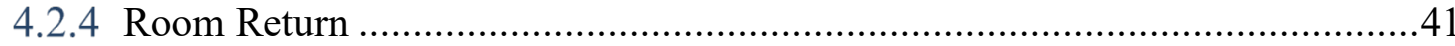

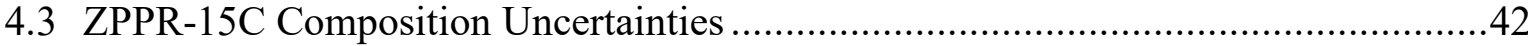

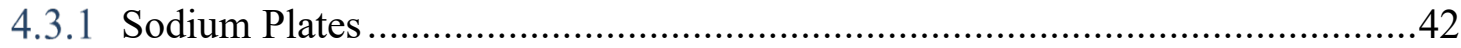

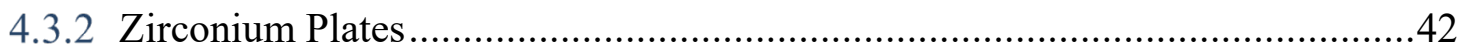

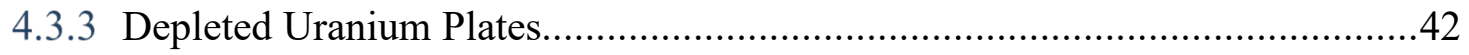

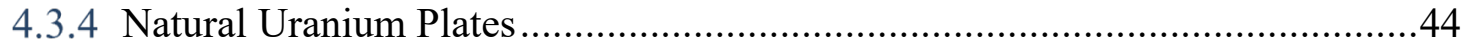

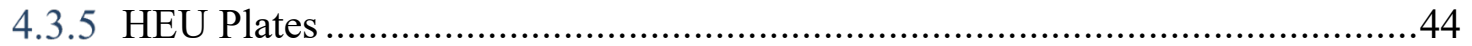

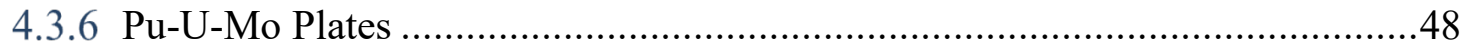

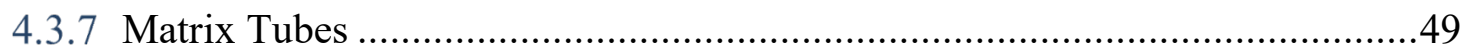

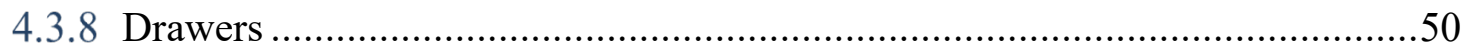

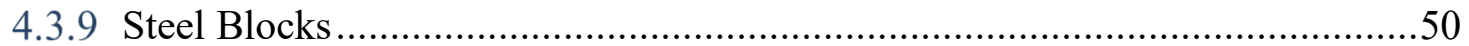

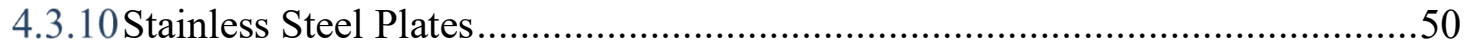

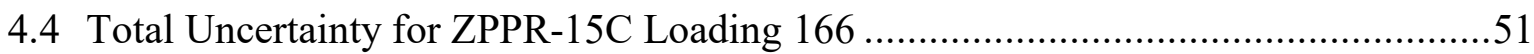

4.5 Biases or Adjustments for ZPPR-15C Loading 166 …..........................................51

4.6 Final Adjusted Experimental keff for ZPPR-15C Loading $166 \ldots \ldots \ldots \ldots \ldots \ldots \ldots \ldots \ldots \ldots \ldots \ldots . . .53$

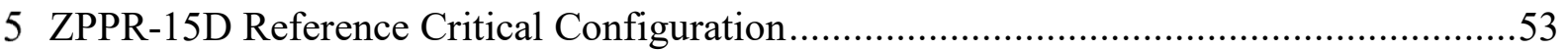

5.1 ZPPR-15D Measurement Technique Uncertainties................................................54

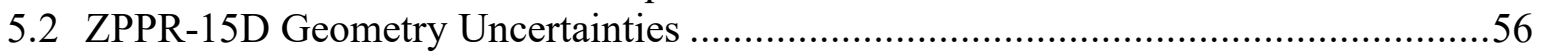

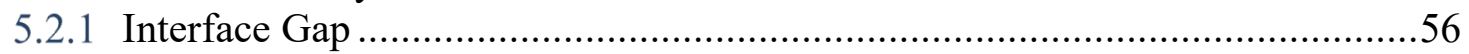

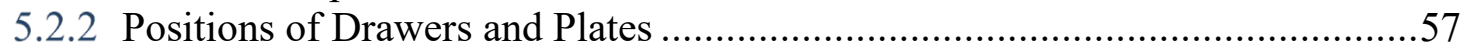

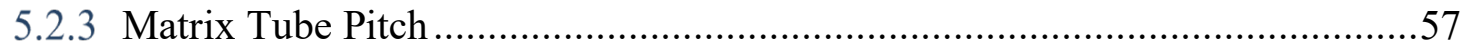

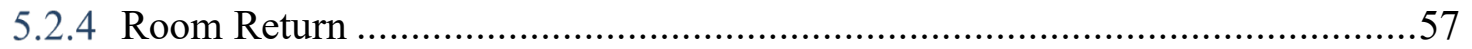

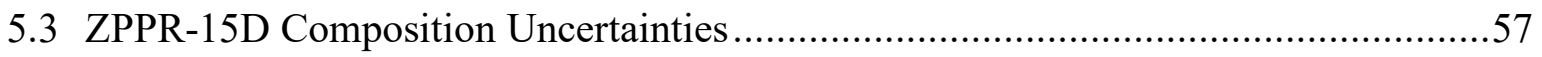

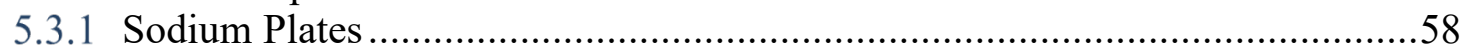

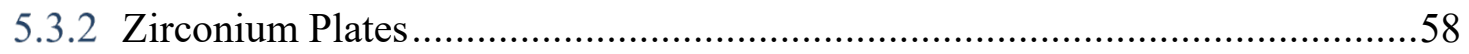

5.3.3 Depleted Uranium Plates.....................................................................5

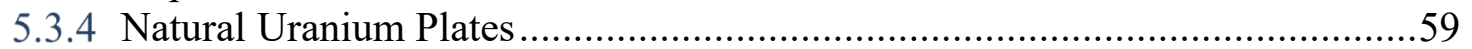

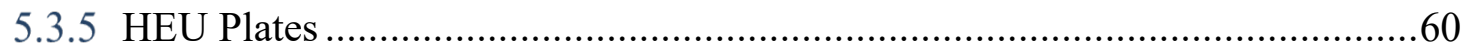

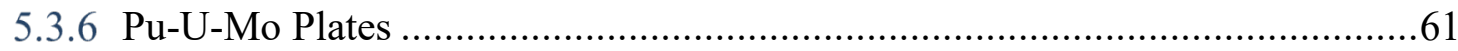




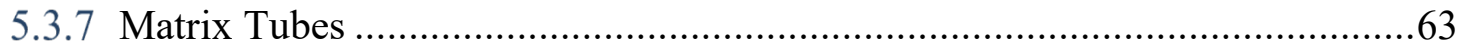

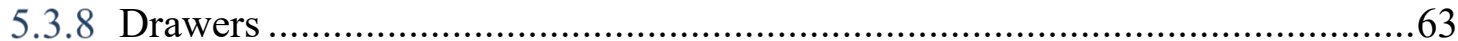

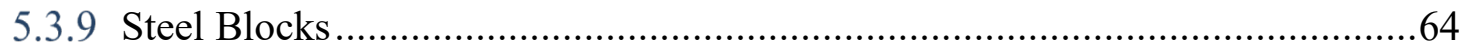

5.3.10 Stainless Steel Plates...........................................................................64

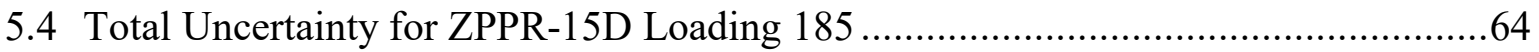

5.5 Biases or Adjustments for ZPPR-15D Loading 185 .....................................65

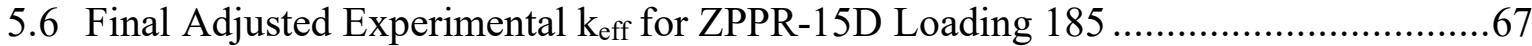

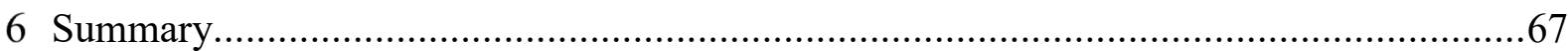

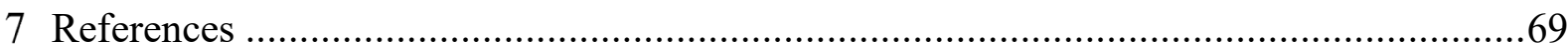




\section{LIST OF FIGURES}

Figure 1.1 Artist's Rendering of the ZPPR Facility ..............................................2

Figure 1.2 Manual Loading of the ZPPR Matrix................................................ 4

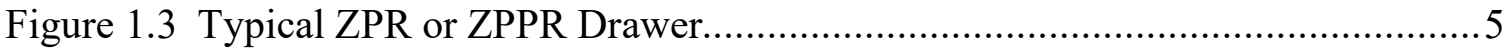

Figure 2.1 Drawer Master 15-0-101 - ZPPR-15A Inner Core Drawer............................ 8

Figure 2.2 Drawer Master 15-0-501 - ZPPR-15 Radial Blanket Drawer. ...................... 9

Figure 2.3 Drawer Master 15-0-401 - ZPPR-15 Radial Reflector Drawer.....................9

Figure 2.4 ZPPR-15A L015 - Matrix Map for Half 1 ............................................ 11

Figure 2.5 ZPPR-15A L015 - Matrix Map for Half 2................................................ 12

Figure 3.1. ZPPR-15B L088 - Matrix Map for Half 1 ...............................................28

Figure 3.2. ZPPR-15B L088 - Matrix Map for Half 2 ...........................................29

Figure 4.1. ZPPR-15C L166 - Matrix Map for Half 1........................................... 39

Figure 4.2. ZPPR-15C L166 - Matrix Map for Half 2 ............................................. 40

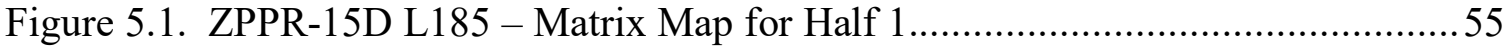

Figure 5.2. ZPPR-15D L185 - Matrix Map for Half 2 .........................................56 


\section{LIST OF TABLES}

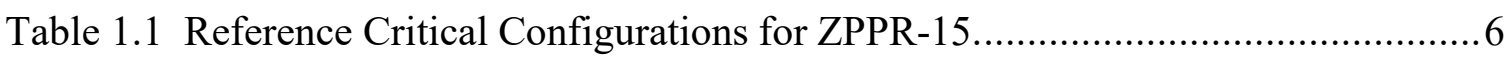

Table 2.1 Worth of Sodium Can Uncertainties in ZPPR-15A...................................... 17

Table 2.2 Worth of Depleted Uranium Plate Uncertainties in ZPPR-15A....................... 18

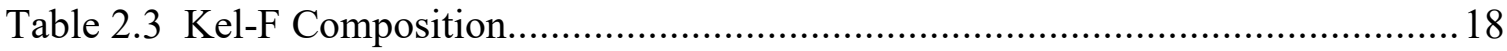

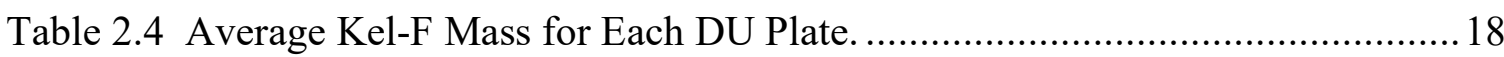

Table 2.5 Average Impurity Content of NUMEC Pu-U-Mo Fuel Meat. .......................22

Table 2.6 Assumed Impurity Composition for Pu-U-Mo Plates.......................................22

Table 2.7. Worth of Pu-U-Mo Alloy Uncertainties in ZPPR-15A.................................23

Table 2.8. Worth of Pu-U-Mo Can Uncertainties in ZPPR-15A...................................23

Table 2.9 Worth of Matrix Tube Uncertainties in ZPPR-15A.......................................23

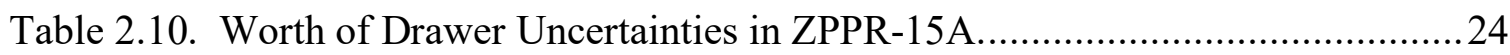

Table 2.11. Worth of Steel Block Uncertainties in ZPPR-15A …….............................24

Table 2.12. Worth of Stainless Steel Plate Uncertainties in ZPPR-15A. .......................25

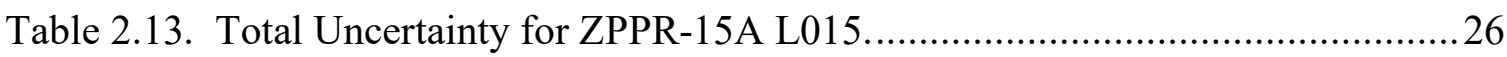

Table 2.14. Biases for ZPPR-15A L015 As-Built Model.........................................27

Table 3.1. Worth of Sodium Can Uncertainties in ZPPR-15B...................................... 31

Table 3.2. Worth of Depleted Uranium Plate Uncertainties in ZPPR-15B.....................32

Table 3.3. Worth of Pu-U-Mo Alloy Uncertainties in ZPPR-15B..................................34

Table 3.4. Worth of Pu-U-Mo Can Uncertainties in ZPPR-15B ....................................34

Table 3.5. Worth of Matrix Tube Uncertainties in ZPPR-15B ........................................34

Table 3.6. Worth of Drawer Uncertainties in ZPPR-15B.................................................35

Table 3.7. Worth of Steel Block Uncertainties in ZPPR-15B. ……...............................35

Table 3.8. Worth of Stainless Steel Plate Uncertainties in ZPPR-15B ............................36

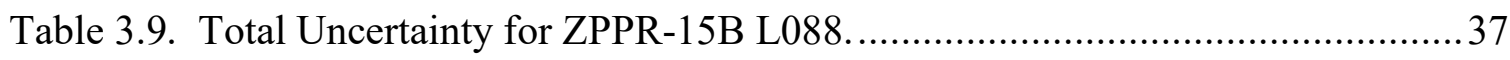

Table 3.10. Biases for ZPPR-15B L088 As-Built Model..............................................

Table 4.1. Worth of Sodium Can Uncertainties in ZPPR-15C. ....................................42

Table 4.2. Worth of Plate Uncertainties for ZPPR Depleted Uranium Plates in ZPPR-15C.

Table 4.3. Worth of Plate Uncertainties for ANL-E Depleted Uranium Plates in ZPPR-

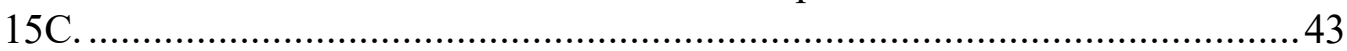

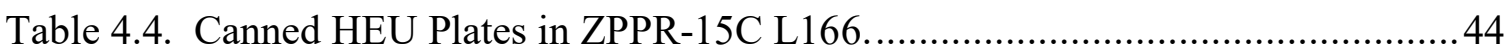

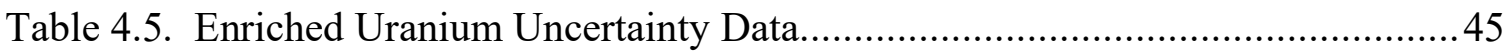

Table 4.6. Worth of HEU Mass and Isotopic Uncertainties in ZPPR-15C. .....................46

Table 4.7. Worth of HEU Can Uncertainties in ZPPR-15C. .........................................48

Table 4.8. Worth of Pu-U-Mo Alloy Uncertainties in ZPPR-15C..................................49

Table 4.9. Worth of Pu-U-Mo Can Uncertainties in ZPPR-15C. ...................................49 
Table 4.10. Worth of Matrix Tube Uncertainties in ZPPR-15C ..............................49

Table 4.11. Worth of Drawer Uncertainties in ZPPR-15C ....................................50

Table 4.12. Worth of Steel Block Uncertainties in ZPPR-15C ..................................50

Table 4.13. Worth of Stainless Steel Plate Uncertainties in ZPPR-15C. .....................51

Table 4.14. Total Uncertainty for ZPPR-15C L166 ..............................................52

Table 4.15. Biases for ZPPR-15C L166 As-Built Model.............................................53

Table 5.1. Worth of Sodium Can Uncertainties in ZPPR-15D..................................58

Table 5.2. Worth of Plate Uncertainties for ZPPR Depleted Uranium Plates in ZPPR-15D.

Table 5.3. Worth of Plate Uncertainties for ANL-E Depleted Uranium Plates in ZPPR$15 \mathrm{D}$. 59

Table 5.4. Canned HEU Plates in ZPPR-15D L185 ...............................................60

Table 5.5. Worth of HEU Mass and Isotopic Uncertainties in ZPPR-15D. .................60

Table 5.6. Worth of HEU Can Uncertainties in ZPPR-15D ....................................61

Table 5.7. Worth of Pu-U-Mo Alloy Uncertainties in ZPPR-15D..............................62

Table 5.8. Worth of Pu-U-Mo Can Uncertainties in ZPPR-15D.................................63

Table 5.9. Worth of Matrix Tube Uncertainties in ZPPR-15D ................................63

Table 5.10. Worth of Drawer Uncertainties in ZPPR-15D.......................................63

Table 5.11. Worth of Steel Block Uncertainties in ZPPR-15D. .................................64

Table 5.12. Worth of Stainless Steel Plate Uncertainties in ZPPR-15D .....................64

Table 5.13. Total Uncertainty for ZPPR-15D L185 ...............................................66

Table 5.14. Biases for ZPPR-15D L185 As-Built Model...........................................67 


\section{Introduction}

The ZPPR-15 program was part of the Integral Fast Reactor (IFR) development work and was performed to simulate binary $(\mathrm{U}-\mathrm{Zr})$ and ternary $(\mathrm{Pu}-\mathrm{U}-\mathrm{Zr})$ fuels by combining highly enriched uranium (HEU) plates, depleted uranium (DU) plates, Pu-U-Mo plates and zirconium plates. The ZPPR-15 Program consisted of four phases: A - D. ZPPR-15D simulated an initial IFR core fueled with enriched uranium, ZPPR-15C simulated a mid-life IFR core containing approximately equal amounts of enriched uranium and plutonium fuel, and ZPPR-15B simulated an IFR core fueled entirely with plutonium. ZPPR-15A was essentially identical to ZPPR-15B but with stainless steel plates in place of zirconium plates.

The ZPPR zirconium plate inventory was not large enough to put zirconium plates into every core drawer. It was thus necessary to divide the core into an inner zone with drawers containing zirconium plates and an outer zone with drawers containing stainless steel plates in place of the zirconium plates. The cores of ZPPR-15B, ZPPR-15C and ZPPR-15D had zirconium plates in the inner core and stainless steel plates in the outer core. ZPPR-15A had stainless steel plates in place of zirconium plates in the inner core, so there were no zirconium plates in ZPPR-15A. ZPPR-15A and ZPPR-15B were essentially identical in all other respects, so ZPPR-15A and ZPPR-15B provided a direct measure of the effect of zirconium on core physics parameters of a plutonium-fueled core.

As-built Monte Carlo models were developed for the four reference critical configurations. The as-built models developed for ZPPR-15 for this analysis are the most accurate models of ZPPR15 that can be developed with the information that exists today. These as-built models include explicit representation of each matrix tube, drawer and plate in the reactor. Each plate in a drawer is placed in the correct location within that drawer, and each drawer is placed at the correct location in the matrix. The material compositions in the models are based on the last ZPPR materials library developed by the ZPPR staff.

A full uncertainty analysis was performed for each reference critical configuration. The measured experimental $\mathrm{k}_{\text {eff }}$ for each critical configuration was adjusted to compensate for features of the reactor that are not included in the as-built models such as minor impurities in some materials.

\subsection{The ZPPR Facility}

For readers who are not familiar with the Zero Power Plutonium Reactor (ZPPR), the following is a brief description. The ZPPR fast critical experiment facility was a horizontal split-table type machine consisting of a large, cast-steel bed supporting two tables, one stationary and the other movable. ZPPR documents generally referred to the stationary half or table as half 1 and to the movable half or table as half 2 . In the remainder of this document, stationary half is identical to half 1 , and movable half is identical to half 2. An artist's rendering of the ZPPR facility which labels the components of the machine is shown in Figure 1.1. A photograph of the ZPPR matrix being loading is shown in Figure 1.2.

Each table was 14 feet $(4.3 \mathrm{~m})$ wide and 5 feet $(1.5 \mathrm{~m})$ long. During loading operations, the tables were separated by 5 feet $(1.5 \mathrm{~m})$. Stainless steel square tubes, nominally 0.040 inches $(1 \mathrm{~mm})$ thick, 2.175 inches $(55 \mathrm{~mm}) \times 2.175$ inches $(55 \mathrm{~mm})$ (outside dimension) and 60 in. (1524 mm) long, were stacked horizontally on both tables to form a 77-row by 77-column 
square "honeycomb" matrix. The matrix tubes were supported by cast-iron, L-shaped structures known as the bed and knees. A plenum region, which included control-rod drives and experimental apparatus, existed beyond the matrix at the outer end of each half. The plenum provided a flow path for cooling air into and out of the assembly matrix. The (horizontal) control rods projected through holes in a steel back plate, and the drive mechanisms were positioned on the outside of this back plate. The matrix machine was near the center of a large cylindrical cell (room) with a diameter of 50 feet $(15 \mathrm{~m})$ and height of 30 feet $(9 \mathrm{~m})$.

A matrix position in ZPPR is specified by three parameters: matrix half ( 1 for stationary and 2 for movable), row number (starting from the top with number 11) and column number (starting from the left with number 11 and looking from the movable half towards the stationary half). In the ZPPR matrix numbering convention, each matrix position is identified by two numbers separated by a hyphen, e.g., 133-27. In this example, 133 refers to row 33 in half 1 , and 27 refers to column 27. Row 33, column 27 in half 2 would be listed as 233-27. The central positions in half 1 and half 2 are 149-49 and 249-49, respectively. Because the column numbers for both halves start from the same side of the machine, the row and column numbers in the stationary and movable tables of the machine align when the tables are brought together. For example, the matrix positions designated as row 33, column 27 (133-27 and 233-27) are directly aligned when the movable table touches the stationary table.

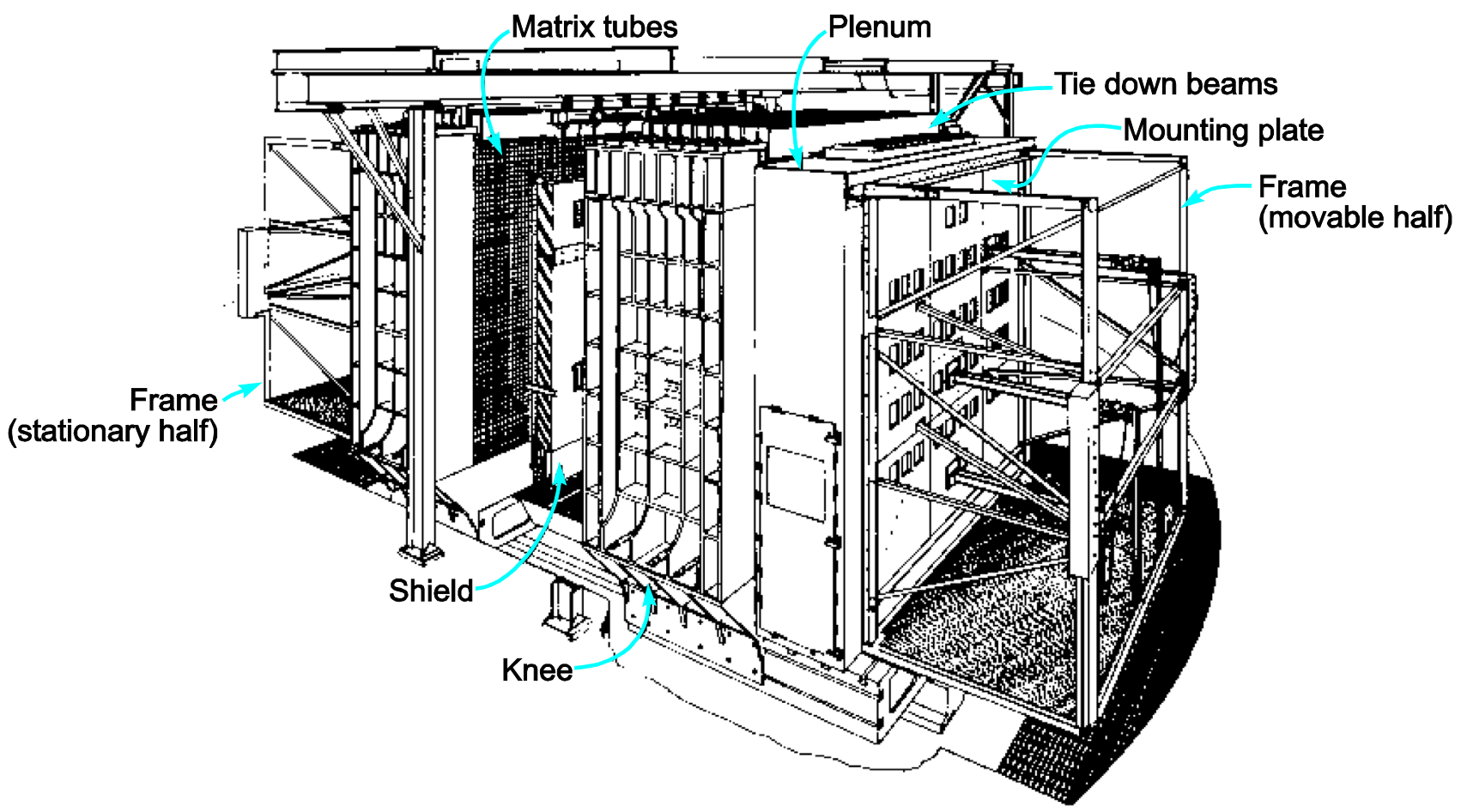

Figure 1.1 Artist's Rendering of the ZPPR Facility

The desired average composition in each region of the reactor to be simulated was achieved by loading the ZPPR matrix with stainless steel drawers containing rectangular plates (or, in some experiments, with cylindrical rods) of different materials such as plutonium, depleted uranium, enriched uranium, stainless steel, sodium, etc. The plates were either bare, had cladding, or in the case of uranium, had a protective coating. Figure 1.3 is a picture of the plates inside of a 
drawer. A specific plate-loading pattern in a drawer is called a drawer master. Physically, a drawer master was a drawing or blueprint showing the location or position of each type of plate in a drawer. The drawer master drawings were guides or templates used by the technicians to load the drawers. In this document, drawer master will refer both to the drawing used by the technicians during drawer loading and to the configuration of plates in a drawer to be placed into a specific matrix location. The specification of which drawer master was in each matrix position is known as a matrix loading map.

It was frequently the case that a given matrix position had two drawers, a front drawer and a back drawer. In that case, there would be two matrix loading maps for each half, a front map and a back map. The standard drawers used in ZPPR-15 were 36.25 in long, which was sufficient to contain 18 in of core, 13 in of axial blanket and 5 in of the steel axial reflector. The remainder of the axial reflector consisted of a $2 \times 2 \times 6$ in block of stainless steel loaded directly into the matrix tube behind the drawer. There were no back drawers behind the standard 36.25 in drawers used in ZPPR-15. The only back drawers used in ZPPR-15 were narrow back drawers placed behind the narrow front drawers in matrix tubes where the PSR control rods were located.

There were usually many plate sizes available for a given material and a limited number of plates of any one size. Consequently, there were often several drawer masters that had essentially the same composition, differing only in the plate sizes used. The number of similar drawer masters was increased by the fact that drawers for the stationary and movable halves had different (opposite, mirror image) drawer masters in many cases.

The ZPPR drawers themselves typically were made of 0.03 -inch-thick $(0.8$-mm) stainless steel, and their front, back and sidewalls were 2 inches $(51 \mathrm{~mm})$ tall.

Two types of control rods could be used in a ZPPR assembly. One type was the poison (or shim) safety rod (PSR or SSR), which contained a blade of boron powder or $\mathrm{B}_{4} \mathrm{C}$ clad with stainless steel. The other type of control rod was the dual-purpose (DP) control rod, so-called because it was a drawer that contained a core unit cell but could be driven in and out within of a matrix tube to adjust reactivity. There were no dual-purpose control rods in ZPPR-15.

A neutron source had to be present in each matrix half during the startup of any ZPPR assembly not containing an inherent source in the core (e.g., ${ }^{240} \mathrm{Pu}$ ). There was no source or associated hardware in any ZPPR-15 loading because each ZPPR-15 core loading contained a significant number of Pu-U-Mo plates. The plutonium component of a Pu-U-Mo plate contained 11 wt.\% ${ }^{240} \mathrm{Pu}$.

Two shields could be moved between the matrix halves when they were separated to reduce radiation exposure for staff members loading or unloading drawers. Figure 1.1 shows a shield. In Figure 1.2, the structure with black and yellow diagonal stripes behind the person loading the drawer is one shield in its withdrawn position. The other movable shield is just visible as the structure with black and yellow diagonal stripes on the left side of the right half of the matrix. 


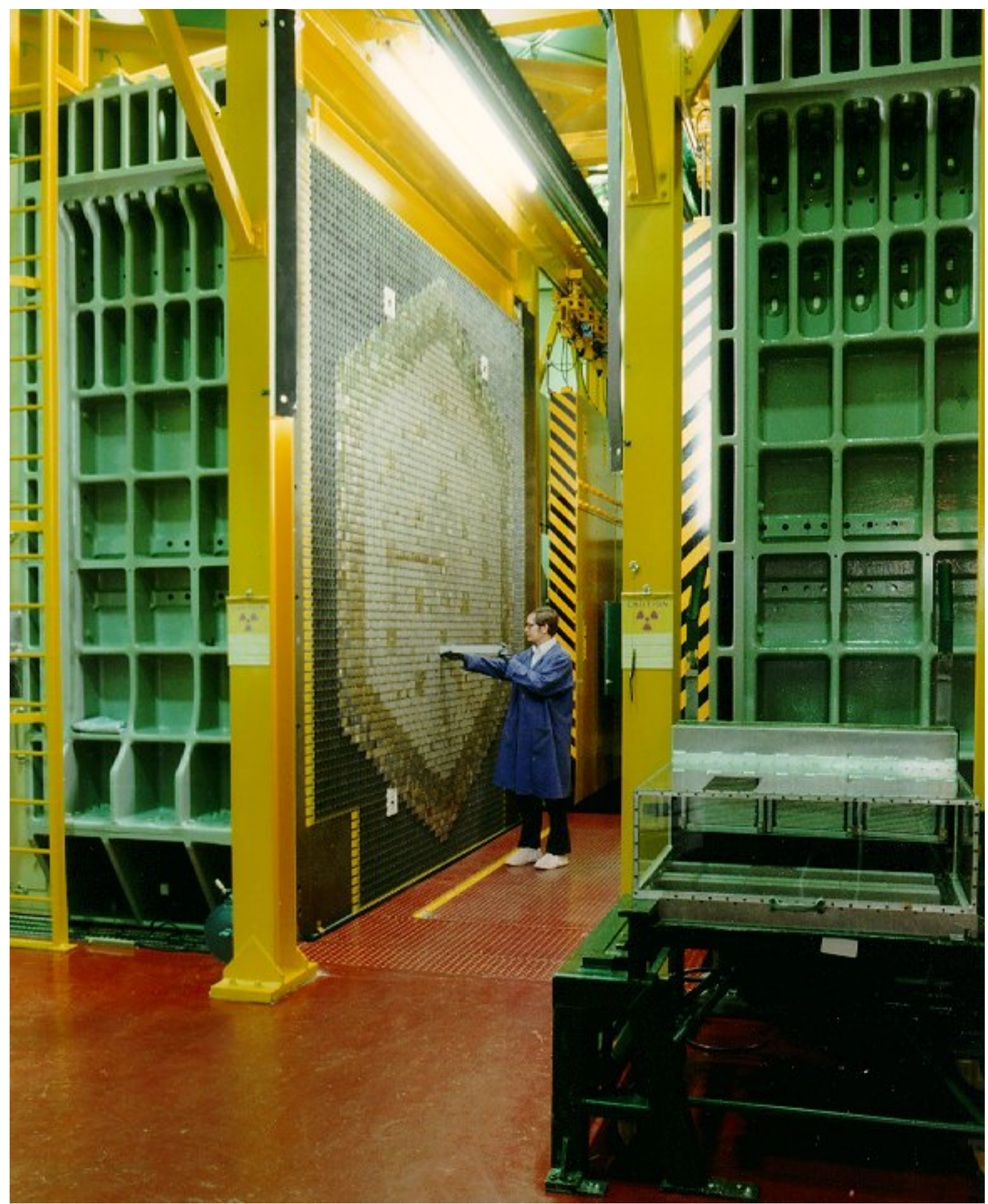

Figure 1.2 Manual Loading of the ZPPR Matrix. 


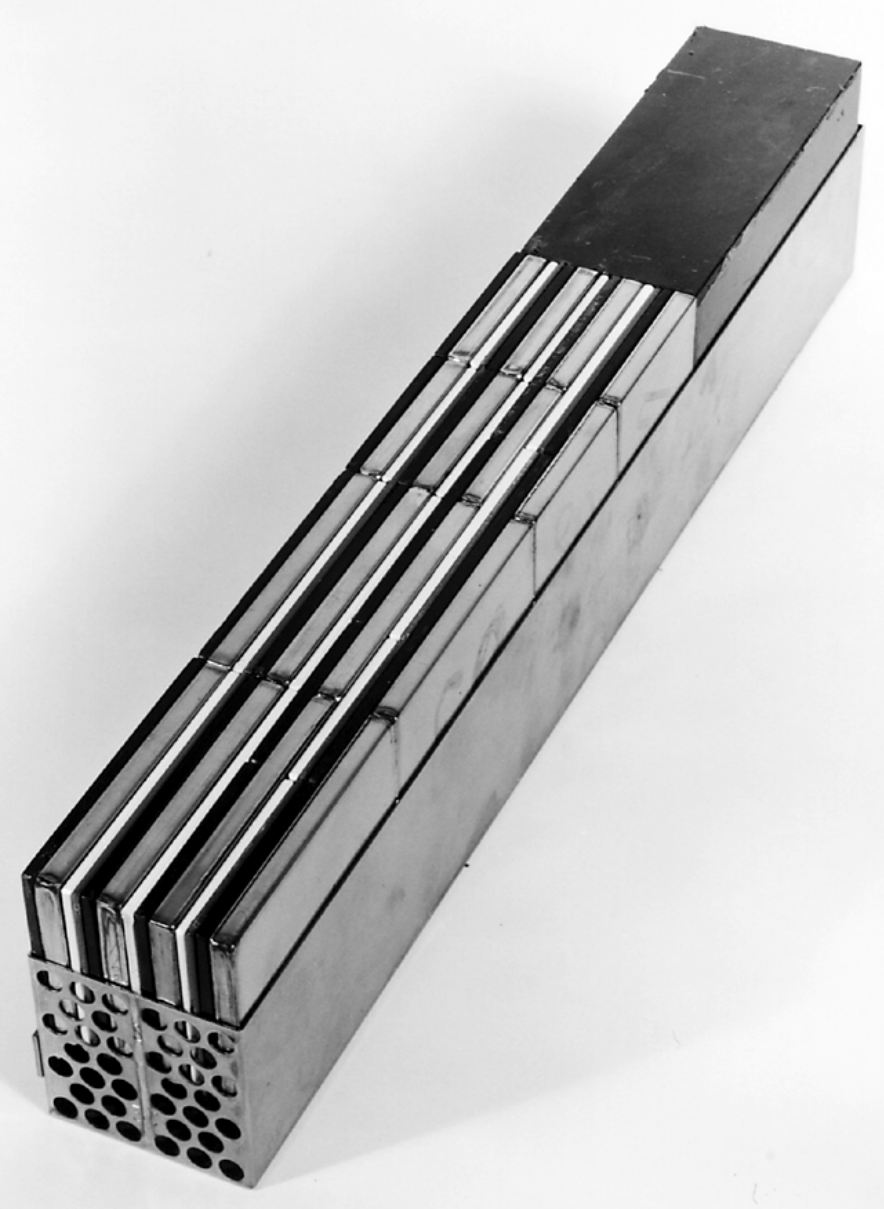

Figure 1.3 Typical ZPR or ZPPR Drawer.1

\subsection{ZPPR-15 Criticality Measurement Uncertainties}

ZPPR-15A was the first configuration studied in ZPPR-15. Each subsequent phase required major core changes from the reference configuration of the previous phase. Consequently, there was a standard approach-to-critical process for each phase followed by establishment of a reference critical configuration for each phase. Table 1.1 lists the core loading that was the reference critical configuration for each phase of ZPPR-15.

1 The plates are elevated above the bottom of the drawer in this photograph. 
Table 1.1 Reference Critical Configurations for ZPPR-15.

\begin{tabular}{|c|c|}
\hline Phase & Reference Critical Loading \\
\hline ZPPR-15A & 15 \\
\hline ZPPR-15B & 88 \\
\hline ZPPR-15C & 166 \\
\hline ZPPR-15D & 185 \\
\hline
\end{tabular}

The ZPPR staff published the excess reactivity and associated uncertainty for each reference critical configuration. The published uncertainty is just the statistical uncertainty in the measured excess reactivity plus some small contributions for the adjustments to a standard temperature and standard control rod positions. The reactor operators established a critical configuration with one or more control rods partially inserted. Excess reactivity is the difference between the critical configuration and the configuration with all control rods in their parked positions after adjustment to a set of standard operating conditions.

The published uncertainty is actually only a small component of the total uncertainty for the criticality measurement. The total uncertainty for each ZPPR-15 reference critical configuration consists of the combined uncertainties in the measured values, uncertainties in configuration geometry and uncertainties in material compositions. Each major uncertainty category consists of multiple components.

Uncertainties affecting criticality were divided into three broad categories for this analysis. They are uncertainties associated with: (1) measurement technique; (2) assembly geometry; and (3) material compositions. Each category is considered in turn and then the combined experimental uncertainty is presented.

The as-built models developed for ZPPR-15 and for this analysis are the most accurate models of ZPPR-15 that can be developed with the information that exists today. The as-built models include explicit representation of each matrix tube, drawer and plate in the reactor. Each plate in a drawer is placed in the correct location within the drawer, and each drawer is placed at the correct location in the matrix. The material compositions in the models are based on the last ZPPR materials library developed by the ZPPR staff.

Some adjustments to the measured excess reactivity are required to compensate for features of the actual reactor that are not included in the as-built models. The adjustments are identified and quantified. Each uncertainty estimate is one standard deviation.

\subsection{ZPPR-15 Uncertainty Calculations}

Evaluating the uncertainties related to measurement technique does not require calculations. Reactivity effects of uncertainties in geometric configurations were calculated with MCNP [1] because the alternatives to Monte Carlo analysis require significant approximations for geometry uncertainties. Most reactivity effects associated with uncertainties in compositions of the plates, drawers, and matrix tubes were calculated with a deterministic model because those reactivity effects are too small to calculate by Monte Carlo methods with reasonable computational resources. In the deterministic modeling of ZPPR-15, a program called "GenerateDeltaComps" (or GDC) was created to generate perturbed plate compositions associated with the known or estimated uncertainties for each plate or other component used in 
a ZPPR-15 loading [2]. GDC can be executed on any given ZPR or ZPPR loading and will create new input files for the BuildZPRmodel (BZM) program [2]. Each input file corresponds to a specific uncertainty (mass or isotopic content) of each plate "type" that is loaded into the given ZPR or ZPPR configuration. As an example of a plate type, the mass uncertainty arising from sodium in all sodium plates loaded is applied as a single perturbation input to BZM.

BZM creates a Cartesian structured grid DIF3D input where each grid point represents an axial segment of a ZPR or ZPPR drawer. The $\mathrm{MC}^{2}-3$ multi-group cross section generation code is used where BZM produces $\mathrm{MC}^{2}-3$ slab geometry input models for active core regions or infinite homogeneous input models for blankets, reflectors, and other regions [3]. The DIF3DVARIANT code is used to solve the steady state eigenvalue form of the transport equation where the differences in the eigenvalues due to plate composition perturbations are translated into the reactivity effects of the composition uncertainties [4].

After the GDC code is used to generate the perturbed plate composition input, the BZM code is used to regenerate the DIF3D input deck and associated $\mathrm{MC}^{2}-3$ input files. As one would expect, this generates a large number of $\mathrm{MC}^{2}-3$ and DIF3D input files. ZPPR-15A has $\sim 11000$ files for all of the stated plate uncertainties. Of course, it is not generally necessary to regenerate cross sections if the perturbation is small, so most of the $\mathrm{MC}^{2}-3$ input files are not needed. The advantage of having the $\mathrm{MC}^{2}-3$ input is that it leads to a consistent modeling approach for the entire ZPR or ZPPR problem and should give the best estimate of the actual uncertainty relative to doing a Monte Carlo calculation of the same plate uncertainty. In practice, the $\mathrm{MC}^{2}-3$ cross sections are regenerated only when the plate composition uncertainty leads to a rather large reactivity impact. No $\mathrm{MC}^{2}-3$ regeneration was needed for any of the plate uncertainties in the ZPPR-15 configurations. For all plate uncertainties, a detailed assessment of space-angleenergy impacts of the deterministic methodology was performed, and the best estimate possible (the highest space-angle-energy result attempted) of the true uncertainty is presented.

\section{ZPPR-15A Reference Critical Configuration}

At the beginning of the ZPPR-15 Program, all matrix tubes were empty. In the first steps of the ZPPR-15A approach-to-critical, stainless steel drawers containing radial blanket and radial reflector materials were loaded into the matrix tubes to construct the radial blanket and radial reflector for ZPPR-15. After the radial blanket and radial reflector were loaded, drawers containing core materials were loaded in groups in the standard approach-to-critical. After a group of core drawers was loaded, half 2 was moved toward half 1 until the two halves touched, and then the inserted control rods were withdrawn to measure the excess reactivity. If the resulting configuration was subcritical, the control rods were inserted, the two halves were separated, another group of core drawers was inserted, and the process was repeated. After some number of loading steps was completed, a critical configuration was established. In some cases, the first critical configuration became the reference critical configuration. In other cases, drawer adjustments were made at the core-blanket interface to produce a configuration with the desired shape or excess reactivity. The reference critical configuration for ZPPR-15A was loading 15 (ZPPR-15A L015).

Figure 2.1 shows a drawer master in the inner core of ZPPR-15A. Figure 2.2 shows a drawer master in the radial blanket of ZPPR-15, and Figure 2.3 shows a drawer master in the radial reflector of ZPPR-15. These are copies of the actual drawer master figures used by the technicians to load drawers for ZPPR-15. 
The letters shown in Figures $2.1-2.3$ were identifiers for the plate type, e.g., NA for sodium plates and PUMN for Pu-U-Mo plates manufactured by NUMEC. Each plate type was designated by an identifier consisting of $1-4$ characters. The numbers designate plate lengths and widths in inches.

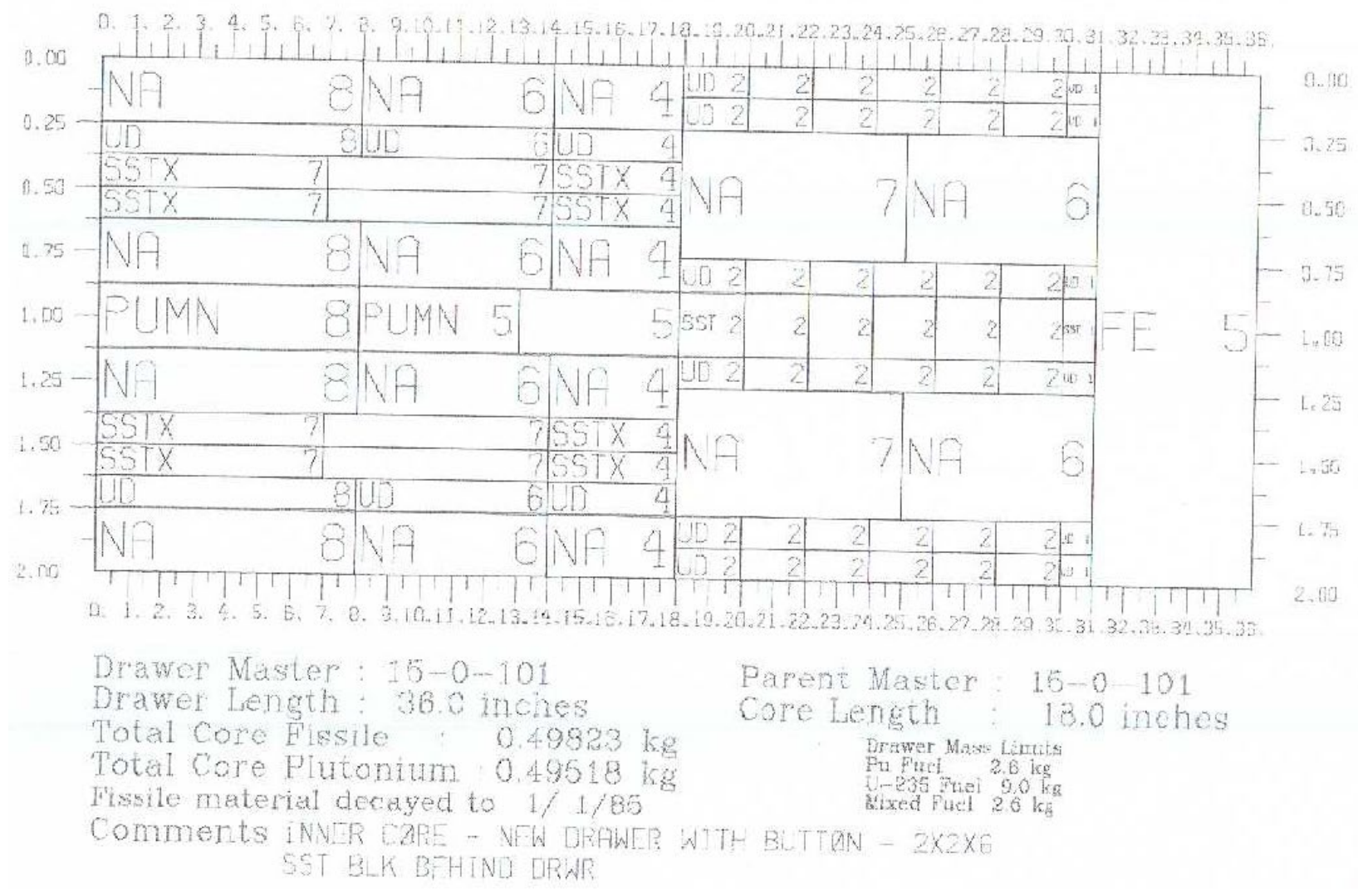

Figure 2.1 Drawer Master 15-0-101 - ZPPR-15A Inner Core Drawer. 


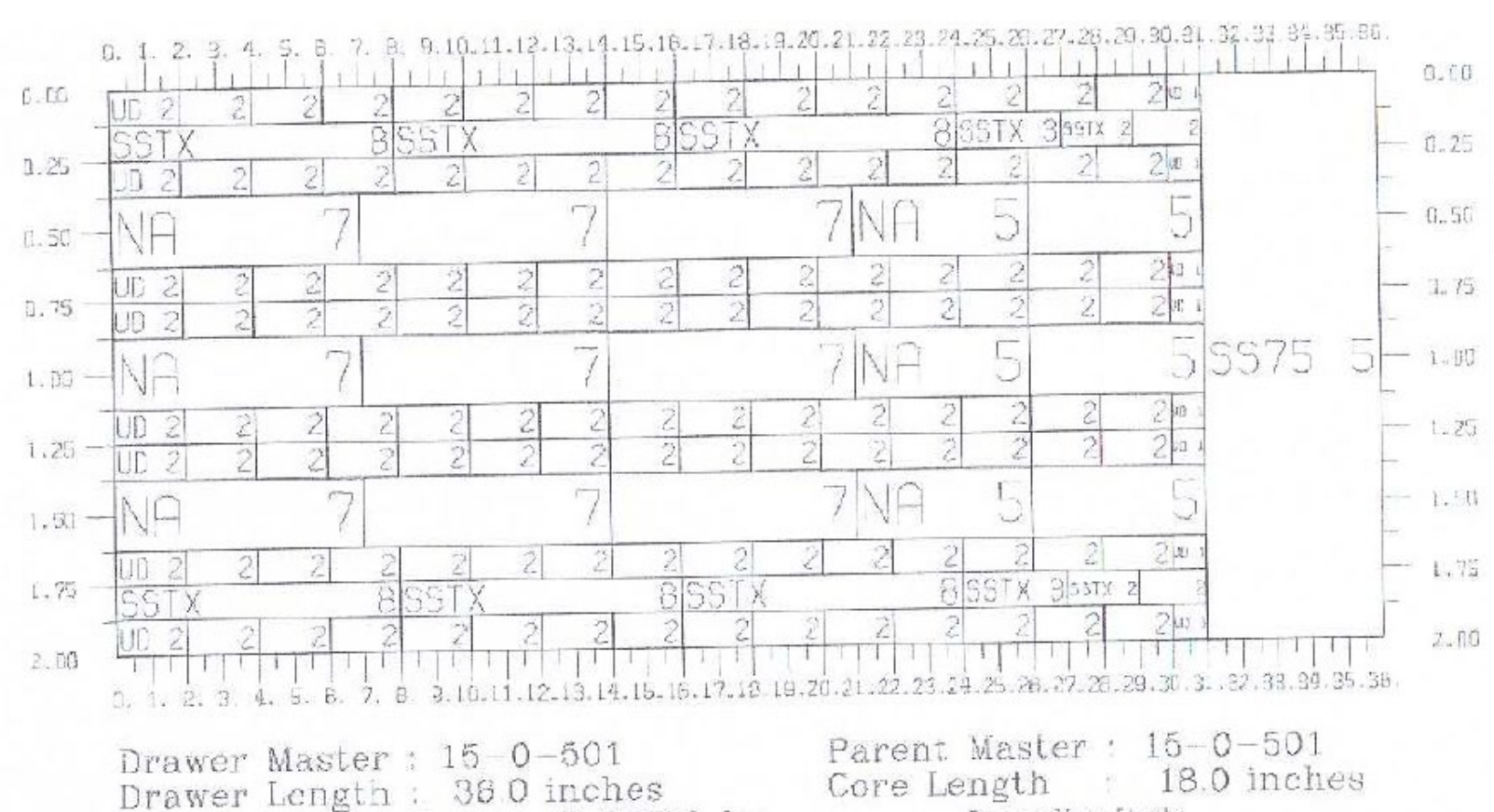

Figure 2.2 Drawer Master 15-0-501 - ZPPR-15 Radial Blanket Drawer.

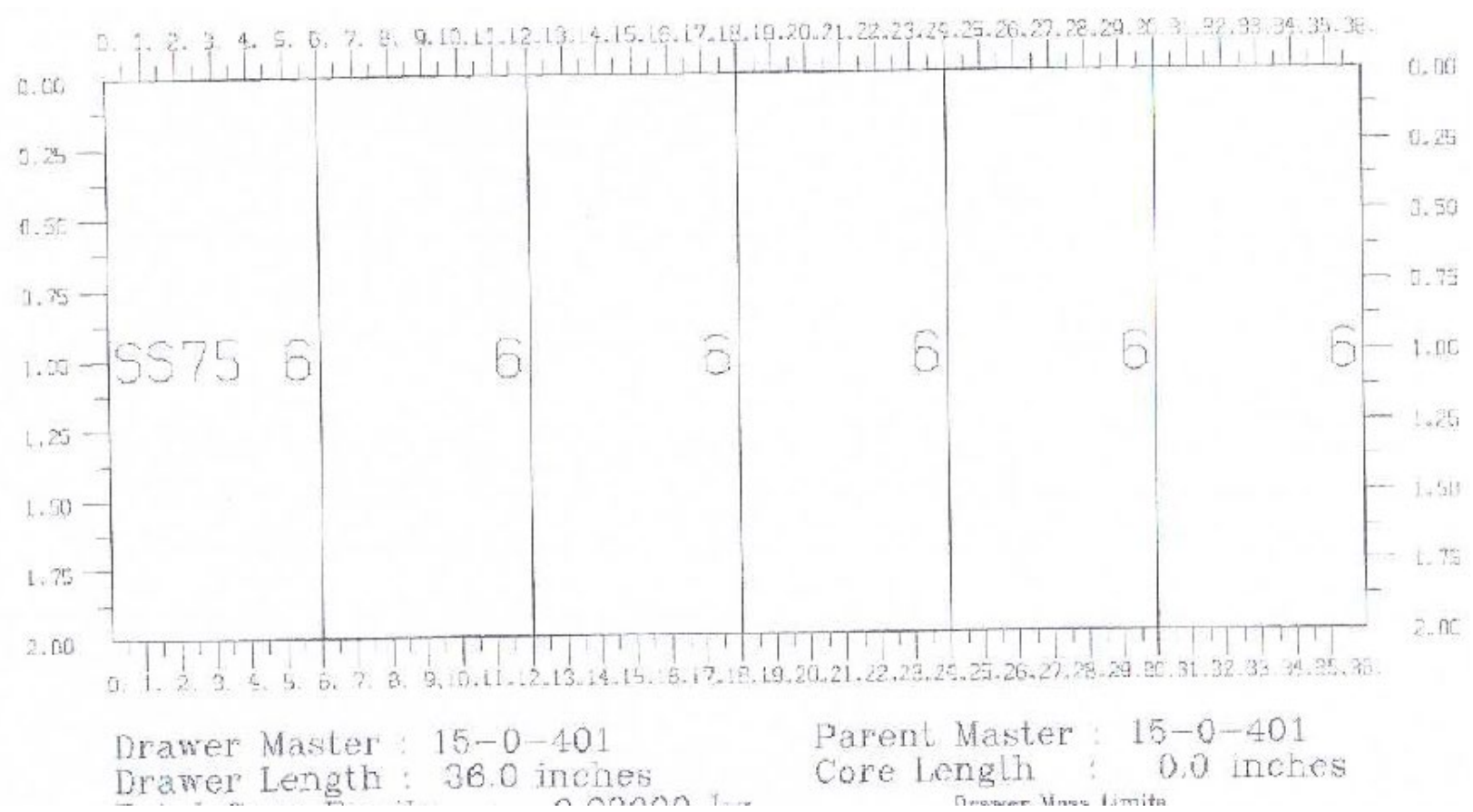

Figure 2.3 Drawer Master 15-0-401 - ZPPR-15 Radial Reflector Drawer.

A matrix map shows the drawer master loaded in each matrix tube. Figures 2.4 and 2.5 shows the matrix maps for half 1 and half 2, respectively, of ZPPR-15A L015, the ZPPR-15A reference critical configuration. The light blue portion of Figures 2.4 and 2.5 is the radial reflector, and the dark blue portion of these figures is the radial blanket. The area consisting almost entirely of white cells inside the radial blanket in Figures 2.4 and 2.5 is the inner core, and the area consisting of mixed green cells and white cells in these figures is the outer core. The white cells in the core are drawer masters containing a single fuel column, and the green 
cells are drawer masters containing two fuel columns. The orange cells are drawer masters containing a detector, and the brown cells are the locations containing a narrow drawer and a PSR control rod. The number in each cell is the third component of the drawer master identifier. For example, "401" in Figures 2.4 and 2.5 is an abbreviation for "15-0-401," the full identifier for one type of radial reflector drawer master. Likewise, "101" in Figures 2.4 and 2.5 is an abbreviation for "15-0-101," the full identifier for one type of ZPPR-15A core drawer master. Empty cells on the outside of the radial reflector are empty matrix tubes. The full ZPPR matrix was $77 \times 77$. The numbers in the top row of the matrix map figures are column numbers in the matrix, and the numbers in the first (leftmost) column of the matrix map figures are row numbers in the matrix. The matrix map figures only show the portion of the matrix containing drawers plus one extra row or column on each side to improve legibility.

\subsection{ZPPR-15A Measurement Technique Uncertainties}

Excess reactivity in a ZPPR configuration is the reactivity with all PSR control rods in their parked (withdrawn) positions. The excess reactivity for the reference critical configuration is measured at the reactor operating temperature and then is converted to excess reactivity at the standard reporting temperature of $20^{\circ} \mathrm{C}$ or $293 \mathrm{~K}$, standard configuration with all control rods parked at a standard position approximately 30 inches from the interface between half 1 and half 2 of the assembly and zero interface gap. The reported excess reactivity for ZPPR-15A L015 was $13.4 \pm 0.1 \phi$, and the reported $\beta_{\text {eff }}$ for ZPPR-15A was 0.003357 . Note that all reported values of $\beta_{\text {eff }}$ for ZPPR-15 were values calculated by the ZPPR staff.

One ZPPR document lists the final adjusted experimental $k_{\text {eff }}$ for ZPPR-15A as 1.00063 . That means the reported excess reactivity of $13.4 \pm 0.1 \notin$ is probably the original measured value before adjustment to the standard conditions of zero interface gap, $293 \mathrm{~K}$ and control rods parked at 30 inches from the core center. Using the measured gap coefficient, the table closure indicator values for ZPPR-15A L015 reactor run 16, the measured temperature coefficient and a reasonable estimate for the average core temperature, it is possible to derive a $\mathrm{k}_{\text {eff }}$ close to 1.00063 .

The uncertainty reported with the excess reactivity, $0.1 \phi$ or $0.34 \mathrm{pcm}$, includes counting statistics, detector calibration and several other factors such as uncertainties related to adjustment to the standard temperature and parked control rod positions. However, there are additional factors that determine the total measurement uncertainty.

The ZPPR cell was maintained at a very uniform temperature, and air was forced through the loaded matrix for cooling purposes. The average core temperature was determined from measurements with thermocouples distributed at a number of locations throughout the matrix. In previous ICSBEP and IRPhEP benchmarks of ZPPR critical configurations [5,6], the estimated uncertainty in thermocouple calibration was $0.5^{\circ} \mathrm{C}$, and the estimated uncertainty in the average core temperature was $1{ }^{\circ} \mathrm{C}$. When added in quadrature, the combined uncertainty in temperature was $1.12^{\circ} \mathrm{C}$. There is no reason to believe that these values are not applicable to ZPPR-15A, so the estimated uncertainty in the ZPPR-15A core temperature is assumed to be $1.12{ }^{\circ} \mathrm{C}$. 


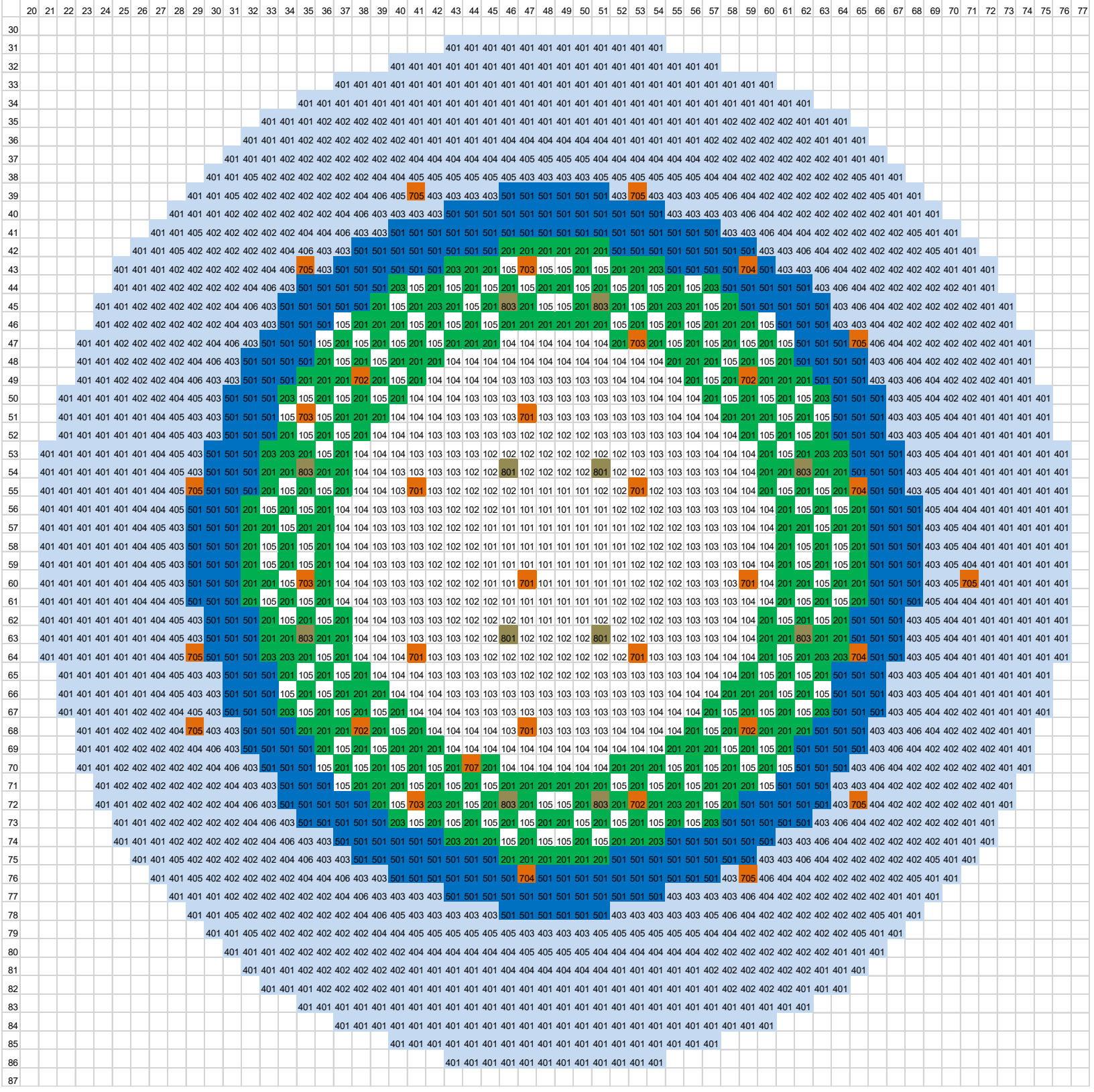

Figure 2.4 ZPPR-15A L015 - Matrix Map for Half 1. 


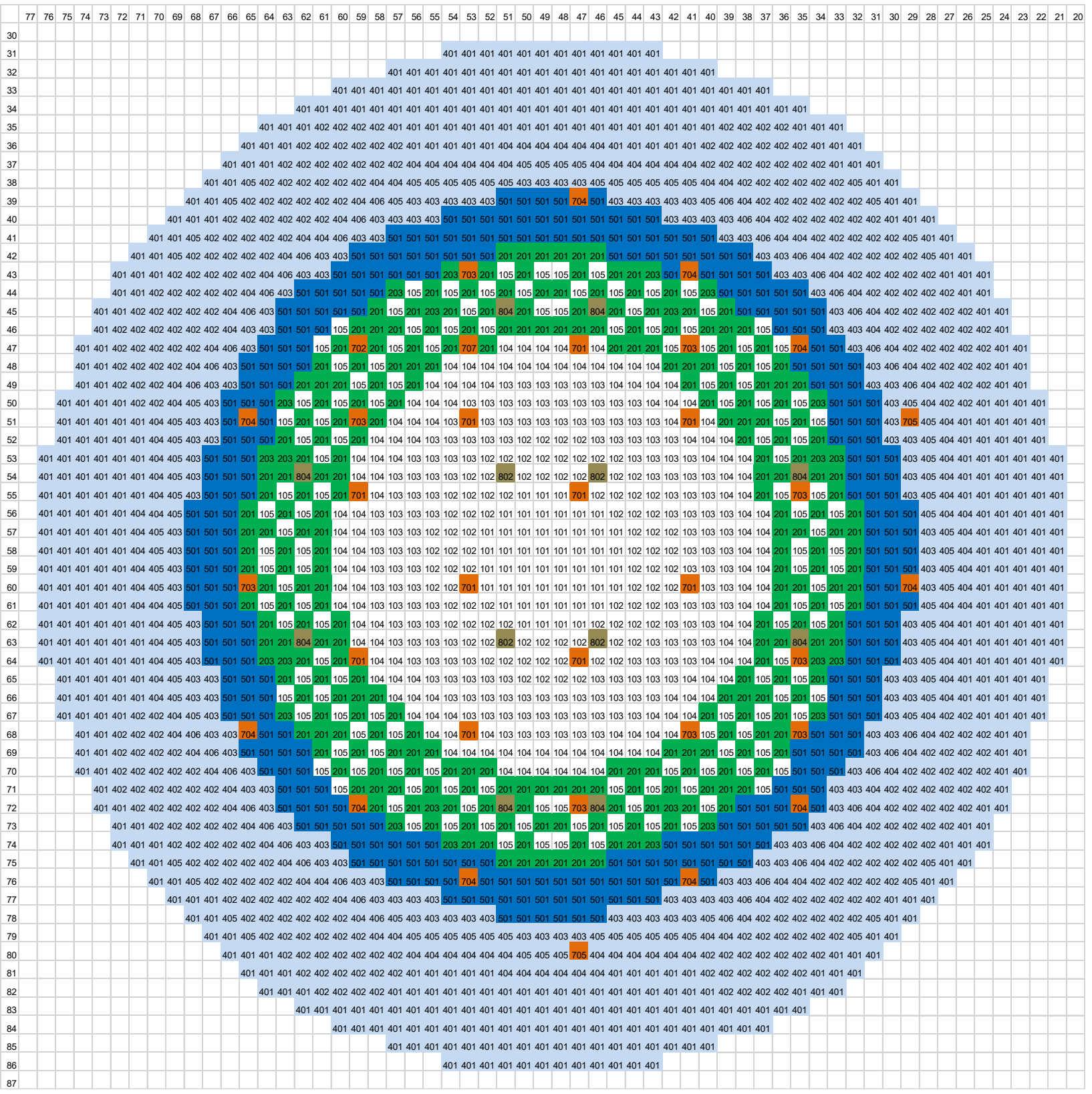

Figure 2.5 ZPPR-15A L015 - Matrix Map for Half 2.

The measured temperature coefficient for ZPPR-15A was $-1.05 \pm 0.1 \notin /{ }^{\circ} \mathrm{C}$ based upon measurements with 15 thermocouples, and the reported value of $\beta_{\text {eff }}$ for ZPPR-15A was 0.003357 . Based on the measured temperature coefficient, the reactivity effect of the $1.12{ }^{\circ} \mathrm{C}$ temperature uncertainty is $1.17 \phi$. However, the measured temperature coefficient is uncertain, and the contribution from the $\pm 0.1 \phi /{ }^{\circ} \mathrm{C}$ uncertainty in the temperature coefficient is $0.11 \phi$. Adding these two components in quadrature, the total reactivity effect of the temperature uncertainty is $1.18 \notin$ or $3.96 \mathrm{pcm}$. 
Uncertainty in configuration reproducibility is due to non-reproducibility in closing the matrix halves and positioning of the control rods, based on repeated measurements of excess reactivity when no material change was made in the matrix loading. In addition, there may be small differences in the reactor temperature distribution between different reactor runs. This uncertainty applies to any criticality measurement in any ZPR or ZPPR assembly. It is a very small effect in most ZPPR assemblies and is typically in the range $0.5-1 \mathrm{pcm}$. Nonreproducibility uncertainty is assumed to be $1 \mathrm{pcm}$ here. Compared to other uncertainties for criticality measurements, the non-reproducibility uncertainty is negligible for ZPPR-15 criticality measurements, so further analysis is not warranted.

Conversion from the natural measurement units, cents, to the calculation units, $\Delta \mathrm{k} / \mathrm{k}_{1} \mathrm{k}_{2}$ or pcm, requires knowledge of the delayed neutron kinetics parameters, particularly $\beta_{\text {eff. }}$ However, $\beta_{\text {eff }}$ is uncertain, and that uncertainty should be added to the excess reactivity expressed in $\% \Delta \mathrm{k} / \mathrm{k}_{1} \mathrm{k}_{2}$ or pcm. The estimated uncertainty in $\beta_{\text {eff }}$ is $5 \%$ which is the value assumed for ICSBEP/IRPhEP benchmarks of ZPR and ZPPR assemblies. The 5\% $\beta_{\text {eff }}$ uncertainty is consistent with the limited number of measurements of $\beta_{\text {eff }}$ performed for ZPR and ZPPR assemblies and with calculations of $\beta_{\text {eff }}$ for ZPR and ZPPR assemblies. The contributions due to the uncertainty in $\beta_{\text {eff }}$ are $2.25 \mathrm{pcm}$ for excess reactivity conversion, $0.20 \mathrm{pcm}$ for the temperature uncertainty conversion and $0.05 \mathrm{pcm}$ for non-reproducibility conversion. The total uncertainty contribution due the uncertainty in $\beta_{\text {eff }}$ is $2.26 \mathrm{pcm}$.

When the reactivity uncertainties due to excess reactivity, temperature, reproducibility and $\beta_{\text {eff }}$ uncertainties are added in quadrature, the total measurement uncertainty for ZPPR-15A L015 is $4.68 \mathrm{pcm}$.

\subsection{ZPPR-15A Geometry Uncertainties}

\subsubsection{Interface Gap}

The two halves of the ZPPR matrix were neither perfectly flat nor perfectly parallel due to normal manufacturing and machining tolerances. In addition, the weight of a large assembly could cause a slight deflection of the support plate. Because the matrix halves were not perfectly aligned, some parts of the two halves were not in physical contact at full closure. In other words, there was a small, non-uniform gap between the two matrix halves at the nominal full closure position. There could also be a small gap because of uncertainty in the actual position of the movable half at full closure relative to the position indicated by the instruments. As-built ZPPR models do not include an interface gap because of its small, non-uniform and imprecisely known size.

The ZPPR staff adjusted the reported excess reactivity to a condition with zero interface gap to facilitate analysis, but uncertainty related to the interface gap contributes to the total uncertainty. Consequently, a gap worth is derived here in conjunction with a gap uncertainty analysis.

There were position indicators at the four corners of the matrix that measured the corner separation, i.e., the separation between the corner of half 1 and the corresponding corner of half 2 , at the nominal full closure position. The size of the interface gap is estimated from the values indicated by those position indicators. The position indicator values were recorded in the reactor logbook for each reactor run. A gap separation unit was one mil, i.e., 0.001 inch. The 
excess reactivity of ZPPR-15A L015 was measured in reactor run 16. According to the ZPPR15 logbook, the measured table closure indicator values were $-32.5,-54.2,-32.6$ and -56.6 for reactor run 16. The average of these four values is -43.975 gap separation units or -0.043975 inches.

The worth of the interface gap was determined experimentally by measuring the interface gap coefficient during the operational measurements after the reference critical configuration was established. The gap coefficient was measured by driving the tables apart from the full closure position without any control rod motion and recording the associated reactivity change as a function of table separation. The measured interface gap coefficient for ZPPR-15A was -0.13 $\pm 0.02 \phi / \mathrm{mil}$. The product of the measured interface gap coefficient and the average gap determined from the position indicators is the gap worth.

The average gap determined from the position indicators is 43.975 mils or $0.1117 \mathrm{~cm}$ for ZPPR15A L015 (reactor run 16) according to the logbook, so the worth of the interface gap was $5.72 \pm 0.88 \notin$ or $-19.19 \pm 2.95 \mathrm{pcm}$.

The interface gap is not uniform. A reasonable estimate of the uncertainty associated with the non-uniform gap is $25 \%$ or $4.80 \mathrm{pcm}$. When this uncertainty is combined with the $2.95 \mathrm{pcm}$ uncertainty due to uncertainty in the measured interface gap coefficient, the final value for the interface gap worth is $-19.19 \pm 5.63 \mathrm{pcm}$.

\subsubsection{Positions of Drawers and Plates}

Besides the interface gap, there are three issues regarding the exact location of materials in the assembly. One is the possibility that the drawer fronts might not have been flush with the front edges of the matrix tubes. This issue was minimized by assuring that tabs on the drawer sides mated with notches in the matrix tubes. Care was taken to make the drawers flush with the matrix. Another issue is the possibility that the plate columns might not have been all the way forward against the drawer fronts. This problem was minimized by taking care when loading the plates in the drawers, by using springs to hold the plates there and by inserting the drawer tabs into the matrix tube notches slowly. The third issue to consider regards deviations from nominal dimensions for plates, drawers and matrix tubes. Deviations in the dimensions that affect the precise $\mathrm{X}$ and $\mathrm{Y}$ positions of materials in the unit cell are too small to impact $\mathrm{k}_{\mathrm{eff}}$ significantly. The dimensions that determine the volumes over which the material masses are distributed can have an effect. The plate lengths, drawer front thickness and the length of the front drawers affect the axial positions of the materials, similar to the interface gap effect. The effects of uncertainties in the axial positions of the plates relative to the drawer front and of deviations in the axial dimensions of the plates were estimated conservatively by introducing a 0.0075 in gap between the drawer front and the front of the plate columns in each drawer in both halves of the matrix. The computed worth of this gap is $-10.02 \pm 2.83 \mathrm{pcm}$.

\subsubsection{Matrix Tube Pitch}

A deviation from the nominal average spacing between matrix tubes would have a small effect on neutron leakage and thus $\mathrm{k}_{\text {eff. }}$ The nominal pitch of the ZPPR matrix tubes was 2.175 in in the X-direction and 2.175 in in the Y-direction. Note that these are the nominal dimensions of the $77 \times 77$ ZPPR matrix in place when ZPPR-15 was built. The original 53 x 55 ZPPR matrix used in early ZPPR assemblies had slightly different matrix tube dimensions. 
Deviations from the nominal matrix tube pitch arise from two sources. First, manufacturing tolerances introduce a small uncertainty in the pitch due to uncertainties in the external dimensions of the matrix tubes. Second, the weight of the loaded drawers could produce a small distortion in the matrix geometry although the size of any such distortion is limited by the clamping structure surrounding the matrix tubes.

It seems likely that the pitch uncertainty for the ZPPR matrix was measured, but no recorded value has been found. The measured uncertainty in the matrix pitch for ZPR-3, the first ZPR split table machine built by Argonne, was 0.001 in. The ZPR-3 matrix tubes were nearly identical to the ZPPR matrix tubes, so the same 0.001 in pitch uncertainty is assumed to apply to ZPPR.

The worth of the matrix tube pitch uncertainty was determined by creating two modified ZPPR15A L015 as-built models. The matrix tube pitch was increased by 0.001 inch in first model; the matrix tube pitch was decreased by 0.001 inch in the second model. The two modified models were each run with MCNP6 for one billion $\left(10^{9}\right)$ histories. The computed worth of the 0.001 in matrix tube pitch uncertainty is $26.04 \pm 2.24 \mathrm{pcm}$.

\subsubsection{Room Return}

An adjustment and an uncertainty are needed for room return of neutrons to the assembly. The assembly description in the as-built model encompasses only the matrix tubes and their contents. In reality, the matrix rests on a steel table with steel structures on the sides and top that constrain the matrix tubes (see Figures 1.1 and 1.2). In addition, there is a steel back plate behind the matrix tubes in each half to support the horizontal control rods and experimental equipment. The matrix machine was near the center of a large cylindrical cell (room) with a diameter of 50 feet $(15 \mathrm{~m})$ and height of 30 feet $(9 \mathrm{~m})$.

The worth of room return depends on the size and composition of the axial and radial blankets and reflectors. In the case of ZPPR-15, the radial blanket thickness was $\sim 15 \mathrm{~cm}$, and the radial reflector consisted of $\sim 40 \mathrm{~cm}$ of stainless steel. The axial blanket and reflector dimensions were similar. Consequently, the effects of room return in ZPPR-15A would be small.

The worth of room return was computed as the difference between the reference as-built model consisting only of the $77 \times 77$ array of matrix tubes and an expanded model in which the steel table, steel structures on the sides and top of the matrix and the surrounding room were added. The computed worth of room return was $5.01 \pm 2.83 \mathrm{pcm}$. The $2.83 \mathrm{pcm}$ Monte Carlo uncertainty is assumed to be the uncertainty in the worth of room return.

When the reactivity uncertainties due to the interface gap, nominal plate and drawer dimensions and positions, and matrix tube pitch are added in quadrature, the total geometry uncertainty for ZPPR-15A L015 is $28.46 \mathrm{pcm}$. Room return is treated as a bias in Section 2.5.

\subsection{ZPPR-15A Composition Uncertainties}

A bit of history about the materials inventory records is needed to appreciate the extent and limitations of the information available on the compositions of materials used in ZPPR-15. The material inventory for Argonne's ZPR and ZPPR facilities was accumulated over a period of more than three decades, starting with ZPR-3 in the mid-1950s. The procurement acceptance 
process required thorough documentation on dimensions, masses, compositions, etc. Information needed for day-to-day operations was extracted and compiled in working documents known informally as "hot constants memos." These memos give batch or lot average values of dimensions, masses and weight fractions of constituents, but they do not include uncertainties. The original documentation on most of the inventory used in ZPPR-15 has been lost, but the hot constants memos are still available. Consequently, indirect evidence and estimates were used to quantify many of the composition uncertainties. Compositions given in these hot constants documents are used directly. That is, weight fractions are not adjusted or renormalized to sum to $100 \%$.

Composition uncertainty for a component is treated in two parts - the uncertainty in total mass and the uncertainties in the weight fractions of the constituents. Since these two uncertainty sources are independent, they are added in quadrature. The reactivity effects of composition uncertainties were determined by computing the changes in $\mathrm{k}_{\mathrm{eff}} \mathrm{using}$ the deterministic model of ZPPR-15A L015 for most cases while MCNP calculations of the as-built model were used in a few cases. For almost all deterministic calculations of composition uncertainties, the energy dependence of the calculated reactivity worth was minor. The use of diffusion theory versus transport was considerably higher, but given that transport theory should always be used, the impact of using diffusion theory is not relevant. The use of high order transport approximations appears to be relatively insignificant. Almost all of the reactivity results were very similar if not identical when using a 33 group versus 230 group structure. Two notable exceptions to the preceding statements were that every $\mathrm{Mn}$ or $\mathrm{Ni}$ perturbation exhibited a strong energy dependent behavior. In every case, the $\mathrm{Mn}$ or Ni reactivity impact became less significant as the energy group structure was refined. The only other notable exception is that the $\mathrm{Cr}$ and $\mathrm{Fe}$ isotopic changes were weakly dependent upon the energy group structure. Given that $\mathrm{Cr}$ and Fe uncertainties are typically small and generally decrease with increasing energy refinement, any additional error caused by using a 230 group structure can be ignored.

Details of the mass measurements are unknown. For the plates and most of the drawers, it is assumed that measurements of masses were within $0.01 \mathrm{~g}$ of the actual values for plates with masses up to tens of grams and within $1 \mathrm{~g}$ for larger plates weighing kilograms (i.e., the uncertainty in weighing was $0.1 \%$ ). The working standard used to calibrate the scale is assumed to have an uncertainty of $0.05 \%$, which is a systematic uncertainty. The uncertainty in weighing could be statistical, but since no details of the process are available, this uncertainty is assumed to be systematic. The total uncertainty in mass is taken to be the sum of these two uncertainties, or $0.15 \%$. The mass uncertainty assumptions made for other items are specified as needed. This treatment of mass uncertainties has been used previously for every ICSBEP and IRPhEP benchmark of ZPR-3, ZPR-6, ZPR-9 and ZPPR assemblies. There is no evidence to support alternative assumptions for ZPPR-15.

\subsubsection{Sodium Plates}

Sodium plates consist of sodium sealed in stainless steel cans. The assumed $0.15 \%$ uncertainty in the mass of the sodium was calculated to be worth $1.55 \mathrm{pcm}$. The sodium in these plates is listed in the hot constants memo as being $99.93 \% \mathrm{Na}, 0.04 \% \mathrm{Ca}, 0.005 \% \mathrm{O}, 0.02 \% \mathrm{C}$, and $0.005 \% \mathrm{Cl}$. An upper bound on the effect of such small impurities was calculated by doubling the existing impurities thereby yielding an uncertainty in $\mathrm{k}_{\mathrm{eff}}$ of $0.12 \mathrm{pcm}$. The quadrature sum of the worths of the $1 \sigma$ mass and impurity uncertainties for the sodium plates is $1.55 \mathrm{pcm}$. 
The nominal can composition corresponds to Type 304 stainless steel. In addition to the uncertainty in the can mass, there is an uncertainty in the weight fractions of the components of the stainless steel. ICSBEP and IRPhEP benchmark evaluations performed to date consistently show that the only uncertainties in the composition of the stainless steel that may make a significant contribution to the total uncertainty are the uncertainties in the weight fractions of $\mathrm{Mn}, \mathrm{Cr}$ and $\mathrm{Ni}$. The Fe weight percent was adjusted to conserve mass when the weight fraction of $\mathrm{Mn}, \mathrm{Cr}$ or $\mathrm{Ni}$ was perturbed. Table 2.1 shows the reactivity effects of the uncertainties in mass and composition of the sodium cans.

Table 2.1 Worth of Sodium Can Uncertainties in ZPPR-15A.

\begin{tabular}{|l|c|c|c|}
\hline $\begin{array}{l}\text { Component } \\
\text { Uncertainty }\end{array}$ & $\begin{array}{c}\text { Assumed } \\
\text { Uncertainty }\end{array}$ & $\begin{array}{c}\text { Nominal } \\
\text { wt.\% }\end{array}$ & $\begin{array}{c}\text { Worth, } \\
\text { pcm }\end{array}$ \\
\hline Mass & 0.15 & & 1.05 \\
\hline $\mathrm{Mn}$ & 0.1 & 1.0 & 1.02 \\
\hline $\mathrm{Cr}$ & 0.2 & 19.0 & 0.11 \\
\hline $\mathrm{Ni}$ & 0.2 & 9.25 & 1.02 \\
\hline Total & & & 1.79 \\
\hline
\end{tabular}

\subsubsection{Zirconium Plates}

There were no zirconium plates in ZPPR-15A.

\subsubsection{Depleted Uranium Plates}

The 0.125 in depleted uranium (DU) plates (designated APW2 in the inventory documents) in ZPPR-15A were part of the original ZPPR plate inventory. The standard $0.15 \%$ mass uncertainty applies to the DU plates. Increasing the DU plate mass by $0.15 \mathrm{wt} . \%$ changed $\mathrm{k}_{\text {eff }}$ by $-12.58 \mathrm{pcm}$.

In addition to the mass uncertainty, there is an uncertainty in the weight fraction of ${ }^{235} \mathrm{U}$ in the DU plates. There is no specific information regarding the manufacturing of the DU plates, but the hot constants memos listed the average ${ }^{235} \mathrm{U}$ mass and average total uranium mass in each type of depleted uranium plate. The uncertainty in the ${ }^{235} \mathrm{U}$ wt. $\%$ in the depleted uranium metal plates used in ZPPR-15 is taken to be $0.01 \mathrm{wt} . \%$ based upon the spread in ${ }^{235} \mathrm{U}$ fractions in these DU plates in the hot constants memos. This value is consistent with the uncertainty in the ${ }^{235} U$ content in the depleted $\mathrm{U}_{3} \mathrm{O}_{8}$ plates manufactured by NUMEC for ZPPR. The ${ }^{235} \mathrm{U}$ concentration was increased by this amount, and the mass was preserved by decreasing the ${ }^{238} U$ concentration for the calculation of the worth of the ${ }^{235} U$ uncertainty. Any ${ }^{234} U$ or ${ }^{236} U$ in the DU plates is included in the mass of ${ }^{238} \mathrm{U}$ in the plates; there are no available records of the specific masses of ${ }^{234} \mathrm{U}$ or ${ }^{236} \mathrm{U}$ in the DU plates. Increasing the ${ }^{235} \mathrm{U}$ content in the DU plates by $0.01 \mathrm{wt} \% \%$ increased $\mathrm{k}_{\mathrm{eff}}$ by $29.58 \mathrm{pcm}$.

Available documents do not list the impurities in the DU plates, and they are not included in the as-built models. A 2018 chemical analysis of depleted uranium shipped from Y-12 to CERCA showed total impurities of $\sim 2000 \mathrm{ppm}$. The principal components were $769 \mathrm{ppm} \mathrm{Fe}$ and 954 ppm Al. The other significant impurities were $73 \mathrm{ppm} \mathrm{Cu}, 82 \mathrm{ppm} \mathrm{Ni}$ and $30 \mathrm{ppm} \mathrm{Si}$. It has been assumed here that the reactivity worth of the DU impurities is approximately equal to the worth of the $0.15 \%$ mass uncertainty and that the associated uncertainty in the worth of 
the DU impurities is $100 \%$. The assumed worth of the DU impurities which have been neglected is treated as a bias with an associated uncertainty.

Table 2.2 shows the reactivity worths of the uncertainties for the DU plates.

Table 2.2 Worth of Depleted Uranium Plate Uncertainties in ZPPR-15A.

\begin{tabular}{|c|c|c|}
\hline $\begin{array}{c}\text { Component } \\
\text { Uncertainty }\end{array}$ & $\begin{array}{c}\text { Uncertainty, } \\
\text { wt. } \%\end{array}$ & Worth, pcm \\
\cline { 3 - 3 } & & $\begin{array}{c}0.125 \text { in. } \\
\text { APW2 }\end{array}$ \\
\hline Mass & 0.15 & 12.58 \\
\hline${ }^{235}$ U Enrichment & 0.01 & 29.58 \\
\hline Total & & 32.15 \\
\hline
\end{tabular}

The depleted uranium impurity uncertainty is not listed in Table 2.2 because neglecting the impurities in the depleted uranium plates is treated as a bias in Section 2.5. The impurity uncertainty is included with the bias uncertainties.

The depleted uranium plates used at Argonne's ZPR and ZPPR facilities were coated with Kel$\mathrm{F}$ to prevent uranium corrosion and material loss during handling. Kel-F was a paint-like substance with a composition shown in Table 2.3. The Kel-F coating wore off during handling, so the plates were recoated periodically.

The thickness of the Kel-F coating on the DU plates is not recorded, but the initial average mass of Kel-F per plate was recorded. For practical purposes, the Kel-F coating can be regarded as similar to a coat of paint. Table 2.4 shows the types of DU plates used in ZPPR-15A L015, the number of DU plates of each type in the assembly and the average initial mass of Kel-F per plate for the DU plates.

Table 2.3 Kel-F Composition.

\begin{tabular}{|c|c|}
\hline Element & Weight Percent \\
\hline Hydrogen & 0.5 \\
\hline Carbon & 20.6 \\
\hline Chlorine & 30.5 \\
\hline Fluorine & 48.4 \\
\hline
\end{tabular}

Table 2.4 Average Kel-F Mass for Each DU Plate.

\begin{tabular}{|c|c|c|}
\hline $\begin{array}{c}\text { Plate Type } \\
\text { (Size, in.) }\end{array}$ & $\begin{array}{c}\text { Number of Plates } \\
\text { in ZPPR-15A L015 }\end{array}$ & $\begin{array}{c}\text { Kel-F Mass per } \\
\text { Plate, } g\end{array}$ \\
\hline $1 / 8 \times 2 \times 1$ & 16976 & 0.030 \\
\hline $1 / 8 \times 2 \times 2$ & 118992 & 0.057 \\
\hline $1 / 8 \times 2 \times 3$ & 2024 & 0.085 \\
\hline $1 / 8 \times 2 \times 4$ & 2712 & 0.11 \\
\hline $1 / 8 \times 2 \times 5$ & 4404 & 0.14 \\
\hline $1 / 8 \times 2 \times 6$ & 2584 & 0.16 \\
\hline $1 / 8 \times 2 \times 7$ & 2780 & 0.19 \\
\hline $1 / 8 \times 2 \times 8$ & 2626 & 0.22 \\
\hline
\end{tabular}

The Kel-F is not normally included in the as-built models. To determine the worth of the KelF, the reference model of ZPPR-15A L015 was modified to add the mass of Kel-F shown in 
column 3 of Table 2.4 to the depleted uranium plates in the model. The Kel-F was mixed homogeneously with the depleted uranium because it is not practical to include the Kel-F as a separate coating and because any heterogeneity effect would be negligible in the ZPPR-15 spectrum. In addition, any thickness assigned to the coating would be entirely arbitrary.

The worth of the Kel-F was determined as the difference between $k_{\text {eff }}$ for the reference model without Kel-F and $\mathrm{k}_{\text {eff }}$ for the modified model with the Kel-F. The computed worth of the Kel$\mathrm{F}$ was $-28.06 \pm 2.24 \mathrm{pcm}$. Some of the Kel-F wore off during handling, and ICSBEP/IRPhEP benchmarks for ZPR and ZPPR assemblies typically assume that the uncertainty in the Kel-F mass due to normal handling is $10 \%$. With this assumption, the total worth of the Kel-F in ZPPR-15A L015 is $-28.06 \pm 3.59 \mathrm{pcm}$, which is treated as a bias and associated uncertainty since the Kel-F is neglected in the reference as-built model.

\subsubsection{Natural Uranium Plates}

ZPPR-15A L015 contained a small number of natural uranium plates. The computed worth of the $0.15 \%$ mass uncertainty for these plates is $0.01 \mathrm{pcm}$ which is negligible. Any worths determined for impurities, etc. would also be negligible because of the small number of natural uranium plates used in ZPPR-15.

\subsubsection{HEU Plates}

Canned HEU plates were used in ZPPR-15C and ZPPR-15D. There were no HEU plates in ZPPR-15A or ZPPR-15B.

\subsubsection{Pu-U-Mo Plates}

The fuel for ZPPR-15A and ZPPR-15B consisted of Pu-U-Mo plates. In addition to being the core fuel for ZPPR-15A and ZPPR-15B, the Pu-U-Mo plates were required for reactivity worth measurements such as sodium void worth and control rod worth measurements in ZPPR-15. Except for measurements of very small reactivity worths, such as small sample worths, most reactivity worth measurements in ZPPR were based on the modified source multiplication technique. This technique required a subcritical reference configuration and a distributed source of neutrons in the core. The standard Pu-U-Mo plates used at ZPPR contained 28 wt.\% plutonium, $69.5 \mathrm{wt} . \%$ depleted uranium and $2.5 \mathrm{wt} . \%$ molybdenum with $11 \mathrm{wt} . \%{ }^{240} \mathrm{Pu}$ in the plutonium component. The ${ }^{240} \mathrm{Pu}$ in the $\mathrm{Pu}-\mathrm{U}-\mathrm{Mo}$ plates provided the distributed neutron source required for the modified source multiplication technique and provided the neutron source for reactor startup.

The estimated uncertainty in the plutonium composition is based upon some knowledge of the fuel plate manufacturing process. Thousands of $\mathrm{Pu}-\mathrm{U}-\mathrm{Mo}$ plates, in sizes ranging from 1 in $(2.5 \mathrm{~cm})$ to 8 in $(20 \mathrm{~cm})$ were made from 1100 melts. Each melt yielded several $0.25 \times 2 \times 15$ in $(0.64 \times 5 \times 38 \mathrm{~cm})$ castings. One casting per melt was used for three assays to measure the composition of the melt with samples taken from the top, middle, and bottom of the casting. The other castings were cut and milled to precise plate dimensions, weighed, clad in stainless steel and then weighed again. A data file containing the recorded weight of each isotope in each individual plate of Pu-U-Mo type is still available. It was used to generate mass and weight percent statistics for the Pu-U-Mo fuel plate types in ZPPR-15 L015. As such, the following 
expression (taken from historical ZPPR treatment) was used to estimate the variance in the plutonium mass:

$$
\frac{\sigma_{1}^{2}+\sigma_{2}^{2}}{n} \frac{N-n}{N-1}+\frac{\sigma_{3}^{2}}{M}+\sigma_{4}^{2}+\sigma_{5}^{2},
$$

where

$\sigma_{1}$ is the plate-to-plate variation in Pu mass, $\sigma_{2}$ is the error in using the cast-average $\mathrm{Pu}$ fraction for the plate-average $\mathrm{Pu}$ fraction, $\sigma_{3}$ is the random error in the cast-average $\mathrm{Pu}$ fraction, $\sigma_{4}$ is the systematic error in the chemical assay, $0.05 \%$, $\sigma_{5}$ is the systematic error in plate weighing, $0.05 \%$, $\mathrm{n}$ is the number of plates of this type used in the assembly, $\mathrm{N}$ is the number of plates of this type in the inventory, and $\mathrm{M}$ is the number of melts used to produce the inventory.

This expression was developed to account for a phenomenon that can be significant for Pu-UMo fuel. The phenomenon is that the plutonium component of the alloy deposited preferentially at the location where the liquid metal entered the mold. Consequently, the element fractions comprising the alloy varied somewhat, depending upon the location in the casting. A small number of samples were extracted from various locations in castings produced from a given melt. The average of chemical analysis results from the melt was used to assign a plutonium mass fraction to all of the plates from that melt. Thus, the declared plate-wise plutonium masses, which were evaluated statistically to derive $\sigma_{1}$, have some associated error in them. The $\sigma_{2}$ and $\sigma_{3}$ terms were introduced to account for this. With a nominal plutonium mass fraction of 0.28 for standard $\mathrm{Pu}-\mathrm{U}-\mathrm{Mo}$ plates, these terms can impact the computed uncertainty. Systematic errors are accounted for by the terms $\sigma_{4}$ and $\sigma_{5}$.

The values of $\mathrm{N}, \sigma_{1}$, and plutonium mass per plate for the $\mathrm{Pu}-\mathrm{U}-\mathrm{Mo}$ plates were derived from the available data file. They correspond to the dates of plate manufacture (i.e., before any decay of ${ }^{241} \mathrm{Pu}$ to $\left.{ }^{241} \mathrm{Am}\right)$. For the fuel plates, $\sigma_{3}$ was estimated from variations in the assay data to be $1.1 \%$. The $\sigma_{2}$ was taken to be $1 / 4$ of $\sigma_{3}$. The uncertainty in the plutonium contribution from each of the plate types used in the assembly had to be combined when applying the expression above. This was done by converting percent uncertainty to gram uncertainty and summing the mass contributions. The uncertainty in the total plutonium mass was computed to be 0.0787 wt.\%. Changing the plutonium (plus americium) mass by this amount in the deterministic model changed $\mathrm{k}_{\text {eff }}$ by $46.46 \mathrm{pcm}$.

The uncertainties in the plutonium isotopic weight fractions were determined using the same data sources and a similar formula to those used for plutonium mass, namely:

$$
\frac{\sigma_{6}^{2}}{\mathrm{n}} \frac{\mathrm{N}-\mathrm{n}}{\mathrm{N}-1}+\frac{\sigma_{7}^{2}}{\mathrm{M}}+\sigma_{8}^{2}
$$

where 
$\sigma_{6}$ is the plate-to-plate variation in the isotope weight percent, $\sigma_{7}$ is the random uncertainty in an isotopic assay, and $\sigma_{8}$ is the systematic error in the isotopic assay.

Like $\sigma_{1}, \sigma_{6}$ was derived from a statistical analysis of the plate-wise mass data. The $\sigma_{7}$ and $\sigma_{8}$ are isotope dependent, and the values used by the Argonne-West Analytical Laboratory were used here. For the major constituent, ${ }^{239} \mathrm{Pu}$, they are $0.25 \%$ and $0.0025 \%$, respectively. Again, the uncertainty contributions from the plate types were combined by converting percent uncertainty to gram uncertainty and summing the mass contributions.

The data and formula were used to modify the core composition in the deterministic model. The relative uncertainty in the ${ }^{239} \mathrm{Pu}$ weight percent was computed to be $0.0092 \%$. In the deterministic model, the ${ }^{239} \mathrm{Pu}$ concentration was increased by this amount and mass was preserved by decreasing just the ${ }^{240} \mathrm{Pu}$ concentration (a simplification justified by the very small size of the other isotopic concentrations). The resulting change in $\mathrm{k}_{\mathrm{eff}}$ is $4.20 \mathrm{pcm}$.

The weight percent of ${ }^{238} \mathrm{Pu},{ }^{241} \mathrm{Pu}$, and ${ }^{242} \mathrm{Pu}$ in the assembly before decaying ${ }^{241} \mathrm{Pu}$, was less than $2 \%$. The only isotope besides ${ }^{239} \mathrm{Pu}$ whose uncertainty would be expected to impact $\mathrm{k}_{\text {eff }}$ appreciably is ${ }^{240} \mathrm{Pu}$. The relative uncertainty in the ${ }^{240} \mathrm{Pu}$ weight percent is $0.0416 \%$ using values of $0.50 \%$ and $0.035 \%$ for $\sigma_{7}$ and $\sigma_{8}$, respectively. Modification of the ${ }^{240} \mathrm{Pu}$ weight percent led to a calculated effect on $\mathrm{k}_{\mathrm{eff}}$ of $2.58 \mathrm{pcm}$. The combined uncertainty in $\mathrm{k}_{\mathrm{eff}}$ due to the uncertainties in the original weight fractions of the remaining three isotopes is assumed to be no larger than this (i.e., it is taken to be $2.58 \mathrm{pcm}$ ). In principle, the total uncertainty in the plutonium isotopic fractions could be reduced by using the constraint that the sum of these fractions was unity. Because this uncertainty component does not make a significant contribution to the total uncertainty in the system reactivity, further analysis was deemed unwarranted.

Some of the ${ }^{241} \mathrm{Pu}$ that was in the fuel plates when they were manufactured decayed prior to the ZPPR-15 Program. The Pu-U-Mo NUMEC and Dow plates were manufactured in the late 1960s and ZPPR-15A L015 was made critical on May 9, 1985. A nominal ${ }^{241} \mathrm{Pu}$ half-life of 14.29 years was used to decay the isotope. The actual isotopic content numbers in the inventory database were decayed to a reference date of January 1, 1977 by the ZPPR staff. The estimated uncertainty in the ${ }^{241} \mathrm{Pu}$ decay constant is $1 \%$. Increasing the decay constant increases the ${ }^{241} \mathrm{Am}$ mass and decreases the ${ }^{241} \mathrm{Pu}$ mass. Increasing the decay constant by $1 \%$ reduces $\mathrm{k}_{\text {eff }}$ by 3.03 pcm.

The specification for production of the NUMEC Pu-U-Mo plates required a ${ }^{235} \mathrm{U}$ enrichment of $0.22 \pm 0.02 \mathrm{wt} . \%$ in the uranium component. It appears that the $0.02 \mathrm{wt} . \%$ represented the two sigma confidence interval, so the corresponding one sigma uncertainty is $0.01 \mathrm{wt} . \%$. The ${ }^{235} \mathrm{U}$ mass was increased by $0.01 \%$ and the ${ }^{238} \mathrm{U}$ mass was reduced correspondingly in the deterministic model. The resulting uncertainty in $\mathrm{k}_{\mathrm{eff}}$ is $26.78 \mathrm{pcm}$.

The uncertainty in the mass of molybdenum in the Pu-U-Mo fuel alloy was computed in the same way as the plutonium mass uncertainty. The computed molybdenum mass uncertainty is $0.0835 \%$. Changing the core region molybdenum atom density by this amount changes $\mathrm{k}_{\mathrm{eff}}$ by $0.17 \mathrm{pcm}$. 
The trace impurities in the Pu-U-Mo are not listed. The ZPPR hot constants memo lists the average mass of each $\mathrm{Pu}$ isotope, ${ }^{241} \mathrm{Am},{ }^{235} \mathrm{U},{ }^{238} \mathrm{U}$ and $\mathrm{Mo}$ in the plate core, i.e., the Pu-U-Mo fuel meat, for each $\mathrm{Pu}-\mathrm{U}-\mathrm{Mo}$ plate type. The hot constants memos also list the average core mass for each $\mathrm{Pu}-\mathrm{U}-\mathrm{Mo}$ plate type. It is assumed here that the difference between the average core mass and the sum of the average masses of the $\mathrm{Pu}, \mathrm{Am}, \mathrm{U}$ and Mo in each $\mathrm{Pu}-\mathrm{U}-\mathrm{Mo}$ plate type is the average impurity mass for that plate type. Table 2.5 lists the average impurity mass, average core mass and average impurity weight percent for each NUMEC Pu-U-Mo plate type used in ZPPR-15.

Table 2.5 Average Impurity Content of NUMEC Pu-U-Mo Fuel Meat.

\begin{tabular}{|c|c|c|c|}
\hline $\begin{array}{c}\text { Nominal Plate } \\
\text { Dimensions, in }\end{array}$ & Impurity Mass, $g$ & Core Mass, $g$ & Impurity wt.\% \\
\hline $1 / 4 \times 2 \times 4$ & 0.0485 & 437.8925 & 0.0111 \\
\hline $1 / 4 \times 2 \times 5$ & 0.0792 & 554.0931 & 0.0143 \\
\hline $1 / 4 \times 2 \times 6$ & 0.0739 & 669.2417 & 0.0110 \\
\hline $1 / 4 \times 2 \times 7$ & 0.0873 & 783.7256 & 0.0111 \\
\hline $1 / 4 \times 2 \times 8$ & 0.0998 & 901.1828 & 0.0111 \\
\hline
\end{tabular}

The actual impurities are not listed in the hot constants memos. The principal source of impurities in the $\mathrm{Pu}-\mathrm{U}-\mathrm{Mo}$ plates would be the depleted uranium that represents $\sim 69.5 \mathrm{wt} \% \%$ of the core of each $\mathrm{Pu}-\mathrm{U}-\mathrm{Mo}$ plate with a smaller contribution carried over from production of the plutonium in these plates. Table 2.6 shows the assumed impurities in the Pu-U-Mo plates based upon the depleted uranium shipped from Y-12 to CERCA that was discussed for the depleted uranium in Section 2.2.3.

Table 2.6 Assumed Impurity Composition for Pu-U-Mo Plates.

\begin{tabular}{|c|c|c|}
\hline Element & ppm & Fraction \\
\hline $\mathrm{C}$ & 787 & 0.27251 \\
\hline $\mathrm{Ni}$ & 82 & 0.02839 \\
\hline $\mathrm{Fe}$ & 769 & 0.26627 \\
\hline $\mathrm{Cu}$ & 73 & 0.02528 \\
\hline $\mathrm{Si}$ & 30 & 0.01039 \\
\hline $\mathrm{Al}$ & 954 & 0.33033 \\
\hline $\mathrm{O}$ & 193 & 0.06683 \\
\hline Total & 2888 & 1.00000 \\
\hline
\end{tabular}

The computed worth of the impurities in the Pu-U-Mo plates in ZPPR-15A L015 is $2.00 \pm 2.83$ pcm. These impurities are neglected in the as-built model, so the computed impurity worth is assumed as the bias for neglecting the impurities in the Pu-U-Mo plates in ZPPR-15A L015.

Table 2.7 shows the reactivity effects of the uncertainties in the mass and composition of the $\mathrm{Pu}-\mathrm{U}-\mathrm{Mo}$ alloy in the Pu-U-Mo plates in ZPPR-5A L015. 
Table 2.7. Worth of Pu-U-Mo Alloy Uncertainties in ZPPR-15A.

\begin{tabular}{|l|c|}
\hline Component Uncertainty & Worth, pcm \\
\hline $\mathrm{Pu}$ mass & 46.46 \\
\hline${ }^{239} \mathrm{Pu}$ fraction & 4.20 \\
\hline${ }^{240} \mathrm{Pu}$ fraction & 2.58 \\
\hline Other Pu isotopes & 2.58 \\
\hline${ }^{241} \mathrm{Pu}$ decay & 3.03 \\
\hline${ }^{235} \mathrm{U}$ in depleted uranium & 26.78 \\
\hline Mo mass & 0.17 \\
\hline Total & 53.99 \\
\hline
\end{tabular}

The Pu-U-Mo alloy was clad in stainless steel. The nominal can composition corresponds to Type 304 stainless steel. In addition to the uncertainty in the can mass, there is an uncertainty in the weight fractions of the components of the stainless steel. Based upon the experience with many ICSBEP/IRPhEP benchmarks of ZPR and ZPPR assemblies, the only uncertainties in the composition of the stainless steel that may make a significant contribution to the total uncertainty are the uncertainties in the weight fractions of $\mathrm{Mn}, \mathrm{Cr}$ and $\mathrm{Ni}$. Table 2.8 shows the reactivity effects of the uncertainties in mass and composition for the $\mathrm{Pu}-\mathrm{U}-\mathrm{Mo}$ cans.

Table 2.8. Worth of Pu-U-Mo Can Uncertainties in ZPPR-15A.

\begin{tabular}{|l|c|c|c|}
\hline $\begin{array}{l}\text { Component } \\
\text { Uncertainty }\end{array}$ & $\begin{array}{c}\text { Assumed } \\
\text { Uncertainty }\end{array}$ & $\begin{array}{c}\text { Nominal } \\
\text { wt.\% }\end{array}$ & $\begin{array}{c}\text { Worth, } \\
\text { pcm }\end{array}$ \\
\hline Mass & 0.15 & & 0.42 \\
\hline $\mathrm{Mn}$ & 0.1 & 1.0 & 0.35 \\
\hline $\mathrm{Cr}$ & 0.2 & 19.0 & 0.05 \\
\hline $\mathrm{Ni}$ & 0.2 & 9.25 & 0.35 \\
\hline Total & & & 0.65 \\
\hline
\end{tabular}

\subsubsection{Matrix Tubes}

The matrix tubes were made of Type 304 stainless steel. The nominal matrix was 77 x77 although the matrix tubes in the lower corners (approximately $10 \times 10$ ) were removed to provide space for detectors and other equipment. Each matrix tube had nominal outer dimensions of $5.5245 \times 5.5245 \times 152.4 \mathrm{~cm}$ and a nominal thickness of $0.1016 \mathrm{~cm}$.

The uncertainty in the matrix tube mass was assumed to be $2 \%$ in all ICSBEP and IRPhEP benchmarks, and the same mass uncertainty will be assumed here. The uncertainties assumed above for the weight fractions of $\mathrm{Mn}, \mathrm{Cr}$ and $\mathrm{Ni}$ in the stainless steel apply to the matrix tubes. Table 2.9 shows the reactivity effects of the uncertainties in mass and composition for the matrix tubes in ZPPR-15A.

Table 2.9 Worth of Matrix Tube Uncertainties in ZPPR-15A.

\begin{tabular}{|l|c|c|c|}
\hline $\begin{array}{l}\text { Component } \\
\text { Uncertainty }\end{array}$ & $\begin{array}{c}\text { Assumed } \\
\text { Uncertainty }\end{array}$ & $\begin{array}{c}\text { Nominal } \\
\text { wt. } \%\end{array}$ & $\begin{array}{c}\text { Worth, } \\
\text { pcm }\end{array}$ \\
\hline Mass & 2.0 & & 15.80 \\
\hline $\mathrm{Mn}$ & 0.1 & 1.0 & 1.49 \\
\hline $\mathrm{Cr}$ & 0.2 & 19.0 & 0.29 \\
\hline $\mathrm{Ni}$ & 0.2 & 9.25 & 0.91 \\
\hline Total & & & 15.89 \\
\hline
\end{tabular}




\subsubsection{Drawers}

There were two types of drawers present in ZPPR-15A. The overwhelming majority of these drawers were normal 36.252 in drawers with a nominal interior width slightly larger than two inches to accommodate the normal two inch width plate loading. Twelve drawers in each half were PSR drawers, which were 0.5 in narrower than normal drawers to allow for the presence of 0.5 in control rod guide tubes.

The drawers were made of Type 304 stainless steel. The uncertainty in the drawer mass is $0.15 \%$, the standard component mass uncertainty. The uncertainties assumed above for the weight fractions of $\mathrm{Mn}, \mathrm{Cr}$ and $\mathrm{Ni}$ in the stainless steel apply to the drawers. Table 2.10 shows the reactivity effects of the uncertainties in mass and composition for the drawers in ZPPR$15 \mathrm{~A}$.

Table 2.10. Worth of Drawer Uncertainties in ZPPR-15A.

\begin{tabular}{|l|c|c|c|c|}
\hline Component & Assumed & Nominal & \multicolumn{2}{|c|}{ Worth, pcm } \\
\cline { 4 - 5 } Uncertainty & Uncertainty & wt. $\%$ & Normal Drawers & PSR Drawers \\
\hline Mass & 0.15 & & 0.70 & $<0.01$ \\
\hline $\mathrm{Mn}$ & 0.1 & 1.0 & 0.85 & $<0.01$ \\
\hline $\mathrm{Cr}$ & 0.2 & 19.0 & 0.16 & $<0.01$ \\
\hline $\mathrm{Ni}$ & 0.2 & 9.25 & 0.54 & $<0.01$ \\
\hline Total & & & 1.24 & 0.01 \\
\hline
\end{tabular}

\subsubsection{Steel Blocks}

There was a steel block at the back of each core drawer except the PSR drawers and the detector drawers. This block simulated the first 5 inches of the axial reflector in ZPPR-15. No specifications for these steel blocks have been found, but the composition listed in the inventory records is consistent with low carbon steel such as SAE/AISI 1020 or SAE/AISI 1030. The $\mathrm{Mn}, \mathrm{C}$ and $\mathrm{Cr}$ weight percents are $0.71,0.17$ and 0.03 , respectively, in these blocks. Table 2.11 shows the reactivity effects of the uncertainties in mass and composition for the steel blocks in ZPPR-15A.

Table 2.11. Worth of Steel Block Uncertainties in ZPPR-15A

\begin{tabular}{|l|c|}
\hline $\begin{array}{l}\text { Component } \\
\text { Uncertainty }\end{array}$ & $\begin{array}{c}\text { Worth, } \\
\text { pcm }\end{array}$ \\
\hline Mass & $<0.01$ \\
\hline $\mathrm{Mn}$ & $<0.01$ \\
\hline $\mathrm{Cr}$ & $<0.01$ \\
\hline $\mathrm{C}$ & 0.02 \\
\hline Total & 0.02 \\
\hline
\end{tabular}

\subsubsection{Stainless Steel Plates}

There were four different groups of stainless steel plates present in ZPPR-15A L015. The identifiers for those groups are SST, SS75, SSTX and SSET in the inventory records. Aside from identifying separate lots of stainless steel plates, those identifiers have no particular significance. These four groups of stainless steel plates were obtained at different times from 
different suppliers. Consequently, the four groups of stainless steel plates will be treated as being independent for purposes of uncertainty analysis.

These plates were made of Type 304 stainless steel. The uncertainty in plate mass is $0.15 \%$, the standard component mass uncertainty. The uncertainties assumed above for the weight fractions of $\mathrm{Mn}, \mathrm{Cr}$ and $\mathrm{Ni}$ in the stainless steel apply to these plates. Table 2.12 shows the reactivity effects of the uncertainties in mass and composition for the stainless steel plates in ZPPR-15A.

Table 2.12. Worth of Stainless Steel Plate Uncertainties in ZPPR-15A.

\begin{tabular}{|l|c|c|c|c|c|c|}
\hline Component & Assumed & Nominal & \multicolumn{4}{|c|}{ Worth, pcm } \\
\cline { 4 - 7 } Uncertainty & Uncertainty & wt. $\%$ & SST & SS75 & SSTX & SSET \\
\hline Mass & 0.15 & 0.15 & 1.00 & 0.16 & 2.95 & $<0.01$ \\
\hline $\mathrm{Mn}$ & 0.1 & 1.0 & 0.95 & 0.21 & 3.26 & $<0.01$ \\
\hline $\mathrm{Cr}$ & 0.2 & 19.0 & 0.30 & 0.19 & 0.12 & $<0.01$ \\
\hline $\mathrm{Ni}$ & 0.2 & 9.25 & 0.72 & 0.27 & 2.33 & $<0.01$ \\
\hline Total & & & 1.59 & 0.42 & 4.98 & $<0.01$ \\
\hline
\end{tabular}

In earlier work, an uncertainty of $0.1 \mathrm{pcm}$ was computed for the effects of humidity for another ZPPR Program. That uncertainty is assumed to apply in ZPPR-15 as well. The effect of humidity is negligible, so refining this value would have no significant effect on the total uncertainty.

The total composition uncertainty is $65.09 \mathrm{pcm}$.

\subsection{Total Uncertainty for ZPPR-15A Loading 15}

Table 2.13 summarizes the uncertainty components for measurement technique, configuration geometry and material compositions and lists the total uncertainty for ZPPR-15A L015. Note that Table 2.13 does not include the effects of bias for items that are not included in the as-built model. Bias is addressed in Section 2.5.

The reported experimental $\mathrm{k}_{\mathrm{eff}}$ after adjustment to standard reporting conditions was 1.00063 . When the total uncertainty listed in Table 2.13 is included, the experimental $\mathrm{k}_{\text {eff }}$ is $1.00063 \pm$ 0.00071 .

\subsection{Biases or Adjustments for ZPPR-15A Loading 15}

Four adjustments to the experimental $\mathrm{k}_{\mathrm{eff}}$ are required to account for features that are not included in the as-built model. The interface gap is not included in the as-built model, but the ZPPR staff adjusted the reported excess reactivity to a condition with zero interface gap. Consequently, there is no bias associated with neglecting the interface gap in the as-built model.

The reference as-built model does not include the split tables, clamping structure or the room in which the machine was located. Addition of room return increases the reactivity by $5.01 \pm$ $2.83 \mathrm{pcm}$, so neglecting room return reduces the reactivity by $-5.01 \pm 2.83 \mathrm{pcm}$.

Available documents do not list the impurities in the depleted uranium plates, and the depleted uranium impurities are neglected in the as-built model. The worth of the depleted uranium plate impurities is assumed to be approximately equal to the $0.15 \%$ uncertainty in the mass of the depleted uranium plates. Increasing the depleted uranium plate masses by $0.15 \%$ for the 
assumed mass uncertainty reduced $\mathrm{k}_{\text {eff }}$ by $-12.58 \mathrm{pcm}$. Adding the impurities to the depleted uranium plates would have approximately the same effect. The uncertainty in the impurity level is assumed to be $100 \%$, so neglecting the impurities in the depleted uranium increases reactivity by $12.58 \pm 12.58 \mathrm{pcm}$.

Table 2.13. Total Uncertainty for ZPPR-15A L015.

\begin{tabular}{|c|c|}
\hline Uncertainty Component & Uncertainty, pcm \\
\hline \multicolumn{2}{|c|}{ Measurement Technique } \\
\hline Excess reactivity & 0.34 \\
\hline Temperature & 3.96 \\
\hline Reproducibility & 1.00 \\
\hline$\beta_{\text {eff }}$ uncertainty & 2.26 \\
\hline Subtotal & 4.68 \\
\hline \multicolumn{2}{|l|}{ Geometry } \\
\hline Interface gap & 5.60 \\
\hline Nominal plate, drawer dimensions & 10.02 \\
\hline Matrix tube pitch & 26.04 \\
\hline Subtotal & 28.46 \\
\hline \multicolumn{2}{|c|}{ Composition } \\
\hline Pu-U-Mo alloy & 53.99 \\
\hline Pu-U-Mo plate clad & 0.65 \\
\hline Sodium & 1.55 \\
\hline Sodium plate clad & 1.79 \\
\hline Natural uranium & 0.01 \\
\hline Depleted uranium - APW2 & 32.15 \\
\hline Matrix tubes & 15.89 \\
\hline Drawers - standard & 1.24 \\
\hline Drawers - PSR (control rod) & 0.01 \\
\hline Steel blocks - FE & 0.02 \\
\hline Stainless steel - SST & 1.59 \\
\hline Stainless steel - SS75 & 0.42 \\
\hline Stainless steel - SSTX & 4.98 \\
\hline Stainless steel - SSET & 0.00 \\
\hline Humidity & 0.10 \\
\hline Subtotal & 65.09 \\
\hline Total Uncertainty & 71.19 \\
\hline
\end{tabular}

The depleted uranium plates were coated with Kel-F to prevent corrosion and material loss during handling. Kel-F is generally neglected in the as-built model. Adding the Kel-F to the as-built model lowers $\mathrm{k}_{\mathrm{eff}}$ by $-28.06 \pm 3.59 \mathrm{pcm}$, so neglecting the Kel-F increases reactivity by $28.06 \pm 3.59 \mathrm{pcm}$.

The impurities in the $\mathrm{Pu}-\mathrm{U}-\mathrm{Mo}$ fuel meat are neglected in the as-built model. Adding the impurities to the $\mathrm{Pu}-\mathrm{U}-\mathrm{Mo}$ fuel meat increases the reactivity by $2.00 \pm 2.83 \mathrm{pcm}$, so neglecting the $\mathrm{Pu}-\mathrm{U}-\mathrm{Mo}$ fuel meat impurities reduces reactivity by $-2.00 \pm 2.83 \mathrm{pcm}$. 
Table 2.14 shows the computed biases and associated uncertainties for ZPPR-15A L015.

Table 2.14. Biases for ZPPR-15A L015 As-Built Model.

\begin{tabular}{|l|c|c|}
\hline Component & Bias, $\mathrm{pcm}$ & $\sigma, \mathrm{pcm}$ \\
\hline Room return & -5.01 & 2.83 \\
\hline DU impurities & 12.58 & 12.58 \\
\hline DU Kel-F coating & 28.06 & 3.59 \\
\hline Pu-U-Mo impurities & -2.00 & 2.83 \\
\hline Total & 33.63 & 13.68 \\
\hline
\end{tabular}

\subsection{Final Adjusted Experimental $k_{\text {eff }}$ for ZPPR-15A Loading 15}

The experimental $\mathrm{k}_{\text {eff }}$ for ZPPR-15A L015 is $1.00063 \pm 0.00071$ when the total uncertainty derived in Section 2.4 is included. This value is for the measured configuration and does not include the total bias listed in Table 2.14. When the total bias from Section 2.5 is included, the final adjusted experimental $\mathrm{k}_{\text {eff }}$ for ZPPR-15A L015, the ZPPR-15A reference critical configuration, is $1.00097 \pm 0.00072$.

Consequently, the final adjusted experimental $k_{\text {eff }}$ for the described as-built model of ZPPR$15 \mathrm{~A} \mathrm{L015}$ is $1.00097 \pm 0.00072$.

\section{ZPPR-15B Reference Critical Configuration}

The last loading in Phase A of the ZPPR-15 program was loading 68. Loading 69 began the transition from ZPPR-15A to ZPPR-15B. This transition consisted of replacing some stainless steel plates and depleted uranium plates in the inner half of the core by zirconium plates gradually in a series of steps in a standard approach-to-critical. The reference critical configuration for ZPPR-15B was established in loading 88 on November 27, 1985 in reactor run 168.

Figures 3.1 and 3.2 show the matrix maps for half 1 and half 2 of ZPPR-15B L088 (loading 88 ), respectively. The light blue portion of Figures 3.1 and 3.2 is the radial reflector, and the dark blue portion of these figures is the radial blanket. The area consisting almost entirely of white cells inside the radial blanket in Figures 3.1 and 3.2 is the inner core, and the area consisting of green cells and white cells in these figures is the outer core. The white core cells are drawer masters containing a single fuel column, and the green cells are drawer masters containing two fuel columns. The orange cells are drawer masters containing a detector, and the brown cells are the locations containing a narrow drawer and a PSR control rod.

\subsection{ZPPR-15B Measurement Technique Uncertainties}

The reported excess reactivity for ZPPR-15B L088 was $12.7 \pm 0.1 \phi$, and the reported $\beta_{\text {eff }}$ for ZPPR-15B was 0.003361. Based upon the discussion in Section 2.1, it is likely that the $12.7 \pm$ $0.1 \varnothing$ excess reactivity is the excess reactivity prior to adjustment to $293 \mathrm{~K}$, PSR control rods parked at 30 inches and zero interface gap.

The uncertainty reported with the excess reactivity, $0.1 \notin$ or $0.34 \mathrm{pcm}$, includes counting statistics, detector calibration and several other factors such as uncertainties related to adjustment to the standard temperature and parked control rod positions. Additional factors contribute to the total measurement uncertainty. 
The estimated $0.5{ }^{\circ} \mathrm{C}$ uncertainty in thermocouple calibration and $1{ }^{\circ} \mathrm{C}$ uncertainty in the average core temperature discussed in Section 2 for ZPPR-15A apply to all ZPPR-15 loadings. When added in quadrature, the combined uncertainty in temperature is $1.12^{\circ} \mathrm{C}$.

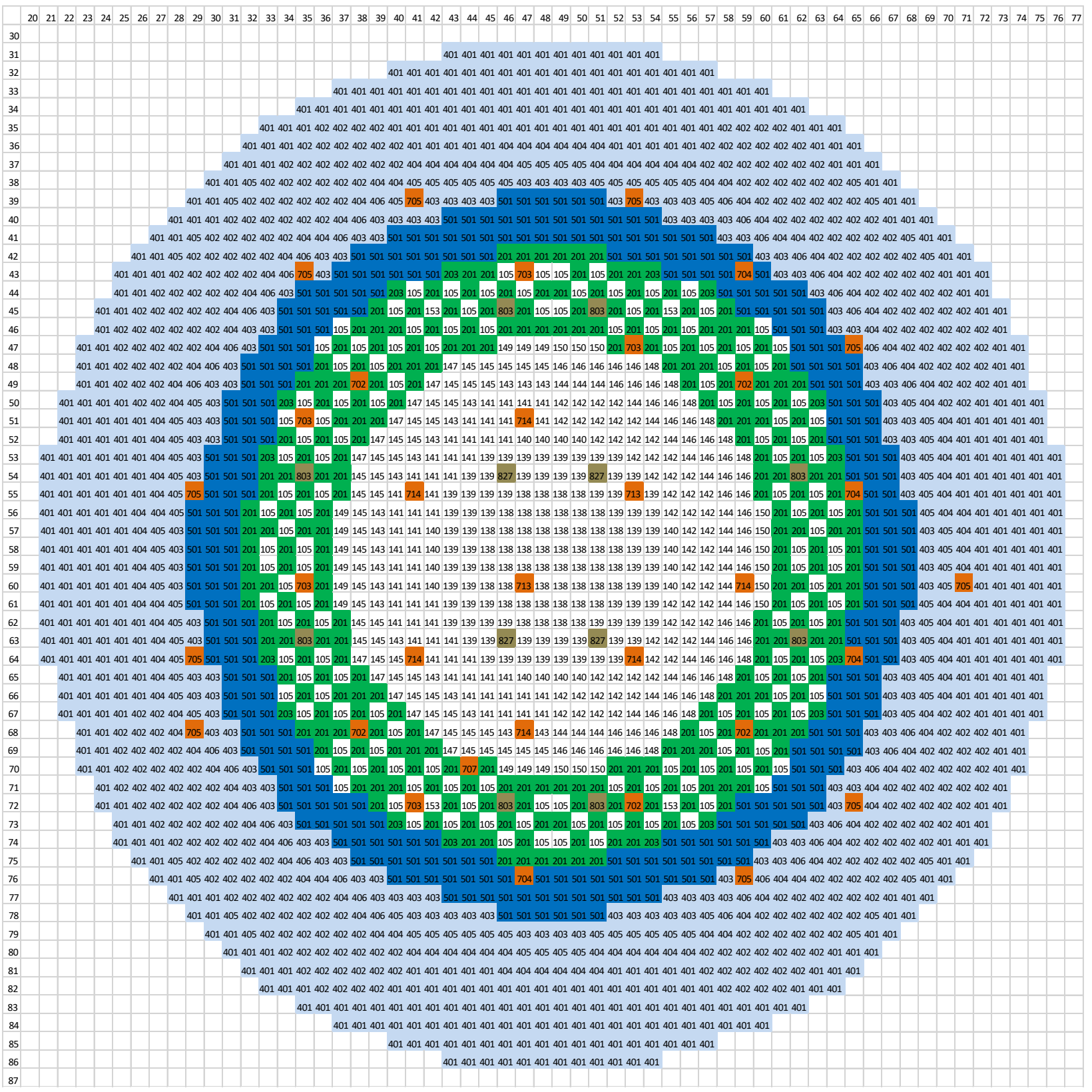

Figure 3.1. ZPPR-15B L088 - Matrix Map for Half 1. 


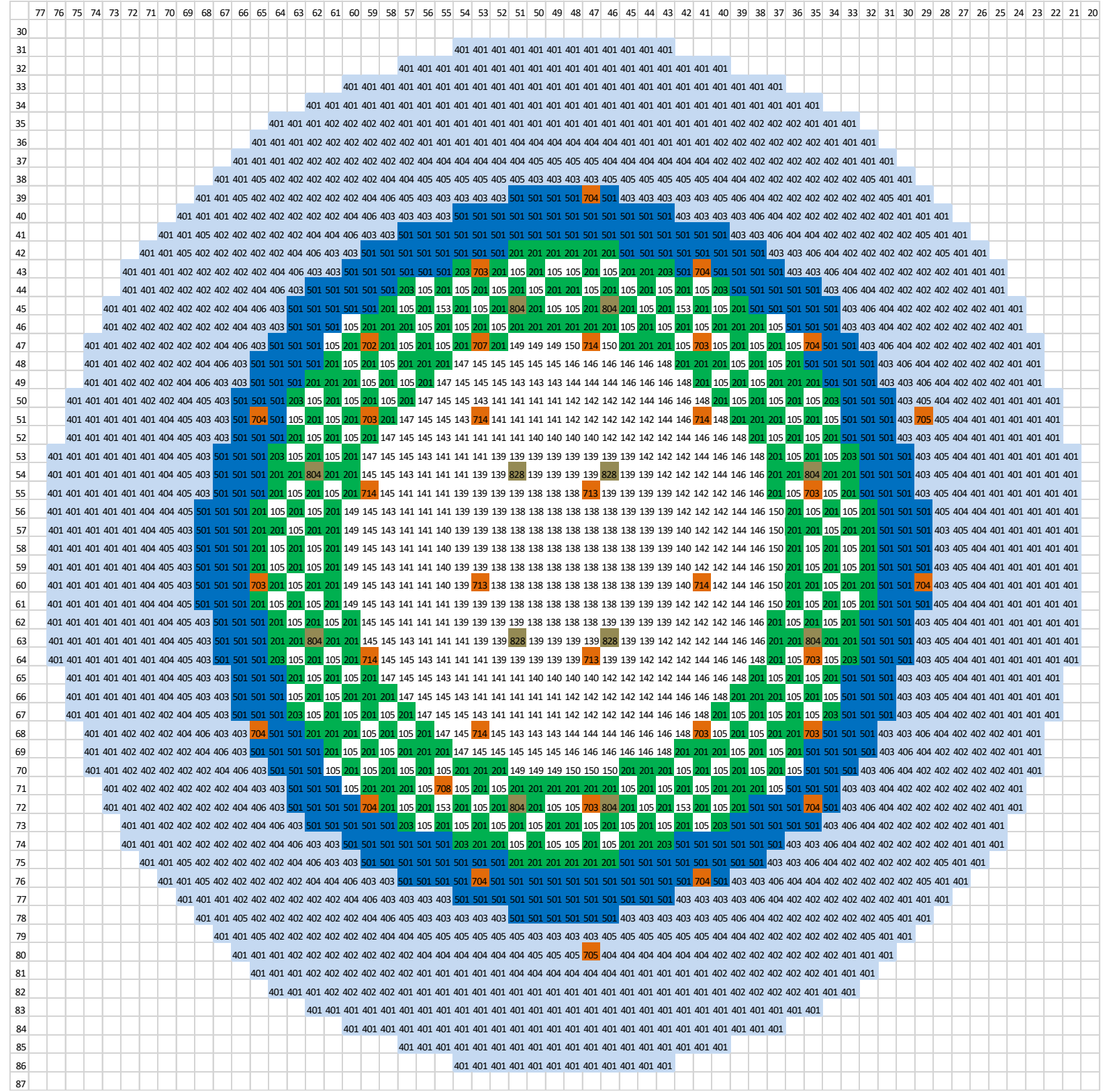

Figure 3.2. ZPPR-15B L088 - Matrix Map for Half 2.

No measured temperature coefficient has been found for ZPPR-15B. The measured temperature coefficient for ZPPR-15A, $-1.05 \pm 0.1 \phi /{ }^{\circ} \mathrm{C}$, was assumed to apply to ZPPR-15B because ZPPR-15A and ZPPR-15B are very similar except for replacement of some stainless steel plates and depleted uranium plates by zirconium plates in the inner core of ZPPR-15B. The contribution of the temperature uncertainty to the total uncertainty is very small, so the effects of this assumption are negligible for practical purposes.

Based upon the assumed temperature coefficient, the reactivity effect of the $1.12{ }^{\circ} \mathrm{C}$ temperature uncertainty is $1.17 \phi$. The measured temperature coefficient is uncertain, and the contribution from the $\pm 0.1 \phi /{ }^{\circ} \mathrm{C}$ uncertainty in the temperature coefficient is $0.11 \phi$. Adding these two components in quadrature, the total reactivity effect of the temperature uncertainty is $1.18 \phi$ or $3.96 \mathrm{pcm}$. 
The $1 \mathrm{pcm}$ non-reproducibility uncertainty discussed in Section 2 for ZPPR-15A applies to all ZPPR-15 loadings.

The 5\% estimated uncertainty in $\beta_{\text {eff }}$ discussed in Section 2 for ZPPR-15A also applies to all ZPPR-15 loadings. The contributions due to the uncertainty in $\beta_{\text {eff }}$ are $2.13 \mathrm{pcm}$ for excess reactivity conversion, $0.20 \mathrm{pcm}$ for the temperature uncertainty conversion and $0.05 \mathrm{pcm}$ for non-reproducibility conversion. The total uncertainty contribution due the uncertainty in $\beta_{\text {eff }}$ is $2.14 \mathrm{pcm}$.

When the reactivity uncertainties due to excess reactivity, temperature, reproducibility and $\beta_{\mathrm{eff}}$ uncertainties are added in quadrature, the total measurement uncertainty for ZPPR-15B L088 is $4.63 \mathrm{pcm}$.

\subsection{ZPPR-15B Geometry Uncertainties}

\subsubsection{Interface Gap}

No published interface gap coefficient has been found for ZPPR-15B. However, the ZPPR staff did publish a gap coefficient for ZPPR-15C. They stated that no gap coefficient was measured for ZPPR-15C and that the published gap coefficient for ZPPR-15C was the measured value for ZPPR-15B scaled by the ratio of the $\beta_{\text {eff }}$ values for the two configurations. The published gap coefficient for ZPPR-15C is $-0.0852 \pm 0.013 \phi / \mathrm{mil}$. Reversing the derivation of the ZPPR$15 \mathrm{C}$ value, the interface gap coefficient for ZPPR-15B is $-0.132 \pm 0.02 \phi / \mathrm{mil}$. This is very close to the measured value for ZPPR-15A, which is consistent with the fact that the ZPPR-15A and ZPPR-15B cores were very similar.

According to the ZPPR-15 logbook, the measured table indicator values for ZPPR-15B L088 reactor run 168 were 32.3, 54.3, 33.9 and 58.1 gap separation units (mils). The average of these four table indicator values is 44.65 mils or $0.1134 \mathrm{~cm}$ for ZPPR-15B L088. Consequently, the worth of the interface gap was $-5.89 \pm 0.89 \notin$ or $-19.81 \pm 3.00 \mathrm{pcm}$.

A reasonable estimate of the uncertainty associated with the non-uniform gap is $25 \%$ or 4.95 $\mathrm{pcm}$. When this uncertainty is combined with the $3.00 \mathrm{pcm}$ uncertainty due to the uncertainty in the gap coefficient, the final value for the interface gap worth is $-19.81 \pm 5.79 \mathrm{pcm}$. The experimenters adjusted the reported excess reactivity to zero interface gap, but the $5.79 \mathrm{pcm}$ uncertainty in the interface gap worth still contributes to the total uncertainty.

\subsubsection{Positions of Drawers and Plates}

The discussion in Section 2.2.2 above regarding the effects of uncertainty in the positions of drawers and plates applies to all ZPPR-15 configurations. The effects of uncertainties in the axial positions of the plates relative to the drawer front and of deviations in the axial dimensions of the plates were estimated conservatively by introducing a 0.0075 in gap between the drawer front and the front of plate columns in each drawer in both halves of the matrix. The computed worth of this gap is $-12.04 \pm 2.24 \mathrm{pcm}$.

\subsubsection{Matrix Tube Pitch}

The worth of the assumed 0.001 inch uncertainty in the matrix tube pitch was calculated with MCNP. One billion $\left(10^{9}\right)$ histories were run for each configuration. The computed worth of the 0.001 inch matrix tube pitch uncertainty is $26.58 \pm 2.24 \mathrm{pcm}$ for ZPPR-15B L088. 


\subsubsection{Room Return}

The worth of the room return was computed as the difference between the reference ZPPR-15B L088 as-built model and an expanded model in which the steel table, steel structures on the sides and top of the matrix and the surrounding room were added. The computed worth of room return was $0.00 \pm 2.83 \mathrm{pcm}$. The $2.83 \mathrm{pcm}$ Monte Carlo uncertainty is assumed to be the uncertainty in the worth of room return. The axial blanket in ZPPR-15 had a length of $\sim 33 \mathrm{~cm}$, and the radial blanket had a thickness of $\sim 15 \mathrm{~cm}$. The axial reflector in ZPPR-15 consisted of $\sim 28 \mathrm{~cm}$ of steel, and the radial reflector in ZPPR- 15 consisted of $\sim 40 \mathrm{~cm}$ of steel. The computed worth of room return here just demonstrates the fact that room return is very small in ZPPR-15 and that it is difficult to compute a statistically meaningful value for the room return.

\subsection{ZPPR-15B Composition Uncertainties}

The $0.15 \%$ uncertainty in mass for plates and drawers discussed in Section 2.3 for ZPPR-15A applies to all ZPPR-15 configurations.

\subsubsection{Sodium Plates}

The assumed $0.15 \%$ uncertainty in the mass of sodium in the sodium plates was calculated to be worth $1.64 \mathrm{pcm}$. The sodium is listed in the hot constants memo as being $99.93 \% \mathrm{Na}, 0.04 \%$ $\mathrm{Ca}, 0.005 \% \mathrm{O}, 0.02 \% \mathrm{C}$, and $0.005 \% \mathrm{Cl}$. An upper bound on the effect of such small impurities was calculated by doubling the existing impurities thereby yielding an uncertainty in keff of 0.12 $\mathrm{pcm}$. The quadrature sum of the worths of the $1 \sigma$ mass and impurity uncertainties for the sodium plates is $1.65 \mathrm{pcm}$.

The same types of sodium plates used in ZPPR-15A were used in ZPPR-15B, ZPPR-15C and ZPPR-15D. These sodium plates consist of sodium in stainless steel cans. The nominal can composition corresponds to Type 304 stainless steel. The uncertainties discussed for sodium plates in Section 2.3 apply to ZPPR-15B as well. The Fe weight percent was adjusted to conserve mass when the weight percent of $\mathrm{Mn}, \mathrm{Cr}$ or $\mathrm{Ni}$ was perturbed. Table 3.1 shows the reactivity effects of the uncertainties in mass and composition of the sodium cans in ZPPR$15 \mathrm{~B}$.

Table 3.1. Worth of Sodium Can Uncertainties in ZPPR-15B.

\begin{tabular}{|l|c|c|c|}
\hline $\begin{array}{l}\text { Component } \\
\text { Uncertainty }\end{array}$ & $\begin{array}{c}\text { Assumed } \\
\text { Uncertainty }\end{array}$ & $\begin{array}{c}\text { Nominal } \\
\text { wt.\% }\end{array}$ & $\begin{array}{c}\text { Worth, } \\
\text { pcm }\end{array}$ \\
\hline Mass & 0.15 & & 1.10 \\
\hline $\mathrm{Mn}$ & 0.1 & 1.0 & 0.96 \\
\hline $\mathrm{Cr}$ & 0.2 & 19.0 & 0.12 \\
\hline $\mathrm{Ni}$ & 0.2 & 9.25 & 1.07 \\
\hline Total & & & 1.81 \\
\hline
\end{tabular}

\subsubsection{Zirconium Plates}

The $0.15 \%$ uncertainty in the mass of the zirconium plates was calculated to be worth $0.77 \mathrm{pcm}$. There is no information available regarding impurities in the zirconium plates. The mass uncertainty for the zirconium plates is very small, so the effects of impurities were assumed to be negligible. 


\subsubsection{Depleted Uranium Plates}

The uncertainties in mass, ${ }^{235} \mathrm{U}$ wt.\% and impurity content for the 0.125 inch depleted uranium (DU) plates were discussed in Section 2.3.3 for ZPPR-15A. Those uncertainties apply to ZPPR$15 \mathrm{~B}$ as well because the same types of DU plates were used in ZPPR-15B.

Table 3.2 shows the reactivity worths of the uncertainties for the DU plates in ZPPR-15B.

Table 3.2. Worth of Depleted Uranium Plate Uncertainties in ZPPR-15B.

\begin{tabular}{|l|c|c|}
\hline Component & Uncertainty, & Worth, pcm \\
\cline { 3 - 3 } Uncertainty & wt. $\%$ & $\begin{array}{c}0.125 \text { in. } \\
\text { APW2 }\end{array}$ \\
\hline Mass & 0.15 & 12.65 \\
\hline${ }^{235}$ U Enrichment & 0.01 & 29.70 \\
\hline Total & & 32.28 \\
\hline
\end{tabular}

It has been assumed here that the reactivity worth of the DU impurities is approximately equal to the worth of the $0.15 \%$ mass uncertainty and that the associated uncertainty in the worth of the DU impurities is $100 \%$ (see Section 2.3.3). The depleted uranium impurity uncertainty is not listed in Table 3.2 because neglecting the impurities in the depleted uranium plates is treated as a bias in Section 3.5. The impurity uncertainty is included with the bias uncertainties.

The depleted uranium plates used at Argonne's ZPR and ZPPR facilities were coated with Kel$F$ to prevent uranium corrosion and material loss during handling. The Kel-F composition and average Kel-F coating mass per plate were discussed in Section 2.3.3.

The Kel-F is not normally included in as-built models. To determine the worth of the Kel-F, the reference model of ZPPR-15B L088 was modified to add the masses of Kel-F shown in column 3 of Table 2.4 to the depleted uranium plates in the model. The Kel-F was mixed homogeneously with the depleted uranium because it is not practical to include the Kel-F as a separate coating and because any heterogeneity effect would be negligible in the ZPPR-15 spectrum.

The worth of the Kel-F was determined as the difference between $\mathrm{k}_{\text {eff }}$ for the reference model without Kel-F and $\mathrm{k}_{\text {eff }}$ for the modified model with the Kel-F. The computed worth of the Kel$\mathrm{F}$ was $-31.11 \pm 1.41 \mathrm{pcm}$. Some of the Kel-F wore off during handling, and ICSBEP/IRPhEP benchmarks for ZPR and ZPPR assemblies typically assume that the uncertainty in the Kel-F mass due to normal handling was $10 \%$. With this assumption, the total worth of the Kel-F in ZPPR-15B L088 is $-31.11 \pm 3.42 \mathrm{pcm}$, which is treated as a bias and associated uncertainty since the Kel-F is neglected in the reference as-built model.

\subsubsection{Natural Uranium Plates}

ZPPR-15B L088 contained a small number of natural uranium plates. The computed worth of the $0.15 \%$ mass uncertainty for these plates is $0.01 \mathrm{pcm}$ which is negligible. Further analysis for the natural uranium plates is not warranted because any worths determined for impurities, etc. would also be negligible. 


\subsubsection{HEU Plates}

Canned HEU plates were used in ZPPR-15C and ZPPR-15D. There were no HEU plates in ZPPR-15A or ZPPR-15B.

\subsubsection{Pu-U-Mo Plates}

The fuel for ZPPR-15A and ZPPR-15B consisted of Pu-U-Mo plates. The Pu-U-Mo plates used at ZPPR contained $\sim 28 \mathrm{wt} . \%$ plutonium with $11 \mathrm{wt} . \%{ }^{240} \mathrm{Pu}$ in the plutonium component. Section 2.3.6 discussed the methodology for determining the composition uncertainties for the $\mathrm{Pu}-\mathrm{U}-\mathrm{Mo}$ fuel meat in the plates.

The uncertainty in the total plutonium mass was computed to be $0.0787 \mathrm{wt} . \%$. Changing the plutonium (plus americium) mass by this amount in the deterministic model changed $k_{\text {eff }}$ by $46.51 \mathrm{pcm}$.

The relative uncertainty in the ${ }^{239} \mathrm{Pu}$ weight percent was computed to be $0.0093 \%$. In the deterministic model, the ${ }^{239} \mathrm{Pu}$ concentration was increased by this amount and mass was preserved by decreasing just the ${ }^{240} \mathrm{Pu}$ concentration (a simplification justified by the very small size of the other isotopic concentrations). The resulting change in $\mathrm{k}_{\mathrm{eff}}$ is $4.33 \mathrm{pcm}$.

The weight percent of ${ }^{238} \mathrm{Pu},{ }^{241} \mathrm{Pu}$, and ${ }^{242} \mathrm{Pu}$ in the assembly before decaying ${ }^{241} \mathrm{Pu}$, was less than $2 \%$. The only isotope besides ${ }^{239} \mathrm{Pu}$ whose uncertainty would be expected to impact $\mathrm{k}_{\text {eff }}$ appreciably is ${ }^{240} \mathrm{Pu}$. The relative uncertainty in the ${ }^{240} \mathrm{Pu}$ weight percent is $0.0417 \%$. Modification of the ${ }^{240} \mathrm{Pu}$ weight percent led to a calculated effect on $\mathrm{k}_{\text {eff }}$ of $2.58 \mathrm{pcm}$. The combined uncertainty in keff due to the uncertainties in the original weight fractions of the remaining three isotopes is assumed to be no larger than this (i.e., it is taken to be $2.58 \mathrm{pcm}$ ). In principle, the total uncertainty in the plutonium isotopic fractions could be reduced by using the constraint that the sum of these fractions was unity. Because this uncertainty component does not make a significant contribution to the total uncertainty in the system reactivity, further analysis was deemed unwarranted.

Some of the ${ }^{241} \mathrm{Pu}$ that was in the fuel plates when they were manufactured decayed by the time ZPPR-15 was built. The Pu-U-Mo NUMEC and Dow plates were made in the late 1960s, ZPPR-15B L088 was made critical on November 27, 1985, and a nominal ${ }^{241} \mathrm{Pu}$ half-life of 14.29 years was assumed. The numbers in the inventory database are normalized to January 1 , 1977. The estimated uncertainty in the decay constant is $1 \%$. Increasing the decay constant increases the ${ }^{241} \mathrm{Am}$ mass and decreases the ${ }^{241} \mathrm{Pu}$ mass. Increasing the decay constant by $1 \%$ reduces $k_{\text {eff }}$ by $3.14 \mathrm{pcm}$.

Impurities in the Pu-U-Mo fuel meat were discussed in Section 2.3. The computed worth of the impurities in the Pu-U-Mo plates in ZPPR-15B L088 is $2.00 \pm 2.83 \mathrm{pcm}$. These impurities are neglected in the as-built model, so the computed impurity worth is assumed as bias for neglecting the impurities in the Pu-U-Mo plates in ZPPR-15B L088.

The specification for production of the NUMEC Pu-U-Mo plates required a ${ }^{235} \mathrm{U}$ enrichment of $0.22 \pm 0.02 \mathrm{wt} . \%$ in the uranium component. It appears that the $0.02 \mathrm{wt} . \%$ represented the two sigma confidence interval, so the corresponding one sigma uncertainty is $0.01 \mathrm{wt} . \%$. The ${ }^{235} \mathrm{U}$ mass was increased by $0.01 \%$ and the ${ }^{238} \mathrm{U}$ mass was reduced correspondingly in the deterministic model. The resulting uncertainty in $\mathrm{k}_{\text {eff }}$ is $26.77 \mathrm{pcm}$. 
The uncertainty in the mass of Mo in the Pu-U-Mo fuel alloy was computed in the same way as the $\mathrm{Pu}$ mass uncertainty. The computed Mo mass uncertainty is $0.0836 \%$. Changing the core region Mo atom density by this amount changes $\mathrm{k}_{\mathrm{eff}}$ by $0.17 \mathrm{pcm}$.

Table 3.3 shows the reactivity effects of the uncertainties in the mass and composition of the $\mathrm{Pu}-\mathrm{U}-\mathrm{Mo}$ alloy in the Pu-U-Mo plates used in ZPPR-5B L088.

Table 3.3. Worth of Pu-U-Mo Alloy Uncertainties in ZPPR-15B.

\begin{tabular}{|l|c|}
\hline Component Uncertainty & Worth, $\mathrm{pcm}$ \\
\hline $\mathrm{Pu}$ mass & 46.51 \\
\hline${ }^{239} \mathrm{Pu}$ fraction & 4.33 \\
\hline${ }^{240} \mathrm{Pu}$ fraction & 2.58 \\
\hline Other $\mathrm{Pu}$ isotopes & 2.58 \\
\hline${ }^{241} \mathrm{Pu}$ decay & 3.14 \\
\hline${ }^{235} \mathrm{U}$ in depleted uranium & 26.77 \\
\hline Mo mass & 0.17 \\
\hline Total & 54.05 \\
\hline
\end{tabular}

The Pu-U-Mo alloy is clad in stainless steel. The nominal can composition corresponds to Type 304 stainless steel. The only uncertainties in the composition of the stainless steel that may make a significant contribution to the total uncertainty are the uncertainties in the can mass and in the weight fractions of $\mathrm{Mn}, \mathrm{Cr}$ and $\mathrm{Ni}$. Table 3.4 shows the reactivity effects of the uncertainties in mass and composition for the Pu-U-Mo cans in ZPPR-15B.

Table 3.4. Worth of Pu-U-Mo Can Uncertainties in ZPPR-15B

\begin{tabular}{|l|c|c|c|}
\hline $\begin{array}{c}\text { Component } \\
\text { Uncertainty }\end{array}$ & $\begin{array}{c}\text { Assumed } \\
\text { Uncertainty }\end{array}$ & $\begin{array}{c}\text { Nominal } \\
\text { wt. } \%\end{array}$ & $\begin{array}{c}\text { Worth, } \\
\text { pcm }\end{array}$ \\
\hline Mass & 0.15 & & 0.42 \\
\hline $\mathrm{Mn}$ & 0.1 & 1.0 & 0.32 \\
\hline $\mathrm{Cr}$ & 0.2 & 19.0 & 0.06 \\
\hline $\mathrm{Ni}$ & 0.2 & 9.25 & 0.36 \\
\hline Total & & & 0.65 \\
\hline
\end{tabular}

\subsubsection{Matrix Tubes}

The uncertainties for the matrix tubes discussed in Section 2.3 apply to ZPPR-15B, ZPPR-15C and ZPPR-15D. The Fe weight percent was adjusted to conserve mass when the weight percent of $\mathrm{Mn}, \mathrm{Cr}$ or Ni was perturbed. Table 3.5 shows the reactivity effects of the uncertainties in mass and composition for the matrix tubes in ZPPR-15B.

Table 3.5. Worth of Matrix Tube Uncertainties in ZPPR-15B.

\begin{tabular}{|l|c|c|c|}
\hline $\begin{array}{l}\text { Component } \\
\text { Uncertainty }\end{array}$ & $\begin{array}{c}\text { Assumed } \\
\text { Uncertainty }\end{array}$ & $\begin{array}{c}\text { Nominal } \\
\text { wt.\% }\end{array}$ & $\begin{array}{c}\text { Worth, } \\
\text { pcm }\end{array}$ \\
\hline Mass & 2.0 & & 16.54 \\
\hline $\mathrm{Mn}$ & 0.1 & 1.0 & 1.40 \\
\hline $\mathrm{Cr}$ & 0.2 & 19.0 & 0.30 \\
\hline $\mathrm{Ni}$ & 0.2 & 9.25 & 0.96 \\
\hline Total & & & 16.63 \\
\hline
\end{tabular}




\subsubsection{Drawers}

The same drawer types were used in all phases of the ZPPR-15 program. The overwhelming majority of the drawers in ZPPR-15 were normal 36.252 in. drawers with a nominal interior width slightly larger than two inches to accommodate the normal two inch width of plates. Twelve drawers in each half in ZPPR-15 were PSR drawers, which were 0.5 in narrower than normal drawers to allow for the presence of 0.5 in control rod guide tubes.

The uncertainties discussed in Section 2.3 for the drawers apply to ZPPR-15B. The Fe weight percent was adjusted to conserve mass when the weight percent of $\mathrm{Mn}, \mathrm{Cr}$ or $\mathrm{Ni}$ was perturbed. Table 3.6 shows the reactivity effects of the uncertainties in mass and composition for the drawers in ZPPR-15B.

Table 3.6. Worth of Drawer Uncertainties in ZPPR-15B.

\begin{tabular}{|l|c|c|c|c|}
\hline \multicolumn{1}{|c|}{$\begin{array}{c}\text { Component } \\
\text { Uncertainty }\end{array}$} & \multirow{2}{*}{$\begin{array}{c}\text { Assumed } \\
\text { Uncertainty }\end{array}$} & \multirow{2}{*}{$\begin{array}{c}\text { Nominal } \\
\text { wt. } \%^{\mathrm{a}}\end{array}$} & $\begin{array}{c}\text { Normal } \\
\text { Drawers }\end{array}$ & $\begin{array}{r}\text { PSR } \\
\text { Drawers }\end{array}$ \\
\cline { 4 - 5 } & & & 0.73 & $<0.01$ \\
\hline $\mathrm{Mass}$ & 0.15 & & 0.80 & $<0.01$ \\
\hline $\mathrm{Mn}$ & 0.1 & 1.0 & 0.16 & $<0.01$ \\
\hline $\mathrm{Cr}$ & 0.2 & 19.0 & 0.57 & $<0.01$ \\
\hline $\mathrm{Ni}$ & 0.2 & 9.25 & 1.23 & 0.01 \\
\hline Total & & & & \\
\hline
\end{tabular}

\subsubsection{Steel Blocks}

The same low carbon steel blocks discussed in section 2.3.9 were used as part of the axial reflector in all phases of the ZPPR-15 program. Table 3.7 shows the reactivity effects of the uncertainties in mass and composition for the steel blocks in the axial reflector in ZPPR-15B.

Table 3.7. Worth of Steel Block Uncertainties in ZPPR-15B.

\begin{tabular}{|l|c|}
\hline \multicolumn{1}{|c|}{$\begin{array}{c}\text { Unmponent } \\
\text { Uncertainty }\end{array}$} & $\begin{array}{c}\text { Worth, } \\
\text { pcm }\end{array}$ \\
\hline Mass & $<0.01$ \\
\hline $\mathrm{Mn}$ & $<0.01$ \\
\hline $\mathrm{Cr}$ & $<0.01$ \\
\hline $\mathrm{C}$ & $<0.01$ \\
\hline Total & 0.01 \\
\hline
\end{tabular}

\subsubsection{Stainless Steel Plates}

The four groups of stainless steel plates used in ZPPR-15A were used in all phases of the ZPPR15 program. The identifiers for those groups are SST, SS75, SSTX and SSET in the inventory records. These four groups of stainless steel plates were obtained at different times from different suppliers. Consequently, the four groups of stainless steel plates will be treated as being independent for purposes of uncertainty analysis.

The uncertainties discussed in Section 2.3 for the SST, SS75, SSTX and SSET stainless steel plates apply to ZPPR-15B. The Fe weight percent was adjusted to conserve mass when the weight percent of $\mathrm{Mn}, \mathrm{Cr}$ or Ni was perturbed. Table 3.8 shows the reactivity effects of the uncertainties in mass and composition for the four types of stainless steel plates in ZPPR-15B. 
Table 3.8. Worth of Stainless Steel Plate Uncertainties in ZPPR-15B

\begin{tabular}{|l|c|c|c|c|c|c|}
\hline \multicolumn{1}{|c|}{$\begin{array}{c}\text { Component } \\
\text { Uncertainty }\end{array}$} & Assumed & Nominal & \multicolumn{4}{|c|}{ Worth, pcm } \\
\cline { 4 - 7 } & Uncertainty & wt. $\%$ & SST & SS75 & SSTX & SSET \\
\hline Mass & 0.15 & & 0.39 & 0.16 & 1.76 & 0.89 \\
\hline $\mathrm{Mn}$ & 0.1 & 1.0 & 0.44 & 0.22 & 1.59 & 1.02 \\
\hline $\mathrm{Cr}$ & 0.2 & 19.0 & 0.37 & 0.19 & 0.28 & 0.10 \\
\hline $\mathrm{Ni}$ & 0.2 & 9.25 & 0.27 & 0.27 & 1.40 & 0.70 \\
\hline Total & & & 0.75 & 0.42 & 2.77 & 1.53 \\
\hline
\end{tabular}

The $0.1 \mathrm{pcm}$ uncertainty for humidity discussed in Section 2.3 applies to ZPPR-15B L088 as well.

The total composition uncertainty is $65.27 \mathrm{pcm}$ for ZPPR-15B.

\subsection{Total Uncertainty for ZPPR-15B Loading 88}

Table 3.9 summarizes all of the uncertainty components for measurement technique, configuration geometry and material compositions and lists the total uncertainty for ZPPR-15B L088.

The reported experimental $k_{\text {eff }}$ after adjustment to standard reporting conditions was 1.00060. When the total uncertainty listed in Table 3.9 is included, the experimental $\mathrm{k}_{\text {eff }}$ is $1.00060 \pm$ 0.00072 .

\subsection{Biases or Adjustments for ZPPR-15B Loading 88}

Several adjustments to the experimental $k_{\text {eff }}$ are required to account for features that are not included in the as-built model. The interface gap is not included in the as-built model, but the ZPPR staff adjusted the reported excess reactivity to a condition with zero interface gap. Consequently, there is no bias associated with neglecting the interface gap in the as-built model.

The reference as-built model does not include the split tables, clamping structure or the room in which the machine was located. Addition of room return increases the reactivity by $0.00 \pm$ $2.83 \mathrm{pcm}$, so neglecting room return reduces the reactivity by $0.00 \pm 2.83 \mathrm{pcm}$.

Available documents do not list the impurities in the depleted uranium plates, and the depleted uranium impurities are neglected in the as-built model. The worth of the depleted uranium plate impurities is assumed to be approximately equal to the $0.15 \%$ uncertainty in the mass of the depleted uranium plates. Increasing the depleted uranium plate masses by the assumed $0.15 \%$ reduced $\mathrm{k}_{\text {eff }}$ by $-12.65 \mathrm{pcm}$. Adding the impurities to the depleted uranium plates would have approximately the same effect. The uncertainty in the impurity level is assumed to be $100 \%$, so neglecting the impurities in the depleted uranium increases reactivity by $12.65 \pm 12.65 \mathrm{pcm}$.

The depleted uranium plates were coated with Kel-F to prevent corrosion and material loss during handling. Kel-F is generally neglected in as-built models. Adding the Kel-F to the asbuilt model lowers keff, by $-31.11 \pm 3.42 \mathrm{pcm}$, so neglecting the Kel-F increases reactivity by $31.11 \pm 3.42 \mathrm{pcm}$. 
Table 3.9. Total Uncertainty for ZPPR-15B L088.

\begin{tabular}{|c|c|}
\hline Uncertainty Component & Uncertainty, pcm \\
\hline \multicolumn{2}{|c|}{ Measurement Technique } \\
\hline Excess reactivity & 0.34 \\
\hline Temperature & 3.96 \\
\hline Reproducibility & 1.00 \\
\hline$\beta_{\text {eff }}$ uncertainty & 2.14 \\
\hline Subtotal & 4.63 \\
\hline \multicolumn{2}{|l|}{ Geometry } \\
\hline Interface gap & 5.79 \\
\hline Nominal plate, drawer dimensions & 12.04 \\
\hline Matrix tube pitch & 26.58 \\
\hline Subtotal & 29.75 \\
\hline \multicolumn{2}{|c|}{ Composition } \\
\hline Pu-U-Mo alloy & 54.05 \\
\hline Pu-U-Mo plate clad & 0.65 \\
\hline Sodium & 1.65 \\
\hline Sodium plate clad & 1.81 \\
\hline Zirconium & 0.77 \\
\hline Natural uranium & 0.01 \\
\hline Depleted uranium - APW2 & 32.28 \\
\hline Matrix tubes & 16.63 \\
\hline Drawers - standard & 1.23 \\
\hline Drawers - PSR (control rod) & 0.01 \\
\hline Steel blocks - FE & 0.01 \\
\hline Stainless steel - SST & 0.75 \\
\hline Stainless steel - SS75 & 0.42 \\
\hline Stainless steel - SSTX & 2.77 \\
\hline Stainless steel - SSET & 1.53 \\
\hline Humidity & 0.10 \\
\hline Subtotal & 65.27 \\
\hline Total Uncertainty & 71.88 \\
\hline
\end{tabular}

The impurities is the Pu-U-Mo fuel are neglected in the as-built model. Adding the impurities to the Pu-U-Mo plates increases reactivity by $2.00 \pm 2.83 \mathrm{pcm}$, so neglecting the Pu-U-Mo impurities reduces reactivity by $-2.00 \pm 2.83 \mathrm{pcm}$.

Table 3.10 shows the computed biases and associated uncertainties for ZPPR-15B L088.

Table 3.10. Biases for ZPPR-15B L088 As-Built Model.

\begin{tabular}{|l|c|c|}
\hline \multicolumn{1}{|c|}{ Component } & Bias, $\mathrm{pcm}$ & $\sigma, \mathrm{pcm}$ \\
\hline Room return & 0.00 & 2.83 \\
\hline DU impurities & 12.65 & 12.65 \\
\hline DU Kel-F coating & 31.11 & 4.20 \\
\hline Pu-U-Mo impurities & -2.00 & 2.83 \\
\hline Total & 41.76 & 13.70 \\
\hline
\end{tabular}




\subsection{Final Adjusted Experimental keff for ZPPR-15B Loading 88}

The reported adjusted experimental $k_{\text {eff }}$ for ZPPR-15B L088 is $1.00060 \pm 0.00072$ when the total uncertainty derived in Section 3.4 is included. This value is for the measured configuration and does not include the total bias listed in Table 3.10. When the total bias from Section 3.5 is included, the final adjusted experimental $k_{\text {eff }}$ for ZPPR-15B L088, the ZPPR-15B reference critical configuration, is $1.00102 \pm 0.00073$.

Consequently, the final adjusted experimental $k_{\text {eff }}$ for the described as-built model of ZPPR15B L088 is $1.00102 \pm 0.00073$.

\section{ZPPR-15C Reference Critical Configuration}

At the end of the ZPPR-15B measurements, the transition to ZPPR-15C began. For this transition, approximately half of the core drawers containing $\mathrm{Pu}-\mathrm{U}-\mathrm{Mo}$ fuel plates were replaced by drawers containing HEU fuel plates. The reference critical configuration for ZPPR15C was established in loading 166 (ZPPR-15C L166) on April 23, 1986 in reactor run 291.

Figures 4.1 and 4.2 shows the matrix maps for half 1 and half 2, respectively, of ZPPR-15C L166. The color scheme for Figures 4.1 and 4.2 is identical to the color scheme for the previous ZPPR-15 matrix maps with one addition. The salmon-colored cells in Figures 4.1 and 4.2 are drawer masters containing HEU fuel plates in place of $\mathrm{Pu}-\mathrm{U}-\mathrm{Mo}$ fuel plates.

\subsection{ZPPR-15C Measurement Technique Uncertainties}

The reported excess reactivity for ZPPR-15C L166 was $9.2 \pm 0.1 \varnothing$ at a temperature of 21.92 ${ }^{\circ} \mathrm{C}$, and the reported $\beta_{\text {eff }}$ for ZPPR-15C was 0.005207. Based upon the discussion in Section 2.1 , it is likely that the $9.2 \pm 0.1 \varnothing$ excess reactivity is the excess reactivity prior to adjustment to $293 \mathrm{~K}$, PSR control rods parked at 30 inches and adjustment to a zero interface gap. The final adjusted experimental $\mathrm{k}_{\mathrm{eff}}$ for ZPPR-15C L166 reported by the ZPPR staff is $1.00052 \pm$ 0.00001 .

The uncertainty reported with the excess reactivity, $0.1 \notin$ or $0.52 \mathrm{pcm}$, includes counting statistics, detector calibration and several other factors such as uncertainties related to adjustment to the standard temperature and parked control rod positions. Additional factors contribute to the total measurement uncertainty.

The estimated $0.5^{\circ} \mathrm{C}$ uncertainty in the thermocouple calibration and $1{ }^{\circ} \mathrm{C}$ uncertainty in the average core temperature discussed in Section 2.1 for ZPPR-15A apply to all ZPPR-15 loadings. When added in quadrature, the combined uncertainty in temperature is $1.12{ }^{\circ} \mathrm{C}$. 


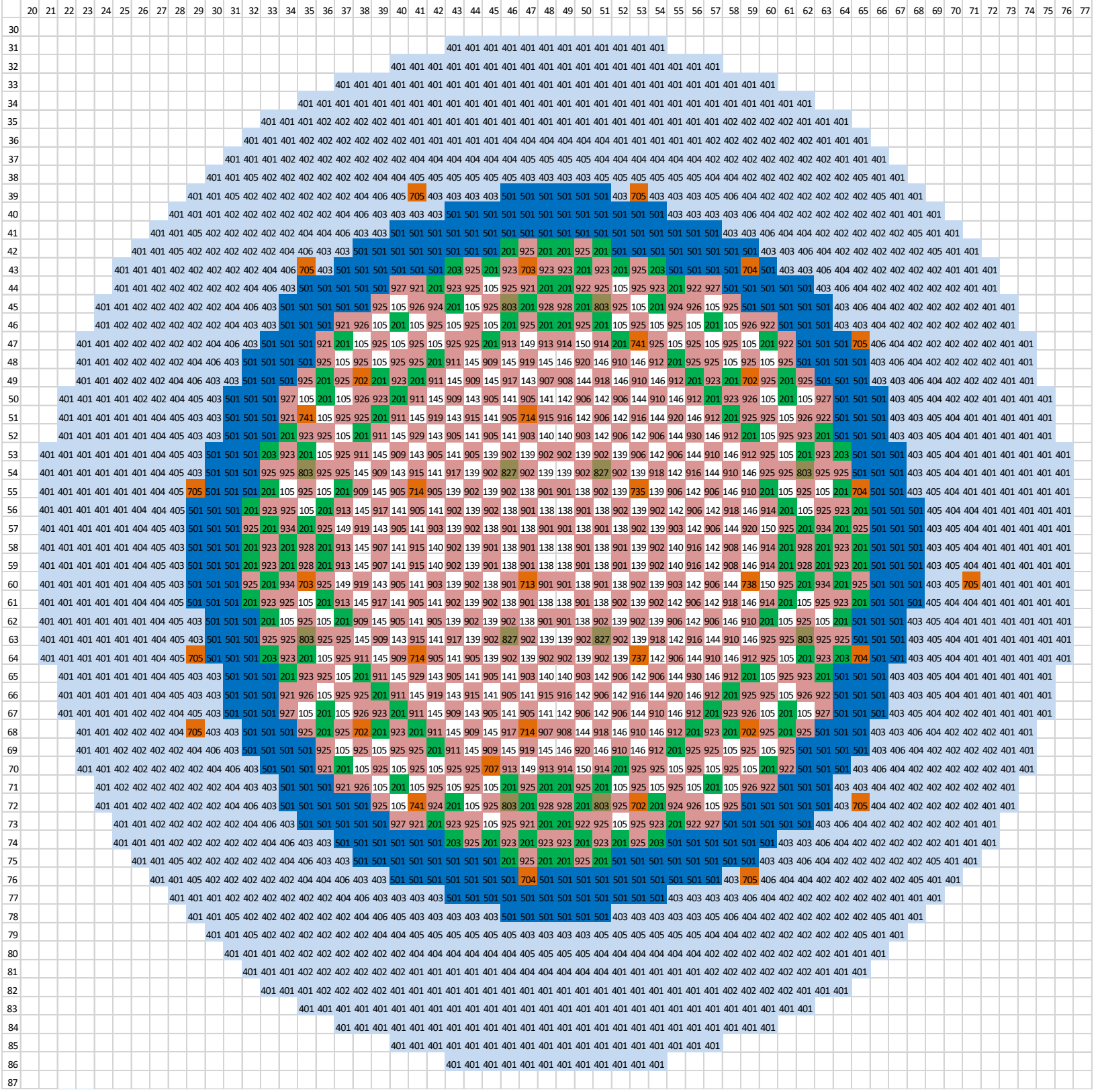

Figure 4.1. ZPPR-15C L166 - Matrix Map for Half 1. 


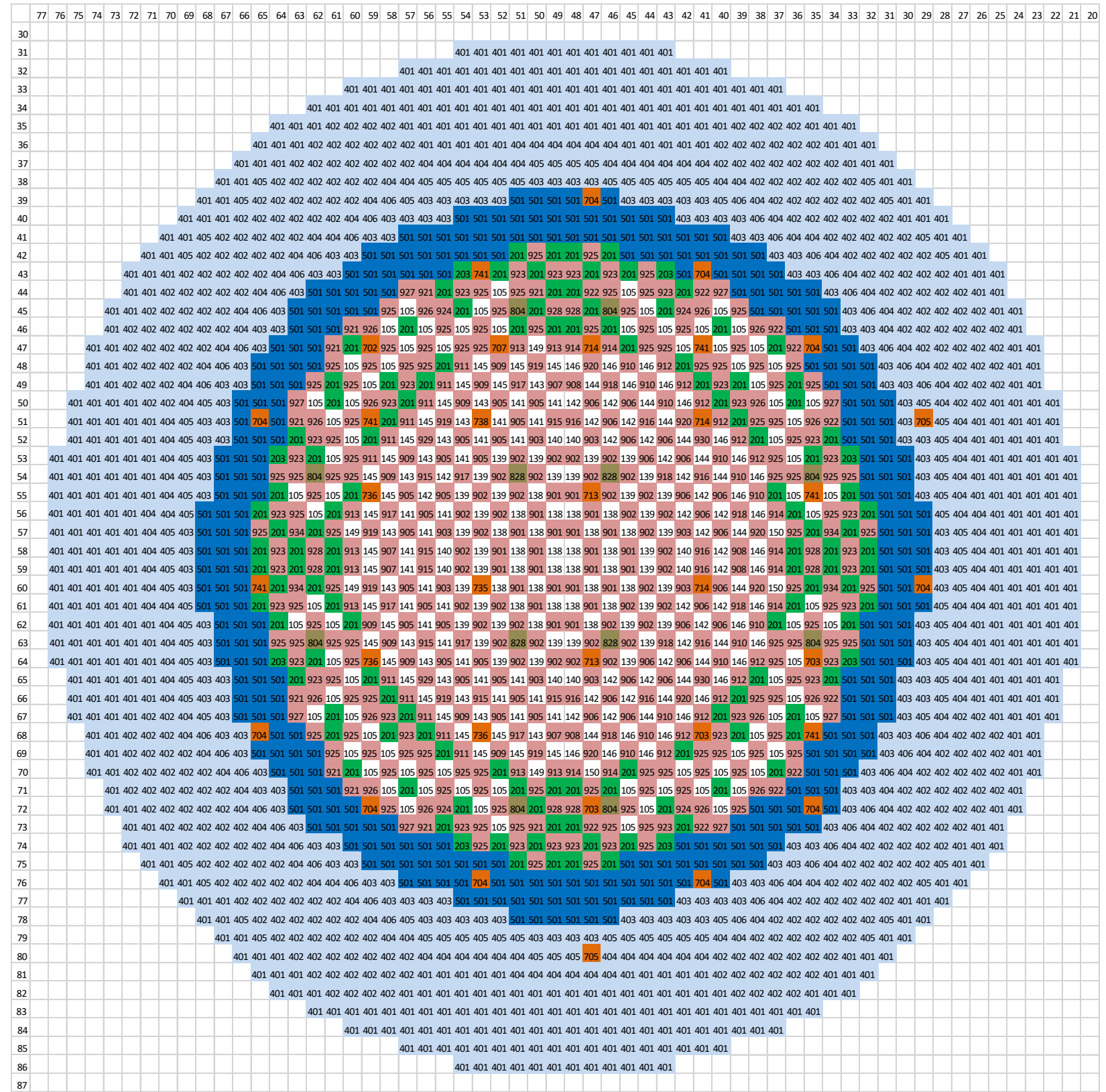

Figure 4.2. ZPPR-15C L166 - Matrix Map for Half 2.

The reported temperature coefficient for ZPPR-15C is $-0.575 \pm 0.11 \notin /{ }^{\circ} \mathrm{C}$. Based upon the reported temperature coefficient, the reactivity effect of the $1.12{ }^{\circ} \mathrm{C}$ temperature uncertainty is $0.64 \phi$. The measured temperature coefficient is uncertain, and the contribution from the $0.11 \notin /{ }^{\circ} \mathrm{C}$ uncertainty in the temperature coefficient is $0.12 \phi$. Adding these two components in quadrature, the total reactivity effect of the temperature uncertainty is $0.65 \phi$ or $3.41 \mathrm{pcm}$.

The 1 pcm non-reproducibility uncertainty discussed in Section 2 for ZPPR-15A applies to all ZPPR-15 loadings. 
The 5\% estimated uncertainty in $\beta_{\text {eff }}$ discussed in Section 2.1 for ZPPR-15A applies to all ZPPR-15 loadings. The contributions due to the uncertainty in $\beta_{\text {eff }}$ are $2.40 \mathrm{pcm}$ for excess reactivity conversion, $0.17 \mathrm{pcm}$ for the temperature uncertainty conversion and $0.05 \mathrm{pcm}$ for non-reproducibility conversion. The total uncertainty contribution due the uncertainty in $\beta_{\text {eff }}$ is $2.40 \mathrm{pcm}$.

When the reactivity uncertainties due to excess reactivity, temperature, reproducibility and $\beta_{\mathrm{eff}}$ uncertainties are added in quadrature, the total measurement uncertainty for ZPPR-15C L066 is $4.32 \mathrm{pcm}$.

\subsection{ZPPR-15C Geometry Uncertainties}

\subsubsection{Interface Gap}

The ZPPR staff did publish a gap coefficient for ZPPR-15C. They stated that no gap coefficient was measured for ZPPR-15C and that the published gap coefficient for ZPPR-15C was the measured value for ZPPR-15B scaled by the ratio of the $\beta_{\text {eff }}$ values for the two configurations. The published gap coefficient for ZPPR-15C is $-0.0852 \pm 0.013 \notin / \mathrm{mil}$.

According to the ZPPR-15 logbook entry, the measured table indicator values for ZPPR-15C L166 reactor run 291 were 32.6, 54.2, 32.7 and 56.7 gap separation units (mils). The average of these four table indicator values is 44.05 mils or $0.1119 \mathrm{~cm}$ for ZPPR-15C L166. Consequently, the worth of the interface gap was $-3.75 \pm 0.57 \not$ or $-19.54 \pm 2.98 \mathrm{pcm}$.

A reasonable estimate of the uncertainty associated with the non-uniform gap is $25 \%$ of the gap worth or $4.89 \mathrm{pcm}$. When this uncertainty is combined with the $2.98 \mathrm{pcm}$ uncertainty due to the uncertainty in the gap coefficient, the final value for the interface gap worth is $-19.54 \pm 5.72$ $\mathrm{pcm}$. The experimenters adjusted the reported excess reactivity to zero interface gap, but the $5.72 \mathrm{pcm}$ uncertainty in the interface gap worth still contributes to the total uncertainty.

\subsubsection{Positions of Drawers and Plates}

The discussion in Section 2.2.2 regarding the effects of uncertainty in the positions of drawers and plates applies to all ZPPR-15 configurations. The effects of uncertainties in the axial positions of the plates relative to the drawer front and of deviations in the axial dimensions of the plates were estimated conservatively by introducing a 0.0075 in gap between the drawer front and the front of plate columns in each drawer in both halves of the matrix in ZPPR-15A L015 and ZPPR-15B L088. The values computed for L015 and L088 did not differ significantly. The computed worth of this gap for ZPPR-15B L088, $-12.04 \pm 2.24 \mathrm{pcm}$, is assumed to apply to ZPPR-15C L166.

\subsubsection{Matrix Tube Pitch}

The worth of the assumed 0.001 inch uncertainty in the matrix tube pitch was calculated with MCNP. One billion $\left(10^{9}\right)$ histories were run for each configuration. The computed worth of the 0.001 inch matrix tube pitch uncertainty is $-22.99 \pm 1.41 \mathrm{pcm}$ for ZPPR-15C L166.

\subsubsection{Room Return}

The worth of room return was computed as the difference between the reference ZPPR-15C L166 as-built model and an expanded model in which the steel table, steel structures on the 
sides and top of the matrix and the surrounding room were added. The computed worth of room return was $0.00 \pm 2.83 \mathrm{pcm}$. The $2.83 \mathrm{pcm}$ Monte Carlo uncertainty is assumed to be the uncertainty in the worth of room return. Room return is neglected in the as-built models. Omission of room return is treated as a bias in Section 4.5.

\subsection{ZPPR-15C Composition Uncertainties}

The $0.15 \%$ uncertainty in mass for plates and drawers discussed in Section 2.3 for ZPPR-15A applies to all ZPPR-15 configurations.

\subsubsection{Sodium Plates}

The assumed $0.15 \%$ uncertainty in the mass of the sodium plates was calculated to be worth $0.23 \mathrm{pcm}$. These plates are listed in the hot constants memo as being $99.93 \% \mathrm{Na}, 0.04 \% \mathrm{Ca}$, $0.005 \% \mathrm{O}, 0.02 \% \mathrm{C}$, and $0.005 \% \mathrm{Cl}$. An upper bound on the effect of such small impurities was calculated by doubling the existing impurities, yielding an uncertainty in $k_{\text {eff }}$ of $0.32 \mathrm{pcm}$. The quadrature sum of the worths of the $1 \sigma$ mass and impurity uncertainties for the sodium plates is $0.39 \mathrm{pcm}$.

The uncertainties discussed for the sodium plate cans in Section 2.3 apply to ZPPR-15C as well. The Fe weight percent was adjusted to conserve mass when the weight percent of $\mathrm{Mn}, \mathrm{Cr}$ or $\mathrm{Ni}$ was perturbed. Table 4.1 shows the reactivity effects of the uncertainties in mass and composition of the sodium cans in ZPPR-15C.

Table 4.1. Worth of Sodium Can Uncertainties in ZPPR-15C.

\begin{tabular}{|l|c|c|c|}
\hline $\begin{array}{c}\text { Component } \\
\text { Uncertainty }\end{array}$ & $\begin{array}{c}\text { Assumed } \\
\text { Uncertainty }\end{array}$ & $\begin{array}{c}\text { Nominal } \\
\text { wt. } \%\end{array}$ & $\begin{array}{c}\text { Worth, } \\
\text { pcm }\end{array}$ \\
\hline Mass & 0.15 & & 0.63 \\
\hline $\mathrm{Mn}$ & 0.1 & 1.0 & 0.15 \\
\hline $\mathrm{Cr}$ & 0.2 & 19.0 & 0.35 \\
\hline $\mathrm{Ni}$ & 0.2 & 9.25 & 0.82 \\
\hline Total & & & 1.10 \\
\hline
\end{tabular}

\subsubsection{Zirconium Plates}

The $0.15 \%$ uncertainty in the mass of the zirconium plates was calculated to be worth $0.60 \mathrm{pcm}$. There is no information available regarding impurities in the zirconium plates. The mass uncertainty for the zirconium plates is very small, so the effects of impurities were assumed to be negligible.

\subsubsection{Depleted Uranium Plates}

Most depleted uranium plates used in ZPPR-15C were part of the original ZPPR plate inventory and were designated APW2 in the hot constants memos. Additional depleted uranium plates used in ZPPR-15C were part of the original Argonne National Laboratory-East (ANL-E) inventory used in ZPR-6 and ZPR-9 in Illinois. The uncertainties in mass, ${ }^{235} \mathrm{U}$ wt.\% and impurity content for the 0.125 inch depleted uranium plates were discussed in Section 2.3.3 for ZPPR-15A. Those uncertainties apply to the APW2 and ANL-E depleted uranium plates used in ZPPR-15C as well. 
Because the ZPPR and ANL-E plate inventories were manufactured at different times, the ZPPR depleted uranium plates and the ANL-E depleted uranium plates will be treated as independent in this analysis. Table 4.2 shows the reactivity worths of uncertainties for the depleted uranium plates from the original ZPPR inventory in ZPPR-15C. Table 4.3 shows the reactivity worths of uncertainties for the depleted uranium plates that were originally part of the ANL-E plate inventory in ZPPR-15C.

Table 4.2. Worth of Plate Uncertainties for ZPPR Depleted Uranium Plates in ZPPR-15C.

\begin{tabular}{|l|c|c|}
\hline $\begin{array}{c}\text { Component } \\
\text { Uncertainty }\end{array}$ & $\begin{array}{c}\text { Uncertainty, } \\
\text { wt. } \%\end{array}$ & Worth, pcm \\
\cline { 3 - 3 } & & $\begin{array}{c}0.125 \text { in. } \\
\text { APW2 }\end{array}$ \\
\hline Mass & 0.15 & -14.08 \\
\hline${ }^{235}$ U Enrichment & 0.01 & 31.31 \\
\hline Total & & 34.33 \\
\hline
\end{tabular}

Table 4.3. Worth of Plate Uncertainties for ANL-E Depleted Uranium Plates in ZPPR-15C.

\begin{tabular}{|l|c|c|}
\hline \multicolumn{1}{r}{$\begin{array}{c}\text { Component } \\
\text { Uncertainty }\end{array}$} & $\begin{array}{c}\text { Uncertainty, } \\
\text { wt. } \%\end{array}$ & Worth, pcm \\
\cline { 3 - 3 } & 0.15 & ANL-E \\
\hline Mass & 0.01 & -1.47 \\
\hline${ }^{235}$ U Enrichment & & 1.98 \\
\hline Total & & 2.47 \\
\hline
\end{tabular}

It has been assumed here that the reactivity worth of the depleted uranium impurities is approximately equal to the worth of the $0.15 \%$ mass uncertainty and that the associated uncertainty in the worth of the depleted uranium impurities is $100 \%$ (see Section 2.3.3). The depleted uranium impurity uncertainty is not listed in Tables 4.2 and 4.3 because neglecting the impurities in the depleted uranium plates is treated as a bias in Section 4.5. The impurity uncertainty is included with the bias uncertainties.

The depleted uranium plates used at Argonne's ZPR and ZPPR facilities were coated with Kel$F$ to prevent uranium corrosion and material loss during handling. The Kel-F composition and average Kel-F coating mass per plate were discussed in Section 2.3.3.

The Kel-F is not normally included in as-built models. To determine the worth of the Kel-F, the reference model of ZPPR-15C L166 was modified to add the masses of Kel-F shown in column 3 of Table 2.4 to the APW2 and ANL-E depleted uranium plates in the model. The Kel-F was mixed homogeneously with the depleted uranium because it is not practical to include the Kel-F as a separate coating and because any heterogeneity effect would be negligible in the ZPPR-15 spectrum.

The worth of the Kel-F was determined as the difference between $\mathrm{k}_{\mathrm{eff}}$ for the reference model without Kel-F and $\mathrm{k}_{\text {eff }}$ for the modified model with Kel-F. The computed worth of the Kel-F was $-19.00 \pm 2.83 \mathrm{pcm}$. Some of the Kel-F wore off during handling, and ICSBEP/IRPhEP benchmarks for ZPR and ZPPR assemblies typically assume that the uncertainty in the Kel-F mass due to normal handling was $10 \%$. With this assumption, the total worth of the Kel-F in ZPPR-15D L185 is $-19.00 \pm 3.41 \mathrm{pcm}$, which is treated as a bias and associated uncertainty since the Kel-F is neglected in the reference as-built model. 


\subsubsection{Natural Uranium Plates}

ZPPR-15C L166 contained a small number of natural uranium plates. The computed worth of the $0.15 \%$ mass uncertainty for these plates is $0.01 \mathrm{pcm}$ which is negligible. Further analysis for the natural uranium plates is not warranted because any worths determined for impurities, etc. would also be negligible.

\subsubsection{HEU Plates}

Canned HEU plates were used in ZPPR-15C and ZPPR-15D. There were eight types of canned HEU plates in ZPPR-15C L166. Table 4.4 shows the HEU plate types, the nominal HEU dimensions for each plate type and the number of each canned HEU plate type present in ZPPR15C L166.

Table 4.4. Canned HEU Plates in ZPPR-15C L166.

\begin{tabular}{|c|c|c|}
\hline Plate Type & $\begin{array}{c}\text { Nominal HEU } \\
\text { Dimensions }{ }^{\mathrm{a}}, \text { in. }\end{array}$ & Plate Count \\
\hline U93A & $1 / 16 \times 2 \times 6$ & 632 \\
\hline U93B & $1 / 16 \times 2 \times 6$ & 1128 \\
\hline U93C & $1 / 16 \times 2 \times 8$ & 632 \\
\hline U93D & $1 / 16 \times 2 \times 4$ & 632 \\
\hline U93F & $1 / 8 \times 2 \times 8$ & 105 \\
\hline U93G & $1 / 8 \times 2 \times 6$ & 270 \\
\hline U93H & $1 / 8 \times 2 \times 6$ & 96 \\
\hline U93I & $1 / 8 \times 2 \times 4$ & 105 \\
\hline
\end{tabular}

a) These are the dimensions of the HEU metal. The stainless steel cans increased the outer plate dimensions slightly.

When the HEU plates were used in ZPR-3, ZPR-6 and ZPR-9, they consisted of HEU metal with a Kel-F coating, and the nominal dimensions of the HEU metal were the actual nominal plate dimensions. After ZPR-6 and ZPR-9 were shut down, the HEU plates were shipped to ZPPR where the Kel-F was removed and the bare metal plates were placed in stainless steel cans. The stainless steel cans slightly increased the outer dimensions of the canned HEU plates relative to the dimensions of the HEU metal shown in Table 4.4.

Different canned HEU plate types contained different mixes of HEU plates even if the canned plates had the same nominal HEU dimensions. Most of the bare HEU metal plates had lengths of 2 in or 3 in, and different canned HEU plate types contained different mixes of HEU metal plates. For example, U93A might contain three 2-in plates, and U93B might contain two 3-in plates. Likewise, a canned plate with a nominal HEU length of eight inches might contain four 2-in plates or two 3-in plates plus one 2-in plate. All canned plates of the same plate type, e.g., U93A, contained the same mix of HEU metal plates.

There are three sources of evidence currently available regarding the uncertainties in the isotopic weight percent for the HEU metal. One is a 1982 internal memorandum on the uncertainty in a measurement that used $1 / 16 \times 2 \times 3$ in plates. These values are shown (rounded to two decimal places) in the third column of Table 4.5. That memo quotes an enrichment of $93.18 \pm 0.02$ wt.\% observed in selected SPM records. This quoted uncertainty appears reasonable. In fact, it is likely that the enrichment for any single fuel fabrication batch would 
have been known even better. However, because of the large inventory of $93 \%$ enriched uranium fuel in the inventory, the enrichment was derived from many fuel batches.

Table 4.5. Enriched Uranium Uncertainty Data.

\begin{tabular}{|c|c|c|c|c|}
\hline Isotope & $\begin{array}{c}\text { Nominal } \\
\text { Value, } \\
\text { wt. } \%\end{array}$ & $\begin{array}{c}\text { Uncertainty, } \\
\text { wt. } \%\end{array}$ & $\begin{array}{c}\text { Uncertainty, } \\
\text { wt. } \%\end{array}$ & $\begin{array}{c}\text { Uncertainty, } \\
\text { wt. } \%\end{array}$ \\
\hline${ }^{234} \mathrm{U}$ & 0.91 & \pm 0.01 & \pm 0.01 & \pm 0.01 \\
\hline${ }^{235} \mathrm{U}$ & 93.17 & \pm 0.02 & \pm 0.02 & \pm 0.05 \\
\hline${ }^{236} \mathrm{U}$ & 0.44 & \pm 0.01 & \pm 0.01 & \pm 0.01 \\
\hline${ }^{238} \mathrm{U}$ & 5.48 & \pm 0.03 & \pm 0.02 & \pm 0.05 \\
\hline
\end{tabular}

a) Uncertainty values quoted in SPM records.

b) Uncertainty values estimated from distribution of 1996 mass spectroscopy measurements.

c) Uncertainty values estimated from distribution of enrichments listed in Hot Constants Memo.

The enrichment values quoted in the SPM records are consistent with the second source which is a series of mass spectroscopy measurements performed on 1/16-in plates in 1996. The quoted uncertainties in measurement of the uranium weight fractions for a single sample were $1 \%$, $0.25 \%, 2.5 \%$ and $0.5 \%$ for ${ }^{234} \mathrm{U},{ }^{235} \mathrm{U},{ }^{236} \mathrm{U}$ and ${ }^{238} \mathrm{U}$, respectively. The observed consistency among 20 samples is much better than the quoted measurement uncertainties. The fourth column of Table 4.5 shows estimated uncertainties based upon the standard deviation of these measured values. The review of a limited number of mass-spectroscopy measurements on 1/8 in plates indicated a similar consistency of the measured values and the mean enrichment values.

Finally, an estimate of the uncertainties in the weight fractions for this enriched uranium can be inferred from the distribution of the enrichment values given in the ZPPR Hot Constants Memo. The ${ }^{235} \mathrm{U}$ weight percent values range from 93.05 to 93.30 . These values appear to have a normal distribution with $\sim 70 \%$ of the values within $\pm 0.05 \%$ of their mean value. Estimated uncertainty values based on the distribution of these quoted enrichments, shown in the last column of Table 4.5, are consistent with the previous values and would appear to cover possible systematic uncertainties without adding unnecessary conservatism. Because the sum of the uranium isotopic fractions should be $100.0 \%$, the uncertainty in the ${ }^{238} \mathrm{U}$ weight fractions is also assumed to be \pm 0.05 wt. $\%$.

Table 4.6 shows the reactivity effects of the HEU mass uncertainty and the uncertainties in the ${ }^{234} \mathrm{U},{ }^{235} \mathrm{U}$ and ${ }^{236} \mathrm{U}$ weight fractions in ZPPR-15C. The ${ }^{235} \mathrm{U}$ mass was increased by $0.05 \%$ of the enriched uranium mass, and the ${ }^{238} \mathrm{U}$ mass was reduced to preserve total uranium mass. The same treatment was applied for ${ }^{234} \mathrm{U}$ and ${ }^{236} \mathrm{U}$. 
Table 4.6. Worth of HEU Mass and Isotopic Uncertainties in ZPPR-15C.

\begin{tabular}{|l|c|c|}
\hline $\begin{array}{c}\text { Component } \\
\text { Uncertainty }\end{array}$ & $\begin{array}{c}\text { Uncertainty, } \\
\text { wt.\% }\end{array}$ & $\begin{array}{c}\text { Worth, } \\
\text { pcm }\end{array}$ \\
\hline HEU mass & 0.15 & 38.84 \\
\hline${ }^{235} \mathrm{U}$ fraction & 0.05 & 14.71 \\
\hline${ }^{234} \mathrm{U}$ fraction & 0.01 & 0.51 \\
\hline${ }^{236} \mathrm{U}$ fraction & 0.01 & 0.01 \\
\hline Total & & 41.54 \\
\hline
\end{tabular}

Impurity content in the enriched uranium is treated in two parts. The first impurity component is the initial impurities that were present in the HEU metal when the original HEU plates were manufactured in the 1950s and 1960s. These initial impurities were present in the uranium when the HEU plates were weighed, so the impurity mass must be subtracted from the measured plate mass to determine the actual uranium mass in the plates. The second impurity component is associated with corrosion of the uranium after the uranium was weighed. The corrosion adds oxygen and hydrogen impurities, i.e., corrosion impurities, without affecting the uranium mass inferred from the reported plate masses.

The initial impurity levels in the enriched uranium were estimated from chemical analyses of the plate material performed in the 1990s and 2000s. Information on the analyses associated with procurement of the HEU plates is no longer available, and the hot constants memos do not list any impurities. However, chemical analysis results are available from a process to recover the enriched uranium from plates damaged by corrosion. Analysis reports were obtained for 20 samples, each of which was analyzed for 18 impurities. The 18 impurities do not include the corrosion related impurities of oxygen and hydrogen. The analysis reports indicate that:

"Less-than values are limits of quantification, which are ten times the minimum detection limit."

From an examination of the 20 reports, it was judged that large variations in the quantification limit and a scarcity of values beyond the quantification limit preclude the determination of a reliable weight ppm value for nine of the impurities. An example is cadmium for which the quantification limit ranges from $10 \mathrm{ppm}$ to $70 \mathrm{ppm}$ over the 20 samples and there is no value beyond the quantification limit. For each of the other nine measured impurities, there are at least six ppm values beyond the quantification limit and the other quantification limits are consistent. An example of this is nickel for which there are 16 values, ranging from $120 \mathrm{ppm}$ to $220 \mathrm{ppm}$, that are beyond the quantification limit and for which there are four reports giving only quantification limits which range from $180 \mathrm{ppm}$ to $290 \mathrm{ppm}$. By averaging the values beyond the quantification limit, the following nine impurity weight ppm estimates were obtained: C 340, Ni 174, Fe 125, Cu 65, Na 63, Ca 40, Si 35, Al 30, Mn 13.

This collection of nine impurity values, which total $885 \mathrm{ppm}$, was taken to be a reasonable approximation to the initial impurity level in the enriched uranium. From one perspective, this can be considered an underestimate of the impurity because it does not include any contribution from the other nine impurities or from elements which were not analyzed. Alternatively, it tends to be an overestimate because some of the measured carbon came from the recovery process which occurred after ZPPR was shut down. It is assumed that these opposing effects approximately balance, and it is estimated that a one-sigma uncertainty of $50 \%$ applies to this impurity model. 
The reported impurity level for the Godiva critical assembly provides some evidence that at least the estimated total impurity level in the enriched uranium is reasonable [7]. Godiva was composed of "virgin material" whose estimated total impurity level is approximately $400 \mathrm{ppm}$, comprised primarily of $160 \mathrm{ppm} \mathrm{C,} 110 \mathrm{ppm} \mathrm{Si}$ and $70 \mathrm{ppm} \mathrm{Fe}$. It is further stated in LA-4208 that "recycled material" has impurity levels that are about twice as large. The presence of ${ }^{236} \mathrm{U}$ indicates that the ZPPR HEU plates must have been made from recycled material. The adopted $885 \mathrm{ppm}$ impurity estimate for the ZPPR HEU plates is consistent with the approximate 800 ppm estimate for recycled material in LA-4208.

The reference MCNP model was modified by replacing $885 \mathrm{ppm}$ of uranium with the nine impurities listed above. The computed worth of the initial impurities is $-26.00 \pm 2.83 \mathrm{pcm}$. The $885 \mathrm{ppm}$ impurity is an average over the set of samples, and it appears that there were significant variations between samples. A 25\% uncertainty in the impurity level has been assumed to cover this variation. With this assumption, the final worth of the initial impurities is $-26.00 \pm 7.09$ $\mathrm{pcm}$. The HEU impurities are not included in the reference as-built MCNP model, so the worth of the initial impurities is treated as a bias and associated uncertainty.

Corrosion of the enriched uranium is discussed in a journal article [8]. When the HEU plates were used at ZPR-3, ZPR-6, and ZPR-9, the plates were coated with Kel-F to prevent corrosion and material loss during handling. After the other facilities were shut down, the HEU plates were shipped to ZPPR. At ZPPR, the uranium was cleaned, dried, and weighed just before it was clad in 1982. Because of the use of porous metal frit end plugs on the cans, the uranium began to corrode. Bulging of the thin cladding walls due to the presence of corrosion products was first noticed in a few plates in 1985. Thereafter, attempts were made to halt the corrosion but a successful strategy was not in place until 1995. By that time the periodic inspections, which had begun in 1985 , had rejected approximately $25 \%$ of the inventory. Shortly before the ZPPR-21 assemblies were built in 1990, every clad plate was inspected, and only plates that passed inspection were used. A small amount of uranium oxide and a much smaller amount of uranium hydride is believed to have been present in the plates used in ZPPR-21. One of the material scientists who studied this corrosion problem estimated the extent of corrosion in those plates [9]. The best estimate is that $1 \%$ of the uranium corroded, $2.5 \%$ of that corrosion was in the form of uranium hydride $\left(\mathrm{UH}_{3}\right)$ and the remaining $97.5 \%$ was in the form of uranium oxide when ZPPR-21 was built. The one-sigma uncertainty on this estimate is $100 \%$.

ZPPR-15C was built in 1986 around the midpoint between the date when the HEU plates were canned and the time when ZPPR-21 was built. In the absence of any other information regarding corrosion of the HEU plates, it has been assumed that a) $0.5 \%$ of the uranium had corroded when ZPPR-15D was built, b) $2.5 \%$ of the corrosion was in the form of uranium hydride, c) $97.5 \%$ of the corrosion was in the form of uranium oxide and d) the one-sigma uncertainty on the estimated corrosion is $100 \%$.

The reference MCNP model was modified by adding enough oxygen and hydrogen to the HEU to match the assumed level of corrosion. The computed worth of the corrosion impurities is $1.00 \pm 3.00 \mathrm{pcm}$. The HEU corrosion impurities are not included in the reference MCNP model, so the worth of the corrosion impurities is treated as a bias which lowers $k_{\text {eff }}$ and associated uncertainty. 
The HEU metal is canned in stainless steel. The nominal can composition corresponds to Type 304 stainless steel. In addition to the uncertainty in the can mass, there is an uncertainty in the weight fractions of the components of the stainless steel. The only uncertainties in the composition of the stainless steel that may make a significant contribution to the total uncertainty are the uncertainties in the weight fractions of $\mathrm{Mn}, \mathrm{Cr}$ and $\mathrm{Ni}$. Table 4.7 shows the reactivity effects of the uncertainties in mass and composition for the HEU cans in ZPPR-15C.

Table 4.7. Worth of HEU Can Uncertainties in ZPPR-15C.

\begin{tabular}{|l|c|c|c|}
\hline $\begin{array}{c}\text { Component } \\
\text { Uncertainty }\end{array}$ & $\begin{array}{c}\text { Assumed } \\
\text { Uncertainty }\end{array}$ & $\begin{array}{c}\text { Nominal } \\
\text { wt.\% }\end{array}$ & $\begin{array}{c}\text { Worth, } \\
\text { pcm }\end{array}$ \\
\hline Mass & 0.15 & & 0.03 \\
\hline $\mathrm{Mn}$ & 0.1 & 1.0 & 0.00 \\
\hline $\mathrm{Cr}$ & 0.2 & 19.0 & 0.02 \\
\hline $\mathrm{Ni}$ & 0.2 & 9.25 & 0.03 \\
\hline Total & & & 0.05 \\
\hline
\end{tabular}

\subsubsection{Pu-U-Mo Plates}

Approximately half of the core drawers in ZPPR-15C contained canned HEU plates; the remaining core drawers contained $\mathrm{Pu}-\mathrm{U}-\mathrm{Mo}$ fuel plates. Section 2.3.6 discussed the methodology for determining the composition uncertainties for the $\mathrm{Pu}-\mathrm{U}-\mathrm{Mo}$ fuel meat in the plates.

The uncertainty in the total plutonium mass was computed to be 0.0807 wt. $\%$. Changing the plutonium (plus americium) mass by this amount in the deterministic model changed $\mathrm{k}_{\text {eff }}$ by 21.57 pcm.

The relative uncertainty in the ${ }^{239} \mathrm{Pu}$ weight percent was computed to be $0.0125 \%$. In the deterministic model, the ${ }^{239} \mathrm{Pu}$ concentration was increased by this amount and mass was preserved by decreasing just the ${ }^{240} \mathrm{Pu}$ concentration (a simplification justified by the very small size of the other isotopic concentrations). The resulting change in $\mathrm{k}_{\mathrm{eff}}$ is $2.60 \mathrm{pcm}$.

The weight percent of ${ }^{238} \mathrm{Pu},{ }^{241} \mathrm{Pu}$, and ${ }^{242} \mathrm{Pu}$ in the assembly before decaying ${ }^{241} \mathrm{Pu}$, was less than $2 \%$. The only isotope besides ${ }^{239} \mathrm{Pu}$ whose uncertainty would be expected to impact $\mathrm{k}_{\text {eff }}$ appreciably is ${ }^{240} \mathrm{Pu}$. The relative uncertainty in the ${ }^{240} \mathrm{Pu}$ weight percent is $0.0509 \%$. Modification of the ${ }^{240} \mathrm{Pu}$ weight percent led to a calculated effect on $\mathrm{k}_{\text {eff }}$ of $1.41 \mathrm{pcm}$. The combined uncertainty in $\mathrm{k}_{\text {eff }}$ due to the uncertainties in the original weight fractions of the remaining three isotopes is assumed to be no larger than this (i.e., $1.41 \mathrm{pcm}$ ). In principle, the total uncertainty in the plutonium isotopic fractions could be reduced by using the constraint that the sum of these fractions was unity. Because this uncertainty component does not make a significant contribution to the total uncertainty in the system reactivity, further analysis was deemed unwarranted.

Some of the ${ }^{241} \mathrm{Pu}$ that was in the fuel plates when they were manufactured decayed by the time ZPPR-15 was built. The Pu-U-Mo NUMEC and Dow plates were made in the late 1960s, ZPPR-15C L166 was made critical on April 23, 1986, and the ${ }^{241} \mathrm{Pu}$ half-life is 14.29 years. The numbers in the inventory database are normalized to January 1, 1977. The estimated uncertainty in the decay constant is $1 \%$. Increasing the decay constant increases the ${ }^{241} \mathrm{Am}$ mass and decreases the $241 \mathrm{Pu}$ mass. Increasing the decay constant by $1 \%$ reduces keff by 1.43 pem. 
Impurities in the Pu-U-Mo fuel meat were discussed in Section 2.3. The computed worth of the impurities in the Pu-U-Mo fuel meat in ZPPR-15C L166 is $5.00 \pm 3.61 \mathrm{pcm}$. These impurities are neglected in the as-built model, so the computed impurity worth is assumed as bias for neglecting the impurities in the Pu-U-Mo plates in ZPPR-15C L166.

The specification for production of the NUMEC Pu-U-Mo plates required a $235 \mathrm{U}$ enrichment of $0.22 \pm 0.02 \mathrm{wt} . \%$ in the uranium component. It appears that the $0.02 \mathrm{wt} . \%$ represented the two sigma confidence interval, so the corresponding one sigma uncertainty is $0.01 \mathrm{wt} . \%$. The $235 \mathrm{U}$ mass was increased by $0.01 \%$ and the $238 \mathrm{U}$ mass was reduced correspondingly in the deterministic model. The resulting uncertainty in keff is $11.61 \mathrm{pcm}$.

The uncertainty in the mass of molybdenum in the Pu-U-Mo fuel alloy was computed in the same way as the plutonium mass uncertainty. The computed molybdenum mass uncertainty is $0.0983 \%$. Changing the core region molybdenum atom density by this amount changes keff by $0.09 \mathrm{pcm}$.

Table 4.8 shows the reactivity effects of the uncertainties in the mass and composition of the $\mathrm{Pu}-\mathrm{U}-\mathrm{Mo}$ alloy in the Pu-U-Mo plates used in ZPPR-5C.

Table 4.8. Worth of Pu-U-Mo Alloy Uncertainties in ZPPR-15C.

\begin{tabular}{|l|c|}
\hline \multicolumn{1}{|c|}{ Component Uncertainty } & Worth, pcm \\
\hline $\mathrm{Pu}$ mass & 21.57 \\
\hline${ }^{239} \mathrm{Pu}$ fraction & 2.60 \\
\hline${ }^{240} \mathrm{Pu}$ fraction & 1.41 \\
\hline Other $\mathrm{Pu}$ isotopes & 1.41 \\
\hline${ }^{241} \mathrm{Pu}$ decay & 1.43 \\
\hline${ }^{235} \mathrm{U}$ in depleted uranium & 11.61 \\
\hline Mo mass & 0.09 \\
\hline Total & 24.76 \\
\hline
\end{tabular}

The Pu-U-Mo alloy is clad in stainless steel. Table 4.9 shows the computed reactivity effects of the uncertainties in mass and composition for the Pu-U-Mo cans in ZPPR-15C.

Table 4.9. Worth of Pu-U-Mo Can Uncertainties in ZPPR-15C.

\begin{tabular}{|l|c|c|c|}
\hline $\begin{array}{c}\text { Component } \\
\text { Uncertainty }\end{array}$ & $\begin{array}{c}\text { Assumed } \\
\text { Uncertainty }\end{array}$ & $\begin{array}{c}\text { Nominal } \\
\text { wt.\% }\end{array}$ & $\begin{array}{c}\text { Worth, } \\
\text { pcm }\end{array}$ \\
\hline Mass & 0.15 & & 0.13 \\
\hline $\mathrm{Mn}$ & 0.1 & 1.0 & 0.02 \\
\hline $\mathrm{Cr}$ & 0.2 & 19.0 & 0.06 \\
\hline $\mathrm{Ni}$ & 0.2 & 9.25 & 0.14 \\
\hline Total & & & 0.20 \\
\hline
\end{tabular}

\subsubsection{Matrix Tubes}

The uncertainties discussed in Section 2.3 for the matrix tubes apply to all phases of the ZPPR15 program. Table 4.10 shows the computed reactivity effects of the uncertainties in mass and composition for the matrix tubes in ZPPR-15C.

Table 4.10. Worth of Matrix Tube Uncertainties in ZPPR-15C.

\begin{tabular}{|l|l|l|l|} 
Component & Assumed & Nominal & Worth, \\
\hline
\end{tabular}




\begin{tabular}{|l|c|c|c|}
\hline \multicolumn{1}{|c|}{ Uncertainty } & Uncertainty & wt. $\%$ & pcm \\
\hline Mass & 2.0 & & 7.74 \\
\hline $\mathrm{Mn}$ & 0.1 & 1.0 & 0.12 \\
\hline $\mathrm{Cr}$ & 0.2 & 19.0 & 0.61 \\
\hline $\mathrm{Ni}$ & 0.2 & 9.25 & 0.69 \\
\hline Total & & & 7.80 \\
\hline
\end{tabular}

\subsubsection{Drawers}

The same drawer types were used in all phases of the ZPPR-15 program. The overwhelming majority of the drawers in ZPPR-15C were normal 36.252 in. drawers with a nominal interior width slightly larger than two inches to accommodate the normal two inch width of plates. Twelve drawers in each half were PSR drawers, which were 0.5 in narrower than normal drawers to allow for the presence of 0.5 in control rod guide tubes.

The uncertainties discussed in Section 2.3 for the drawers apply to ZPPR-15C. The Fe weight percent was adjusted to conserve mass when the weight percent of $\mathrm{Mn}, \mathrm{Cr}$ or Ni was perturbed. Table 4.11 shows the reactivity effects of the uncertainties in mass and composition for the drawers in ZPPR-15C.

Table 4.11. Worth of Drawer Uncertainties in ZPPR-15C.

\begin{tabular}{|l|c|c|c|c|}
\hline \multirow{2}{*}{$\begin{array}{c}\text { Component } \\
\text { Uncertainty }\end{array}$} & Assumed & Nominal & \multicolumn{2}{c|}{ Worth, pcm } \\
\cline { 4 - 5 } & Uncertainty & wt.\% & Normal Drawers & PSR Drawers \\
\hline Mass & 0.15 & & 0.35 & 0.01 \\
\hline $\mathrm{Mn}$ & 0.1 & 1.0 & 0.07 & 0.01 \\
\hline $\mathrm{Cr}$ & 0.2 & 19.0 & 0.34 & 0.01 \\
\hline $\mathrm{Ni}$ & 0.2 & 9.25 & 0.42 & 0.01 \\
\hline Total & & & 0.65 & 0.02 \\
\hline
\end{tabular}

\subsubsection{Steel Blocks}

The same low carbon steel blocks discussed in Section 2.3.9 were used as part of the axial reflector in all phases of the ZPPR-15 program. Table 4.12 shows the reactivity effects of the uncertainties in mass and composition for the steel blocks in ZPPR-15C.

Table 4.12. Worth of Steel Block Uncertainties in ZPPR-15C.

\begin{tabular}{|l|r|}
\hline $\begin{array}{c}\text { Component } \\
\text { Uncertainty }\end{array}$ & $\begin{array}{r}\text { Worth, } \\
\text { pcm }\end{array}$ \\
\hline Mass & 0.01 \\
\hline $\mathrm{Mn}$ & 0.00 \\
\hline $\mathrm{Cr}$ & 0.00 \\
\hline $\mathrm{C}$ & 0.03 \\
\hline Total & 0.03 \\
\hline
\end{tabular}

\subsubsection{Stainless Steel Plates}

Four different groups of stainless steel plates present in ZPPR-15C L166. The identifiers for those groups are SST, SS75, SSTX and SSET in the inventory records. These four groups of stainless steel plates were obtained at different times from different suppliers. Consequently, 
the four groups of stainless steel plates will be treated as being independent for purposes of uncertainty analysis.

The uncertainties discussed in Section 2.3 for the SST, SS75, SSTX and SSET stainless steel plates apply to ZPPR-15C. The Fe weight percent was adjusted to conserve mass when the weight percent of $\mathrm{Mn}, \mathrm{Cr}$ or $\mathrm{Ni}$ was perturbed. Table 4.13 shows the reactivity effects of the uncertainties in mass and composition for the stainless steel plates in ZPPR-15C.

Table 4.13. Worth of Stainless Steel Plate Uncertainties in ZPPR-15C.

\begin{tabular}{|l|c|c|c|c|c|c|}
\hline Component & Assumed & Nominal & \multicolumn{4}{|c|}{ Worth, pcm } \\
\cline { 4 - 7 } Uncertainty & Uncertainty & wt.\% & SST & SS75 & SSTX & SSET \\
\hline Mass & 0.15 & & 0.00 & 0.17 & 0.91 & 0.64 \\
\hline $\mathrm{Mn}$ & 0.1 & 1.0 & 0.27 & 0.21 & 0.09 & 0.47 \\
\hline $\mathrm{Cr}$ & 0.2 & 19.0 & 0.55 & 0.24 & 0.63 & 0.02 \\
\hline $\mathrm{Ni}$ & 0.2 & 9.25 & 0.09 & 0.28 & 0.99 & 0.60 \\
\hline Total & & & 0.62 & 0.46 & 1.49 & 1.00 \\
\hline
\end{tabular}

The 0.1 pcm uncertainty for humidity discussed in section 2.3 applies to ZPPR-15C L166 as well.

The total composition uncertainty is $59.91 \mathrm{pcm}$.

\subsection{Total Uncertainty for ZPPR-15C Loading 166}

Table 4.14 summarizes all of the uncertainty components for measurement technique, configuration geometry and material compositions and lists the total uncertainty for ZPPR-15C L166.

The reported experimental $\mathrm{k}_{\text {eff }}$ after adjustment to standard reporting conditions was $1.00052 \pm$ 0.00001 . When the total uncertainty listed in Table 4.14 is included, the experimental $\mathrm{k}_{\text {eff }}$ is $1.00052 \pm 0.00066$.

\subsection{Biases or Adjustments for ZPPR-15C Loading 166}

Several adjustments to the reported experimental $\mathrm{k}_{\mathrm{eff}}$ are required to account for features that are not included in the as-built model. The interface gap is not included in the as-built model, but the ZPPR staff adjusted the reported excess reactivity to a condition with zero gap. Consequently, there is no bias associated with neglecting the interface gap in the as-built model. The uncertainty resulting from the non-uniform size of the interface gap is addressed in Section 4.2 and is included in the total uncertainty determined in Section 4.4.

The reference as-built model does not include the split tables, clamping structure or the room in which the machine was located. The calculated worth of room return for ZPPR-15C L166 was $0.00 \pm 2.83 \mathrm{pcm}$.

Available documents do not list the impurities in the depleted uranium plates, and the depleted uranium impurities are neglected in the as-built model. The worth of the depleted uranium plate impurities is assumed to be approximately equal to the $0.15 \%$ mass uncertainty in the depleted uranium plates. Increasing the depleted uranium plate masses by $0.15 \%$ reduced $\mathrm{k}_{\text {eff }}$ by -14.08 pcm for the original ZPPR (APW2) depleted uranium plates and by $-1.47 \mathrm{pcm}$ for the ANL-E depleted uranium plates. Adding the impurities to the depleted uranium plates would have approximately the same effect. The uncertainty in the impurity level is assumed to be $100 \%$. 
Neglecting the impurities in the ZPPR depleted uranium increases reactivity by $14.08 \pm 14.08$ pcm. Neglecting the impurities in the ANL-E depleted uranium increases reactivity by $1.47 \pm$ $1.47 \mathrm{pcm}$.

Table 4.14. Total Uncertainty for ZPPR-15C L166.

\begin{tabular}{|c|c|}
\hline Uncertainty Component & Uncertainty, pcm \\
\hline \multicolumn{2}{|c|}{ Measurement Technique } \\
\hline Excess reactivity & 0.52 \\
\hline Temperature & 3.41 \\
\hline Reproducibility & 1.00 \\
\hline$\beta_{\text {eff }}$ uncertainty & 2.40 \\
\hline Subtotal & 4.32 \\
\hline \multicolumn{2}{|l|}{ Geometry } \\
\hline Interface gap & 5.72 \\
\hline Nominal plate, drawer dimensions & 12.04 \\
\hline Matrix tube pitch & 22.99 \\
\hline Subtotal & 26.58 \\
\hline \multicolumn{2}{|c|}{ Composition } \\
\hline Pu-U-Mo alloy & 24.76 \\
\hline Pu-U-Mo plate clad & 0.20 \\
\hline HEU & 41.54 \\
\hline HEU clad & 0.05 \\
\hline Sodium & 0.39 \\
\hline Sodium plate clad & 1.10 \\
\hline Zirconium & 0.60 \\
\hline Natural uranium & 0.01 \\
\hline Depleted uranium - APW2 & 34.33 \\
\hline Depleted uranium - ANL-E & 2.47 \\
\hline Matrix tubes & 7.80 \\
\hline Drawers - standard & 0.65 \\
\hline Drawers - PSR (control rod) & 0.02 \\
\hline Steel blocks - FE & 0.03 \\
\hline Stainless steel - SST & 0.62 \\
\hline Stainless steel - SS75 & 0.46 \\
\hline Stainless steel - SSTX & 1.49 \\
\hline Stainless steel - SSET & 1.00 \\
\hline Humidity & 0.10 \\
\hline Subtotal & 59.91 \\
\hline Total Uncertainty & 65.68 \\
\hline
\end{tabular}

The depleted uranium plates were coated with Kel-F to prevent corrosion and material loss during handling. Kel-F generally is neglected in as-built models. Adding the Kel-F to the asbuilt model lowers $\mathrm{k}_{\mathrm{eff}}$ by $-19.00 \pm 3.41 \mathrm{pcm}$, so neglecting the Kel-F increases reactivity by $19.00 \pm 3.41 \mathrm{pcm}$. 
The impurities is the $\mathrm{Pu}-\mathrm{U}-\mathrm{Mo}$ fuel are neglected in the as-built model. Adding the impurities to the $\mathrm{Pu}-\mathrm{U}-\mathrm{Mo}$ plates increases reactivity by $5.00 \pm 3.61 \mathrm{pcm}$, so neglecting the Pu-U-Mo impurities reduces reactivity by $-5.00 \pm 3.61 \mathrm{pcm}$.

The impurities that were present when the original HEU metal plates were cast lower $\mathrm{k}_{\text {eff }}$ because they replace HEU. Adding the HEU impurities to the as-built model lowers $\mathrm{k}_{\text {eff }}$ by $26.00 \pm 7.09 \mathrm{pcm}$, so neglecting the HEU impurities in the as-built model increases reactivity by $26.00 \pm 7.09 \mathrm{pcm}$.

The end caps that were used when the HEU metal plates were canned were not airtight. As a result, some $\mathrm{HEU}$ plates corroded with formation of $\mathrm{UO}_{2}$ and $\mathrm{UH}_{3}$. Adding the corrosion products to the as-built model raises $\mathrm{k}_{\mathrm{eff}}$ by $1.00 \pm 3.00 \mathrm{pcm}$, so neglecting the corrosion products decreases reactivity by $-1.00 \pm 3.00 \mathrm{pcm}$.

Table 4.15 shows the computed biases and associated uncertainties for ZPPR-15C L166.

Table 4.15. Biases for ZPPR-15C L166 As-Built Model.

\begin{tabular}{|l|c|c|}
\hline \multicolumn{1}{|c|}{ Component } & Bias, $\mathrm{pcm}$ & $\sigma, \mathrm{pcm}$ \\
\hline Room return & 0.00 & 2.83 \\
\hline ZPPR DU impurities & 14.08 & 14.08 \\
\hline ANL-E DU impurities & 1.47 & 1.47 \\
\hline DU Kel-F coating & 19.00 & 3.41 \\
\hline Pu-U-Mo impurities & -5.00 & 3.61 \\
\hline HEU impurities & 26.00 & 7.09 \\
\hline HEU corrosion products & -1.00 & 3.00 \\
\hline Total & 54.55 & 17.10 \\
\hline
\end{tabular}

\subsection{Final Adjusted Experimental keff for ZPPR-15C Loading 166}

The reported experimental $k_{\text {eff }}$ for ZPPR-15C L166 is $1.00052 \pm 0.00066$ when the total uncertainty derived in Section 4.4 is included. This value is for the measured configuration and does not include the total bias listed in Table 4.15. When the total bias from Section 4.5 is included, the final adjusted experimental $k_{\text {eff }}$ for ZPPR-15C L166, the ZPPR-15C reference critical configuration, is $1.00107 \pm 0.00068$.

Consequently, the final adjusted experimental $\mathrm{k}_{\mathrm{eff}}$ for the described as-built model of ZPPR$15 \mathrm{C}$ L166 is $1.00107 \pm 0.00068$.

\section{ZPPR-15D Reference Critical Configuration}

There were relatively few loadings and relatively few measurements in ZPPR-15C. At the end of Phase $\mathrm{C}$, most of the remaining plutonium-fueled drawers were replaced with drawers containing a mixture of HEU plates and depleted uranium plates to establish the required configuration for ZPPR-15D. ZPPR-15D simulated the initial uranium-fueled IFR core. Although ZPPR-15D simulated a uranium-fueled core, some drawers in the outer core zone of ZPPR-15D contained Pu-U-Mo fuel plates rather than HEU plates. The Pu-U-Mo plates were required to provide a distributed neutron source for the modified source multiplication technique used at ZPPR to measure the worth of sodium voiding and simulated IFR control rods. The reference critical configuration for ZPPR-15D was established in loading 185 (ZPPR15D L185) on May 23, 1986 in reactor run 313. 
Figures 5.1 and 5.2 shows the matrix maps for half 1 and half 2, respectively, of ZPPR-15D L185. The color scheme described in Section 2 for the ZPPR-15A matrix maps applies to Figures 5.1 and 5.2 with one addition. Salmon-colored cells in Figures 5.1 and 5.2 are drawer masters containing HEU fuel plates in place of Pu-U-Mo fuel plates.

\subsection{ZPPR-15D Measurement Technique Uncertainties}

The reported excess reactivity for ZPPR-15D L185 was $9.8 \pm 0.1 \varnothing$ at a temperature of 20.63 ${ }^{\circ} \mathrm{C}$, and the reported $\beta_{\text {eff }}$ for ZPPR-15D was 0.006564 . Based on the discussion in Section 2.1, it is likely that the $9.8 \pm 0.1 \varnothing$ excess reactivity is the excess reactivity prior to adjustment to 293 $\mathrm{K}$, PSR control rods parked at 30 inches and a zero interface gap. The final adjusted experimental $\mathrm{k}_{\text {eff }}$ for ZPPR-15D L185 reported by the ZPPR staff is $1.00067 \pm 0.00001$.

The uncertainty reported with the excess reactivity, $0.1 \phi$ or $0.66 \mathrm{pcm}$, includes counting statistics, detector calibration and several other factors such as uncertainties related to adjustment to the standard temperature and parked control rod positions. Additional factors contribute to the total measurement uncertainty.

The estimated $0.5{ }^{\circ} \mathrm{C}$ uncertainty in thermocouple calibration and $1{ }^{\circ} \mathrm{C}$ uncertainty in the average core temperature discussed in Section 2.1 for ZPPR-15A apply to all ZPPR-15 loadings. When added in quadrature, the combined uncertainty in temperature is $1.12^{\circ} \mathrm{C}$.

The reported temperature coefficient for ZPPR-15D is $-0.39 \pm 0.1 \notin /{ }^{\circ} \mathrm{C}$. Based upon the reported temperature coefficient, the reactivity effect of the $1.12{ }^{\circ} \mathrm{C}$ temperature uncertainty is $0.44 \phi$. The measured temperature coefficient is uncertain, and the contribution from the $0.1 \notin /{ }^{\circ} \mathrm{C}$ uncertainty in the temperature coefficient is $0.11 \phi$. Adding these two components in quadrature, the total reactivity effect of the temperature uncertainty is $0.45 \notin$ or $2.95 \mathrm{pcm}$.

The $1 \mathrm{pcm}$ non-reproducibility uncertainty discussed in Section 2 for ZPPR-15A applies to all ZPPR-15 loadings.

The 5\% estimated uncertainty in $\beta_{\text {eff }}$ discussed in Section 2 for ZPPR-15A also applies to all ZPPR-15 loadings. The contributions due to the uncertainty in $\beta_{\text {eff }}$ are $3.22 \mathrm{pcm}$ for excess reactivity conversion, $0.15 \mathrm{pcm}$ for the temperature uncertainty conversion and $0.05 \mathrm{pcm}$ for non-reproducibility conversion. The total uncertainty contribution due the uncertainty in $\beta_{\text {eff }}$ is $3.22 \mathrm{pcm}$.

When the reactivity uncertainties due to excess reactivity, temperature, reproducibility and $\beta_{\mathrm{eff}}$ uncertainties are added in quadrature, the total measurement uncertainty for ZPPR-15D L185 is $4.53 \mathrm{pcm}$. 


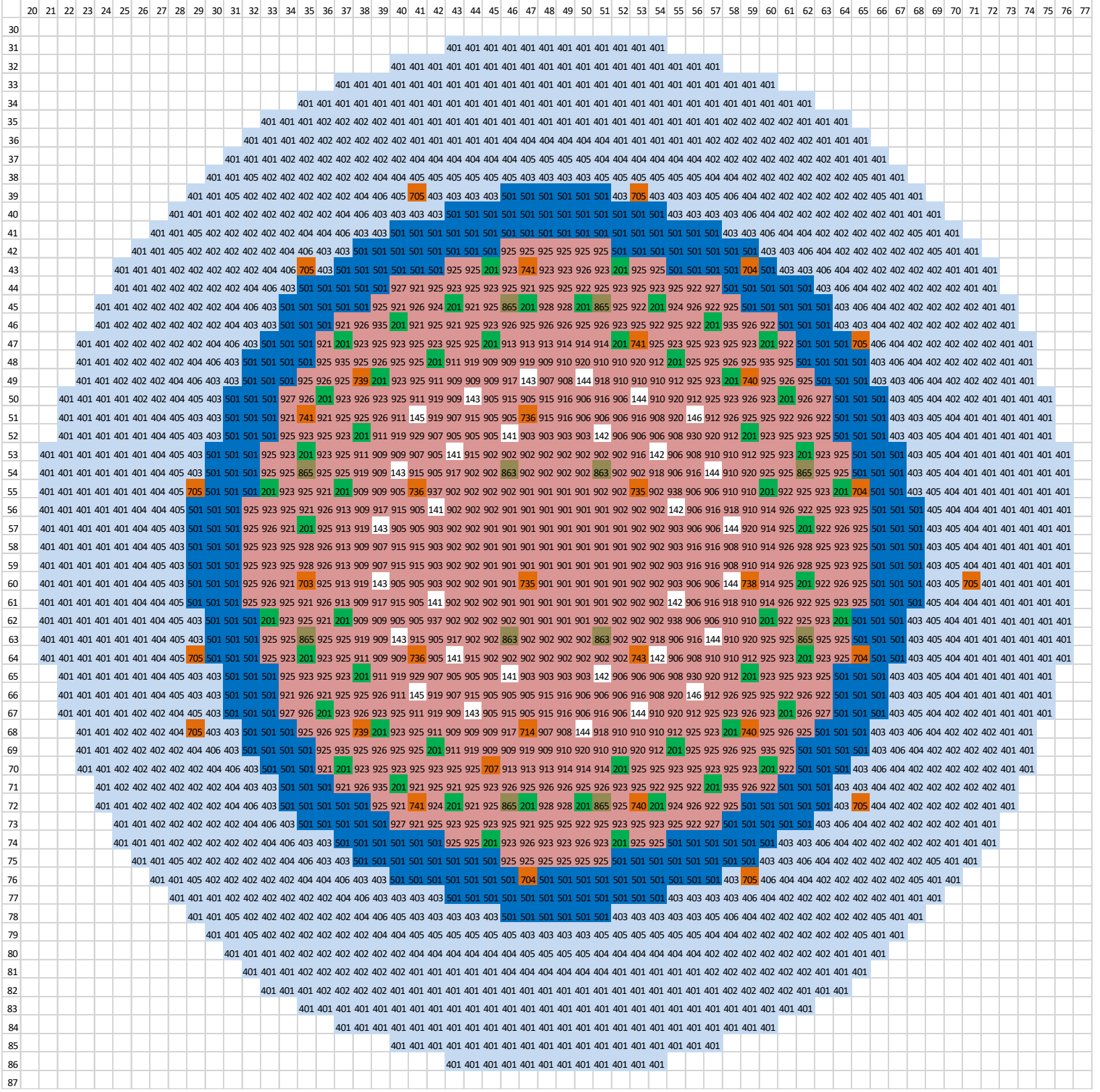

Figure 5.1. ZPPR-15D L185 - Matrix Map for Half 1. 


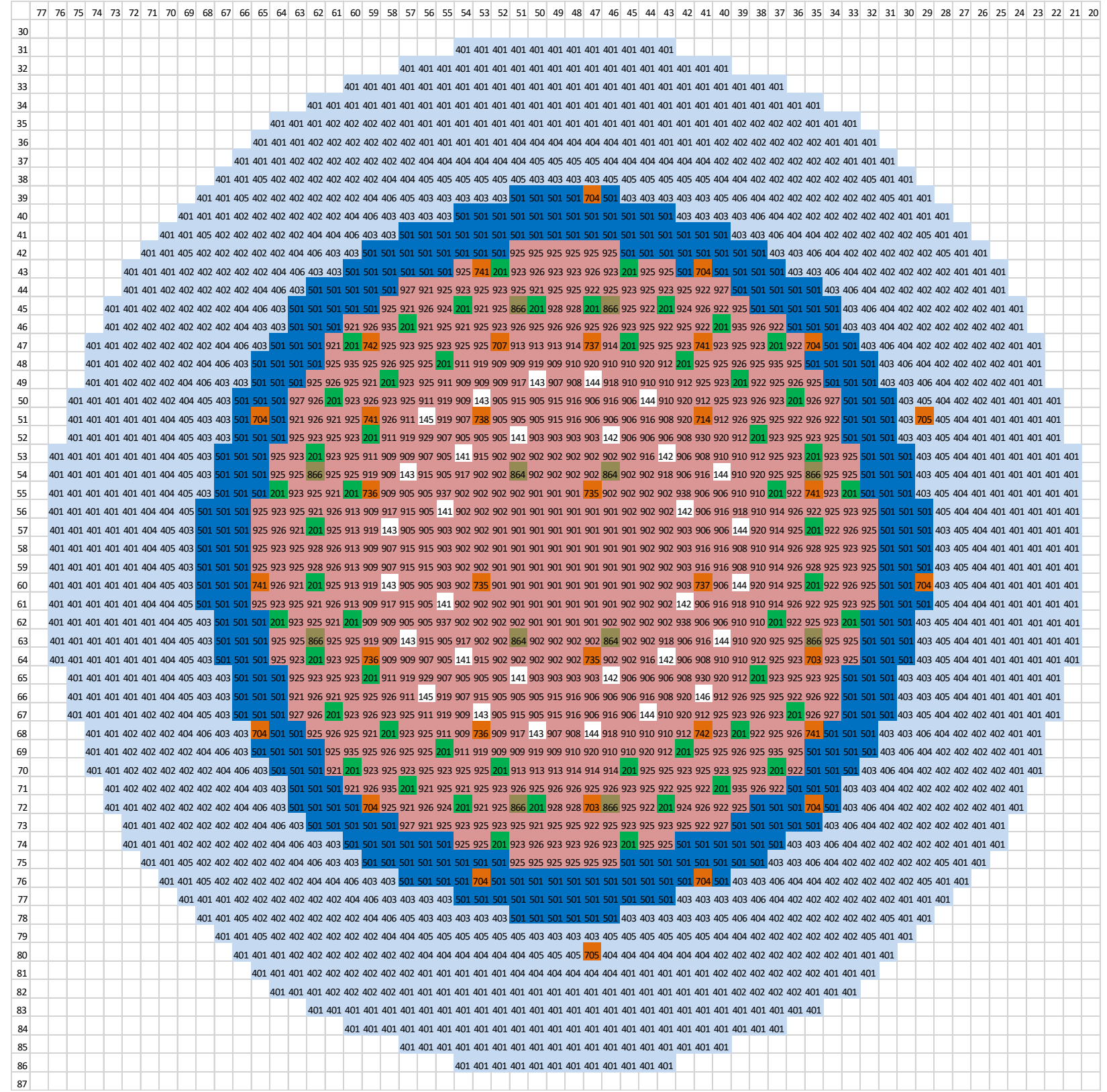

Figure 5.2. ZPPR-15D L185 - Matrix Map for Half 2.

\subsection{ZPPR-15D Geometry Uncertainties}

\subsubsection{Interface Gap}

No published interface gap coefficient has been found for ZPPR-15B or ZPPR-15D. However, the ZPPR staff did publish a gap coefficient for ZPPR-15C. They stated that no gap coefficient was measured for ZPPR-15C and that the published gap coefficient for ZPPR-15C was the measured value for ZPPR-15B scaled by the ratio of the $\beta_{\text {eff }}$ values for the two configurations. The published gap coefficient for ZPPR-15C is $-0.0852 \pm 0.013 \phi / \mathrm{mil}$. Reversing the derivation of the ZPPR-15C value, the interface gap coefficient for ZPPR-15B is $-0.132 \pm 0.02 \varnothing / \mathrm{mil}$. This 
is very close to the measured value for ZPPR-15A, which is consistent with the fact that the ZPPR-15A and ZPPR-15B cores were very similar.

Applying the method used to derive the ZPPR-15C interface gap coefficient to the ZPPR-15D configuration, the interface gap coefficient for ZPPR-15D is $-0.0676 \pm 0.01 \notin / \mathrm{mil}$.

According to the ZPPR-15 logbook entry, the measured table indicator values for ZPPR-15D L185 reactor run 313 were 33.2, 54.5, 31.4 and 54.7 gap separation units (mils). The average of these four table indicator values is $43.45 \mathrm{mils}$ or $0.1104 \mathrm{~cm}$ for ZPPR-15D L185. Consequently, the worth of the interface gap was $-2.94 \pm 0.43 \not$ or $-19.28 \pm 2.85 \mathrm{pcm}$.

A reasonable estimate of the uncertainty associated with the non-uniform gap is $25 \%$ of the gap worth or $4.82 \mathrm{pcm}$. When this uncertainty is combined with the $2.85 \mathrm{pcm}$ uncertainty due to the uncertainty in the gap coefficient, the final value for the interface gap worth is $-19.28 \pm 5.60$ $\mathrm{pcm}$. The experimenters adjusted the reported excess reactivity to zero interface gap, but the $5.60 \mathrm{pcm}$ uncertainty in the interface gap worth still contributes to the total uncertainty.

\subsubsection{Positions of Drawers and Plates}

The discussion in Section 2.2.2 above regarding the effects of uncertainty in the positions of drawers and plates applies to all ZPPR-15 configurations. The effects of uncertainties in the axial positions of the plates relative to the drawer front and of deviations in the axial dimensions of the plates were estimated conservatively by introducing a 0.0075 in the gap between the drawer front and the front of plate columns in each drawer in both halves of the matrix in ZPPR15A L015 and ZPPR-15B L088. The values computed for L015 and L088 did not differ significantly. The computed worth of this gap for ZPPR-15B L088, $-12.04 \pm 2.24 \mathrm{pcm}$, is assumed to apply to ZPPR-15D L185.

\subsubsection{Matrix Tube Pitch}

The worth of the assumed 0.001 inch uncertainty in the matrix tube pitch was calculated with MCNP for the ZPPR-15D L185 as-built model. One billion $\left(10^{9}\right)$ histories were run for each configuration. The computed worth of the 0.001 inch matrix tube pitch uncertainty is $-29.89 \pm$ $2.83 \mathrm{pcm}$.

\subsubsection{Room Return}

The worth of room return was computed as the difference between the reference ZPPR-15D L185 as-built model and an expanded model in which the steel table, steel structures on the sides and top of the matrix and the surrounding room were added. The computed worth of the room return was $0.00 \pm 2.83 \mathrm{pcm}$. The $2.83 \mathrm{pcm}$ Monte Carlo uncertainty is assumed to be the uncertainty in the worth of the room return. The computed worth of room return here just demonstrates the fact that room return is very small in ZPPR-15 and that it is difficult to compute a statistically meaningful value for the room return. Room return is neglected in the as-built models. Omission of room return is treated as a bias in Section 5.5.

\subsection{ZPPR-15D Composition Uncertainties}

The $0.15 \%$ uncertainty in mass for plates and drawers discussed in Section 2.3 for ZPPR-15A applies to all ZPPR-15 configurations. 


\subsubsection{Sodium Plates}

The assumed $0.15 \%$ uncertainty in the mass of sodium in the sodium plates was calculated to be worth $1.47 \mathrm{pcm}$. The sodium in these plates is listed in the hot constants memo as being $99.93 \% \mathrm{Na}, 0.04 \% \mathrm{Ca}, 0.005 \% \mathrm{O}, 0.02 \% \mathrm{C}$, and $0.005 \% \mathrm{Cl}$. An upper bound on the effect of such small impurities was calculated by doubling the existing impurities, yielding an uncertainty in $\mathrm{k}_{\text {eff }}$ of $0.43 \mathrm{pcm}$. The quadrature sum of the worths of the $1 \sigma$ mass and impurity uncertainties for the sodium plates is $1.53 \mathrm{pcm}$.

The uncertainties discussed for the sodium plate cans in Section 2.3 apply to ZPPR-15D as well. The Fe weight percent was adjusted to conserve mass when the weight percent of $\mathrm{Mn}, \mathrm{Cr}$ or Ni was perturbed. Table 5.1 shows the reactivity effects of the uncertainties in mass and composition of the sodium cans in ZPPR-15D.

Table 5.1. Worth of Sodium Can Uncertainties in ZPPR-15D.

\begin{tabular}{|l|c|c|c|}
\hline $\begin{array}{l}\text { Component } \\
\text { Uncertainty }\end{array}$ & $\begin{array}{c}\text { Assumed } \\
\text { Uncertainty }\end{array}$ & $\begin{array}{c}\text { Nominal } \\
\text { wt.\% }\end{array}$ & $\begin{array}{c}\text { Worth, } \\
\text { pcm }\end{array}$ \\
\hline Mass & 0.15 & & 0.29 \\
\hline $\mathrm{Mn}$ & 0.1 & 1.0 & 0.03 \\
\hline $\mathrm{Cr}$ & 0.2 & 19.0 & 0.36 \\
\hline $\mathrm{Ni}$ & 0.2 & 9.25 & 0.72 \\
\hline Total & & & 0.86 \\
\hline
\end{tabular}

\subsubsection{Zirconium Plates}

The $0.15 \%$ uncertainty in the mass of the zirconium plates was calculated to be worth $0.44 \mathrm{pcm}$. There is no information available regarding impurities in the zirconium plates. The mass uncertainty for the zirconium plates is very small, so the effects of impurities were assumed to be negligible.

\subsubsection{Depleted Uranium Plates}

Most depleted uranium plates used in ZPPR-15D were part of the original ZPPR plate inventory and were designated APW2 in the hot constants memos. Additional depleted uranium plates used in ZPPR-15D were part of the original ANL-E inventory used in ZPR-6 and ZPR-9. The uncertainties in mass, ${ }^{235} \mathrm{U}$ wt.\% and impurity content for the 0.125 inch depleted uranium plates were discussed in Section 2.3.3 for ZPPR-15A. Those uncertainties apply to the depleted uranium plates used ZPPR-15D as well.

Because the ZPPR and ANL-E plate inventories were manufactured at different times, the ZPPR depleted uranium plates and the ANL-E depleted uranium plates will be treated as independent in this analysis. Table 5.2 shows the reactivity worths of uncertainties for the depleted uranium plates from the original ZPPR inventory. Table 5.3 shows the reactivity worths of uncertainties for the depleted uranium plates that were originally part of the ANL-E plate inventory. 
Table 5.2. Worth of Plate Uncertainties for ZPPR Depleted Uranium Plates in ZPPR-15D.

\begin{tabular}{|l|c|c|}
\hline Component & Uncertainty, & Worth, pcm \\
\cline { 3 - 3 } & wt. $\%$ & $\begin{array}{c}0.125 \text { in. } \\
\text { UPW } 2\end{array}$ \\
\hline Mass & 0.15 & 13.86 \\
\hline${ }^{235}$ U Enrichment & 0.01 & 31.34 \\
\hline Total & & 34.27 \\
\hline
\end{tabular}

Table 5.3. Worth of Plate Uncertainties for ANL-E Depleted Uranium Plates in ZPPR-15D.

\begin{tabular}{|c|c|c|}
\hline Component & Uncertainty, & Worth, pcm \\
\cline { 3 - 3 } Uncertainty & wt. $\%$ & ANL-E \\
\hline Mass & 0.15 & 2.69 \\
\hline${ }^{235}$ U Enrichment & 0.01 & 3.54 \\
\hline Total & & 4.45 \\
\hline
\end{tabular}

It has been assumed here that the reactivity worth of the depleted uranium impurities is approximately equal to the worth of the $0.15 \%$ mass uncertainty and that the associated uncertainty in the worth of the depleted uranium impurities is $100 \%$ (see Section 2.3.3). The depleted uranium impurity uncertainty is not listed in Tables 5.2 and 5.3 because neglecting the impurities in the depleted uranium plates is treated as a bias in Section 5.5. The impurity uncertainty is included with the bias uncertainties.

The depleted uranium plates used at Argonne's ZPR and ZPPR facilities were coated with Kel$\mathrm{F}$ to prevent uranium corrosion and material loss during handling. The Kel-F composition and average Kel-F coating mass per plate were discussed in Section 2.3.3.

The Kel-F is not normally included in as-built models. To determine the worth of the Kel-F, the reference model of ZPPR-15D L185 was modified to add the masses of Kel-F shown in column 3 of Table 2.4 to the depleted uranium plates in the ZPPR-15D model. The Kel-F was mixed homogeneously with the depleted uranium because it is not practical to include the Kel$\mathrm{F}$ as a separate coating and because any heterogeneity effect would be negligible in the ZPPR15 spectrum.

The worth of the Kel-F was determined as the difference between $\mathrm{k}_{\mathrm{eff}}$ for the reference model without Kel-F and $\mathrm{k}_{\text {eff }}$ for the modified model with the Kel-F. The computed worth of the KelF was $-6.98 \pm 2.83 \mathrm{pcm}$. Some of the Kel-F wore off during handling, and ICSBEP/IRPhEP benchmarks for ZPR and ZPPR assemblies typically assume that the uncertainty in the Kel-F mass due to normal handling was $10 \%$. With this assumption, the total worth of the Kel-F in ZPPR-15D L185 is $-6.98 \pm 2.91 \mathrm{pcm}$, which is treated as a bias and associated uncertainty since the Kel-F is neglected in the reference as-built model.

\subsubsection{Natural Uranium Plates}

ZPPR-15D L185 contained a small number of natural uranium plates. The computed worth of the $0.15 \%$ mass uncertainty for these plates is $0.01 \mathrm{pcm}$ which is negligible. Further analysis for the natural uranium plates is not warranted because any worth determined for impurities, etc. would also be negligible. 


\subsubsection{HEU Plates}

Canned HEU plates were used in ZPPR-15C and ZPPR-15D. There were eight types of canned HEU plates in ZPPR-15D L185. Table 5.4 shows the HEU plate types, the nominal HEU dimensions for each plate type and the number of each canned HEU plate type in ZPPR-15D L185.

Table 5.4. Canned HEU Plates in ZPPR-15D L185.

\begin{tabular}{|c|c|c|}
\hline Plate Type & $\begin{array}{c}\text { Nominal HEU } \\
\text { Dimensions }{ }^{\mathrm{a}}, \text { in. }\end{array}$ & Plate Count \\
\hline U93A & $1 / 16 \times 2 \times 6$ & 1054 \\
\hline U93B & $1 / 16 \times 2 \times 6$ & 2004 \\
\hline U93C & $1 / 16 \times 2 \times 8$ & 1054 \\
\hline U93D & $1 / 16 \times 2 \times 4$ & 1054 \\
\hline U93F & $1 / 8 \times 2 \times 8$ & 210 \\
\hline U93G & $1 / 8 \times 2 \times 6$ & 543 \\
\hline U93H & $1 / 8 \times 2 \times 6$ & 96 \\
\hline U93I & $1 / 8 \times 2 \times 4$ & 210 \\
\hline
\end{tabular}

a) These are the dimensions of the HEU metal. The stainless steel cans increased the outer plate dimensions slightly.

The characteristics of the canned HEU plates were discussed in Section 4.3. The uncertainties in the HEU mass and uranium isotopic distribution in the canned HEU plates discussed in Section 4.3 apply to ZPPR-15D as well. Table 5.5 shows the reactivity effects of the HEU mass uncertainty and the uncertainties in the ${ }^{234} \mathrm{U},{ }^{235} \mathrm{U}$ and ${ }^{236} \mathrm{U}$ weight fractions in ZPPR-15D. The ${ }^{235} \mathrm{U}$ mass was increased by $0.05 \%$ of the enriched uranium mass, and the ${ }^{238} \mathrm{U}$ mass was reduced to preserve total uranium mass. The same treatment was applied for ${ }^{234} \mathrm{U}$ and ${ }^{236} \mathrm{U}$.

The discussion of HEU impurities and corrosion in Section 4.3 applies to ZPPR-15D as well. The reference MCNP model was modified by replacing $885 \mathrm{ppm}$ of uranium with the nine impurities discussed earlier in Section 4.3. The computed worth of the initial impurities is $33.89 \pm 2.83 \mathrm{pcm}$. The $885 \mathrm{ppm}$ impurity is an average over the set of samples, and it appears that there were significant variations between samples. A $25 \%$ uncertainty in the impurity level has been assumed to cover this variation. With this assumption, the final worth of the initial impurities is $-33.89 \pm 8.93 \mathrm{pcm}$. The HEU impurities are not included in the reference MCNP model, so the worth of the initial impurities is treated as a bias and associated uncertainty.

Table 5.5. Worth of HEU Mass and Isotopic Uncertainties in ZPPR-15D.

\begin{tabular}{|c|c|c|}
\hline $\begin{array}{c}\text { Component } \\
\text { Uncertainty }\end{array}$ & $\begin{array}{c}\text { Uncertainty, } \\
\text { wt. } \%\end{array}$ & $\begin{array}{c}\text { Worth, } \\
\text { pcm }\end{array}$ \\
\hline HEU mass & 0.15 & 63.32 \\
\hline${ }^{235}$ U fraction & 0.05 & 23.98 \\
\hline${ }^{234}$ U fraction & 0.01 & 0.90 \\
\hline${ }^{236}$ U fraction & 0.01 & 0.05 \\
\hline Total & & 67.71 \\
\hline
\end{tabular}

ZPPR-15D was built in 1986 around the midpoint between the date when the HEU plates were canned and the time when ZPPR-21 was built. In the absence of any other information 
regarding corrosion of the HEU plates, it has been assumed that a) $0.5 \%$ of the uranium had corroded when ZPPR-15D was built, b) $2.5 \%$ of the corrosion was in the form of uranium hydride, c) $97.5 \%$ of the corrosion was in the form of uranium oxide and d) the one-sigma uncertainty on the estimated corrosion is $100 \%$.

The reference MCNP model was modified by adding enough oxygen and hydrogen to the HEU to match the assumed level of corrosion. The computed worth of the corrosion impurities is $6.97 \pm 7.53 \mathrm{pcm}$. The HEU corrosion impurities are not included in the reference MCNP model, so the worth of the corrosion impurities is treated as a bias which lowers $k_{\text {eff }}$ and associated uncertainty.

The HEU metal is canned in stainless steel. The nominal can composition corresponds to Type 304 stainless steel. In addition to the uncertainty in the can mass, there is an uncertainty in the weight fractions of the components of the stainless steel. The only uncertainties in the composition of the stainless steel that may make a significant contribution to the total uncertainty are the uncertainties in the weight fractions of $\mathrm{Mn}, \mathrm{Cr}$ and Ni. Table 5.6 shows the reactivity effects of the uncertainties in mass and composition for the HEU cans in ZPPR-15D.

Table 5.6. Worth of HEU Can Uncertainties in ZPPR-15D.

\begin{tabular}{|l|c|c|c|}
\hline $\begin{array}{c}\text { Component } \\
\text { Uncertainty }\end{array}$ & $\begin{array}{c}\text { Assumed } \\
\text { Uncertainty }\end{array}$ & $\begin{array}{c}\text { Nominal } \\
\text { wt.\% }\end{array}$ & $\begin{array}{c}\text { Worth, } \\
\text { pcm }\end{array}$ \\
\hline Mass & 0.15 & & 0.03 \\
\hline $\mathrm{Mn}$ & 0.1 & 1.0 & 0.02 \\
\hline $\mathrm{Cr}$ & 0.2 & 19.0 & 0.04 \\
\hline $\mathrm{Ni}$ & 0.2 & 9.25 & 0.05 \\
\hline Total & & & 0.07 \\
\hline
\end{tabular}

\subsubsection{Pu-U-Mo Plates}

Most of the core drawers in ZPPR-15D contained canned HEU plates, but a small number of drawers in the core contained $\mathrm{Pu}-\mathrm{U}-\mathrm{Mo}$ plates to provide the distributed neutron source required for the modified source multiplication method, the technique used at ZPPR to measure reactivity worths in some types of experiments. Section 2.3.6 discussed the methodology for determining the composition uncertainties for the Pu-U-Mo fuel meat in the plates.

The uncertainty in the total plutonium mass was computed to be $0.0890 \mathrm{wt} \%$. Changing the plutonium (plus americium) mass by this amount in the deterministic model changed $\mathrm{k}_{\mathrm{eff}}$ by $5.29 \mathrm{pcm}$.

The relative uncertainty in the ${ }^{239} \mathrm{Pu}$ weight percent was computed to be $0.0217 \%$. In the deterministic model, the ${ }^{239} \mathrm{Pu}$ concentration was increased by this amount and mass was preserved by decreasing just the ${ }^{240} \mathrm{Pu}$ concentration (a simplification justified by the very small size of the other isotopic concentrations). The resulting change in $\mathrm{k}_{\mathrm{eff}}$ is $0.99 \mathrm{pcm}$.

The weight percent of ${ }^{238} \mathrm{Pu},{ }^{241} \mathrm{Pu}$, and ${ }^{242} \mathrm{Pu}$ in the assembly before decaying ${ }^{241} \mathrm{Pu}$, was less than $2 \%$. The only isotope besides ${ }^{239} \mathrm{Pu}$ whose uncertainty would be expected to impact $\mathrm{k}_{\text {eff }}$ appreciably is ${ }^{240} \mathrm{Pu}$. The relative uncertainty in the ${ }^{240} \mathrm{Pu}$ weight percent is $0.0799 \%$. Modification of the ${ }^{240} \mathrm{Pu}$ weight percent led to a calculated effect on $\mathrm{k}_{\text {eff }}$ of $0.48 \mathrm{pcm}$. The 
combined uncertainty in $\mathrm{k}_{\text {eff }}$ due to the uncertainties in the original weight fractions of the remaining three isotopes is assumed to be no larger than this (i.e., it is taken to be $0.48 \mathrm{pcm}$ ). In principle, the total uncertainty in the plutonium isotopic fractions could be reduced by using the constraint that the sum of these fractions was unity. Because this uncertainty component does not make a significant contribution to the total uncertainty in the system reactivity, further analysis appears unwarranted.

Some of the ${ }^{241} \mathrm{Pu}$ that was in the fuel plates when they were manufactured decayed by the time ZPPR-15 was built. The Pu-U-Mo NUMEC and Dow plates were made in the late 1960s, ZPPR-15D L185 was made critical on May 23, 1986, and a nominal ${ }^{241} \mathrm{Pu}$ half-life of 14.29 years was assumed. The numbers in the inventory database are normalized to January 1, 1977. The estimated uncertainty in the decay constant is $1 \%$. Increasing the decay constant increases the ${ }^{241} \mathrm{Am}$ mass and decreases the ${ }^{241} \mathrm{Pu}$ mass. Increasing the decay constant by $1 \%$ reduces $\mathrm{k}_{\text {eff }}$ by $0.32 \mathrm{pcm}$.

Calculations of the worth of impurities in the Pu-U-Mo plates in Section 2.3, 3.3 and 4.3 showed that the worth of these impurities is very small. There are far fewer Pu-U-Mo plates in ZPPR$15 \mathrm{D}$ than there were in ZPPR-15A, ZPPR-15B and ZPPR-15C. The reactivity worth of impurities in the Pu-U-Mo plates in ZPPR-15D is assumed to be negligible.

The specification for production of the NUMEC Pu-U-Mo plates required a ${ }^{235} \mathrm{U}$ enrichment of $0.22 \pm 0.02 \mathrm{wt} . \%$ in the uranium component. It appears that the $0.02 \mathrm{wt} . \%$ represented the two sigma confidence interval, so the corresponding one sigma uncertainty is $0.01 \mathrm{wt} . \%$. The ${ }^{235} \mathrm{U}$ mass was increased by $0.01 \%$ and the ${ }^{238} \mathrm{U}$ mass was reduced correspondingly in the deterministic model. The resulting uncertainty in $\mathrm{k}_{\mathrm{eff}}$ is $2.48 \mathrm{pcm}$.

The uncertainty in the mass of molybdenum in the Pu-U-Mo fuel alloy was computed in the same way as the plutonium mass uncertainty. The computed molybdenum mass uncertainty is $0.1487 \%$. Changing the molybdenum atom density in the Pu-U-Mo alloy by this amount changes $\mathrm{k}_{\mathrm{eff}}$ by $0.03 \mathrm{pcm}$.

Table 5.7 shows the reactivity effects of the uncertainties in the mass and composition of the $\mathrm{Pu}-\mathrm{U}-\mathrm{Mo}$ alloy in the Pu-U-Mo plates used in ZPPR-5D L185.

Table 5.7. Worth of Pu-U-Mo Alloy Uncertainties in ZPPR-15D.

\begin{tabular}{|l|c|}
\hline Component Uncertainty & Worth, pcm \\
\hline $\mathrm{Pu}$ mass & 5.29 \\
\hline${ }^{239} \mathrm{Pu}$ fraction & 0.99 \\
\hline${ }^{240} \mathrm{Pu}$ fraction & 0.48 \\
\hline Other Pu isotopes & 0.48 \\
\hline${ }^{241} \mathrm{Pu}$ decay & 0.32 \\
\hline${ }^{235} \mathrm{U}$ in depleted uranium & 2.48 \\
\hline Mo mass & 0.03 \\
\hline Total & 5.97 \\
\hline
\end{tabular}

The Pu-U-Mo alloy is clad in stainless steel. Table 5.8 shows the reactivity effects of the uncertainties in mass and composition for the Pu-U-Mo cans in ZPPR-15D. 
Table 5.8. Worth of Pu-U-Mo Can Uncertainties in ZPPR-15D.

\begin{tabular}{|l|c|c|c|}
\hline $\begin{array}{l}\text { Component } \\
\text { Uncertainty }\end{array}$ & $\begin{array}{c}\text { Assumed } \\
\text { Uncertainty }\end{array}$ & $\begin{array}{c}\text { Nominal } \\
\text { wt.\% }\end{array}$ & $\begin{array}{c}\text { Worth, } \\
\text { pcm }\end{array}$ \\
\hline Mass & 0.15 & & 0.01 \\
\hline $\mathrm{Mn}$ & 0.1 & 1.0 & 0.03 \\
\hline $\mathrm{Cr}$ & 0.2 & 19.0 & 0.02 \\
\hline $\mathrm{Ni}$ & 0.2 & 9.25 & 0.03 \\
\hline Total & & & 0.05 \\
\hline
\end{tabular}

\subsubsection{Matrix Tubes}

The uncertainties for the matrix tubes discussed in Section 2.3 apply to ZPPR-15D. The Fe weight percent was adjusted to conserve mass when the weight percent of $\mathrm{Mn}, \mathrm{Cr}$ or $\mathrm{Ni}$ was perturbed. Table 5.9 shows the reactivity effects of the uncertainties in mass and composition for the matrix tubes in ZPPR-15D.

Table 5.9. Worth of Matrix Tube Uncertainties in ZPPR-15D.

\begin{tabular}{|l|c|c|c|}
\hline $\begin{array}{c}\text { Component } \\
\text { Uncertainty }\end{array}$ & $\begin{array}{c}\text { Assumed } \\
\text { Uncertainty }\end{array}$ & $\begin{array}{c}\text { Nominal } \\
\text { wt.\% }\end{array}$ & $\begin{array}{c}\text { Worth, } \\
\text { pcm }\end{array}$ \\
\hline Mass & 2.0 & & 1.54 \\
\hline $\mathrm{Mn}$ & 0.1 & 1.0 & 0.17 \\
\hline $\mathrm{Cr}$ & 0.2 & 19.0 & 0.63 \\
\hline $\mathrm{Ni}$ & 0.2 & 9.25 & 0.59 \\
\hline Total & & & 1.77 \\
\hline
\end{tabular}

\subsubsection{Drawers}

The same drawer types were used in all phases of the ZPPR-15 program. The overwhelming majority of the drawers in ZPPR-15D were normal 36.252 in. drawers with a nominal interior width slightly larger than two inches to accommodate the normal two inch width of plates. Twelve drawers in each half were PSR drawers, which were 0.5 in narrower than normal drawers to allow for the presence of 0.5 in control rod guide tubes.

The uncertainties discussed in Section 2.3 for the drawers apply to ZPPR-15D. The Fe weight percent was adjusted to conserve mass when the weight percent of $\mathrm{Mn}, \mathrm{Cr}$ or Ni was perturbed. Table 5.10 shows the reactivity effects of the uncertainties in mass and composition for the drawers in ZPPR-15D.

Table 5.10. Worth of Drawer Uncertainties in ZPPR-15D.

\begin{tabular}{|c|c|c|c|c|}
\hline Component & Assumed & Nominal & \multicolumn{2}{|c|}{ Worth, pcm } \\
\cline { 4 - 5 } Uncertainty & Uncertainty & wt. $\%$ & Normal Drawers & PSR Drawers \\
\hline Mass & 0.15 & & 0.08 & 0.01 \\
\hline $\mathrm{Mn}$ & 0.1 & 1.0 & 0.10 & 0.01 \\
\hline $\mathrm{Cr}$ & 0.2 & 19.0 & 0.35 & 0.01 \\
\hline $\mathrm{Ni}$ & 0.2 & 9.25 & 0.35 & 0.01 \\
\hline Total & & & 0.51 & 0.02 \\
\hline
\end{tabular}




\subsubsection{Steel Blocks}

The same low carbon steel blocks discussed in Section 2.3.9 were used as part of the axial reflector in all phases of the ZPPR-15 program. Table 5.11 shows the reactivity effects of the uncertainties in mass and composition for the steel blocks in the axial reflector in ZPPR-15D.

Table 5.11. Worth of Steel Block Uncertainties in ZPPR-15D.

\begin{tabular}{|l|c|}
\hline $\begin{array}{l}\text { Component } \\
\text { Uncertainty }\end{array}$ & $\begin{array}{c}\text { Worth, } \\
\text { pcm }\end{array}$ \\
\hline Mass & 0.01 \\
\hline $\mathrm{Mn}$ & 0.01 \\
\hline $\mathrm{Cr}$ & 0.01 \\
\hline $\mathrm{C}$ & 0.04 \\
\hline Total & 0.04 \\
\hline
\end{tabular}

\subsubsection{Stainless Steel Plates}

The four groups of stainless steel plates used in ZPPR-15A were used in all phases of the ZPPR15 program. The identifiers for those groups are SST, SS75, SSTX and SSET in the inventory records. These four groups of stainless steel plates were obtained at different times from different suppliers. Consequently, the four groups of stainless steel plates will be treated as being independent for purposes of uncertainty analysis.

The uncertainties discussed in Section 2.3 for the SST, SS75, SSTX and SSET stainless steel plates apply to ZPPR-15D. The Fe weight percent was adjusted to conserve mass when the weight percent of $\mathrm{Mn}, \mathrm{Cr}$ or $\mathrm{Ni}$ was perturbed. Table 5.12 shows the reactivity effects of the uncertainties in mass and composition for the four types of stainless steel plates in ZPPR-15D.

Table 5.12. Worth of Stainless Steel Plate Uncertainties in ZPPR-15D.

\begin{tabular}{|c|c|c|c|c|c|c|}
\hline Component & Assumed & Nominal & \multicolumn{5}{|c|}{ Worth, pcm } \\
\cline { 4 - 7 } Uncertainty & Uncertainty & wt.\% & SST & SS75 & SSTX & SSET \\
\hline Mass & 0.15 & & 0.24 & 0.18 & 0.35 & 0.41 \\
\hline $\mathrm{Mn}$ & 0.1 & 1.0 & 0.38 & 0.20 & 0.28 & 0.32 \\
\hline $\mathrm{Cr}$ & 0.2 & 19.0 & 0.55 & 0.25 & 0.66 & 0.04 \\
\hline $\mathrm{Ni}$ & 0.2 & 9.25 & 0.06 & 0.28 & 0.84 & 0.52 \\
\hline Total & & & 0.71 & 0.46 & 1.16 & 0.74 \\
\hline
\end{tabular}

The $0.1 \mathrm{pcm}$ uncertainty for humidity discussed in Section 2.3 applies to ZPPR-15D L185 as well.

The total composition uncertainty is $76.32 \mathrm{pcm}$.

\subsection{Total Uncertainty for ZPPR-15D Loading 185}

Table 5.13 summarizes all of the uncertainty components for measurement technique, configuration geometry and material compositions and lists the total uncertainty for ZPPR-15D L185.

The reported experimental $\mathrm{k}_{\text {eff }}$ after adjustment to standard reporting conditions was $1.00067 \pm$ 0.00001 . When the total uncertainty listed in Table 5.13 is included, the experimental $\mathrm{k}_{\text {eff }}$ is $1.00067 \pm 0.00083$. 


\subsection{Biases or Adjustments for ZPPR-15D Loading 185}

Several adjustments to the experimental $k_{\text {eff }}$ are required to account for features that are not included in the as-built model. The interface gap is not included in the as-built model, but the ZPPR staff adjusted the reported excess reactivity to a condition with zero gap. Consequently, there is no bias associated with neglecting the interface gap in the as-built model. The uncertainty resulting from the non-uniform size of the interface gap is addressed in Section 5.2 and is included in the total uncertainty determined in Section 5.4.

The reference as-built model does not include the split tables, clamping structure or the room in which the machine was located. Addition of room return increases the reactivity by $0.00 \pm$ $2.83 \mathrm{pcm}$, so neglecting room return reduces the reactivity by $0.00 \pm 2.83 \mathrm{pcm}$. 
Table 5.13. Total Uncertainty for ZPPR-15D L185.

\begin{tabular}{|c|c|}
\hline \begin{tabular}{|l|} 
Uncertainty Component \\
\end{tabular} & Uncertainty, pem \\
\hline \multicolumn{2}{|c|}{ Measurement Technique } \\
\hline Excess reactivity & 0.66 \\
\hline Temperature & 2.95 \\
\hline Reproducibility & 1.00 \\
\hline$\beta_{\text {eff }}$ uncertainty & 3.22 \\
\hline Subtotal & 4.53 \\
\hline \multicolumn{2}{|l|}{ Geometry } \\
\hline Interface gap & 5.60 \\
\hline Nominal plate, drawer dimensions & 12.04 \\
\hline Matrix tube pitch & 29.89 \\
\hline Subtotal & 32.71 \\
\hline \multicolumn{2}{|c|}{ Composition } \\
\hline Pu-U-Mo alloy & 5.97 \\
\hline Pu-U-Mo plate clad & 0.05 \\
\hline HEU & 67.71 \\
\hline HEU clad & 0.07 \\
\hline Sodium & 1.53 \\
\hline Sodium plate clad & 0.86 \\
\hline Zirconium & 0.44 \\
\hline Natural uranium & 0.01 \\
\hline Depleted uranium - APW2 & 34.27 \\
\hline Depleted uranium - ANL-E & 4.45 \\
\hline Matrix tubes & 1.77 \\
\hline Drawers - standard & 0.51 \\
\hline Drawers - PSR (control rod) & 0.02 \\
\hline Steel blocks - FE & 0.04 \\
\hline Stainless steel - SST & 0.71 \\
\hline Stainless steel - SS75 & 0.46 \\
\hline Stainless steel - SSTX & 1.16 \\
\hline Stainless steel - SSET & 0.74 \\
\hline Humidity & 0.10 \\
\hline Subtotal & 76.32 \\
\hline Total Uncertainty & 83.15 \\
\hline
\end{tabular}

Available documents do not list the impurities in the depleted uranium plates, and the depleted uranium impurities are neglected in the as-built model. The worth of the depleted uranium plate impurities is assumed to be approximately equal to the $0.15 \%$ mass uncertainty in the depleted uranium plates. Increasing the depleted uranium plate masses by $0.15 \%$ reduced $\mathrm{k}_{\mathrm{eff}}$ by -13.86 pcm for the original ZPPR (APW2) depleted uranium plates and by $-2.69 \mathrm{pcm}$ for the ANL-E depleted uranium plates. Adding the impurities to the depleted uranium plates would have approximately the same effect. The uncertainty in the impurity level is assumed to be $100 \%$. Neglecting the impurities in the ZPPR depleted uranium increases reactivity by $13.86 \pm 13.86$ 
pcm. Neglecting the impurities in the ANL-E depleted uranium increases reactivity by $2.69 \pm$ $2.69 \mathrm{pcm}$.

The depleted uranium plates were coated with Kel-F to prevent corrosion and material loss during handling. Kel-F is generally neglected in as-built models. Adding the Kel-F to the asbuilt model lowers $\mathrm{k}_{\text {eff }}$ by $-6.98 \pm 2.91 \mathrm{pcm}$, so neglecting the Kel-F increases reactivity by 6.98 $\pm 2.91 \mathrm{pcm}$.

The impurities that were present when the original HEU metal plates were cast lower keff because they replace HEU. Adding the HEU impurities to the as-built model lowers $\mathrm{k}_{\text {eff }}$ by $33.89 \pm 8.93 \mathrm{pcm}$, so neglecting the HEU impurities in the as-built model increases reactivity by $33.89 \pm 8.93 \mathrm{pcm}$.

The end caps that were used when the HEU metal plates were canned were not airtight. As a result, some $\mathrm{HEU}$ plates corroded with formation of $\mathrm{UO}_{2}$ and $\mathrm{UH}_{3}$. Adding the corrosion products to the as-built model raises $\mathrm{k}_{\mathrm{eff}}$ by $6.97 \pm 7.53 \mathrm{pcm}$, so neglecting the corrosion products decreases reactivity by $-6.97 \pm 7.53 \mathrm{pcm}$.

Table 5.14 shows the computed biases and associated uncertainties for ZPPR-15D L185.

Table 5.14. Biases for ZPPR-15D L185 As-Built Model.

\begin{tabular}{|l|c|c|}
\hline Component & Bias, $\mathrm{pcm}$ & $\sigma, \mathrm{pcm}$ \\
\hline Room return & 0.00 & 2.83 \\
\hline ZPPR DU impurities & 13.86 & 13.86 \\
\hline ANL-E DU impurities & 2.69 & 2.69 \\
\hline DU Kel-F coating & 6.98 & 2.91 \\
\hline HEU impurities & 33.89 & 8.93 \\
\hline HEU corrosion products & -6.97 & 7.53 \\
\hline Total & 50.45 & 18.77 \\
\hline
\end{tabular}

\subsection{Final Adjusted Experimental keff for ZPPR-15D Loading 185}

The experimental $k_{\text {eff }}$ for ZPPR-15D L185 is $1.00067 \pm 0.00083$ when the total uncertainty derived in Section 5.4 is included. This value is for the measured configuration and does not include the total bias listed in Table 5.14. When the total bias from Section 5.5 is included, the final adjusted experimental $\mathrm{k}_{\text {eff }}$ for ZPPR-15D L185, the ZPPR-15D reference critical configuration, is $1.00117 \pm 0.00085$.

Consequently, the final adjusted experimental $k_{\text {eff }}$ for the described as-built model of ZPPR15D L185 is $1.00117 \pm 0.00085$.

\section{Summary}

Excess reactivity was measured for the reference critical configuration in each phase of the ZPPR-15 program. The ZPPR staff converted the excess reactivity measurements to values of $\mathrm{k}_{\text {eff }}$ adjusted to a standard set of reporting conditions with a reactor temperature of $293 \mathrm{~K}$, a zero interface gap and all control rods parked 30 inches from the axial centerline of the core. This adjustment facilitated analysis of the ZPPR-15 measurements with the computational tools available in $1985-1986$. 
The uncertainty published by the ZPPR staff for a reference ZPPR-15 critical configuration was just the statistical uncertainty related to the reactivity measurement plus the small uncertainties related to the adjustment to the standard set of reporting conditions.

In reality, the published uncertainty for a ZPPR-15 criticality measurement is just a small component of the total uncertainty for that configuration. In addition to the statistical uncertainty in the measurement and the uncertainties related to the adjustment to standard reporting conditions, there are uncertainties related to measurement technique, configuration geometry and material compositions.

A full uncertainty analysis was performed for the reference critical configuration in each phase of the ZPPR-15 program. The significant uncertainties related to measurement technique, configuration geometry and material compositions were identified and quantified, and a total uncertainty was derived for each ZPPR-15 reference critical configuration.

As-built MCNP models were constructed for the reference critical configurations established in ZPPR-15A L015, ZPPR-15B L088, ZPPR-15C L166 and ZPPR-15D L185. As-built models of ZPPR assemblies neglect the small, non-uniform gap between the matrix halves at full closure, structures outside the matrix tubes and some minor constituents, e.g., impurities, in materials. These biases were identified and quantified. The final values of $\mathrm{k}_{\mathrm{eff}}$ and their associated uncertainties were adjusted to account for the features that are not included in the asbuilt models. 


\section{References}

1. 1. D. B. Pelowitz, ed., "MCNP6 ${ }^{\mathrm{TM}}$ User's Manual," Los Alamos National Laboratory Report, LA-CP-13-00634, 2013.

2. M. A. Smith, Personal Communication, July 23, 2019.

3. C. H. Lee and W. S. Yang, "MC2-3: A Multigroup Cross Section Generation Code for Fast Reactor Analysis," ANL/NE-11-41, Argonne National Laboratory, January 2012.

4. M. A. Smith, E. E. Lewis and E. R. Shemon, "DIF3D-VARIANT 11.0, A Decade of Updates," ANL/NE-14/1, Argonne National Laboratory, 2014.

5. International Handbook of Evaluated Criticality Safety Benchmark Experiments, OECD Nuclear Energy Agency, NEA No. 7360, ISSN: 2618-0421, December 2018.

6. International Handbook of Evaluated Reactor Physics Benchmark Experiments, OECD Nuclear Energy Agency, NEA No. 7361, ISSN: 2617-5614, December 2018.

7. G. E. Hansen and H. C. Paxton, "Reevaluated Critical Specifications of Some Los Alamos Fast-Neutron Systems," LA-4208, Los Alamos Scientific Laboratory, 1969.

8. T. C. Totemeier et al., "Characterization of Corroded Metallic Fuel Plates," Journal of Nuclear Materials, 256, p. 87, 1998.

9. Private Communication, S. L. Hayes, Argonne National Laboratory, July 5, 2001. 
Argonne

Nuclear Science and Engineering Division

Argonne National Laboratory

9700 South Cass Avenue, Bldg. 208

Argonne, IL 60439-4842

www.anl.gov 